\title{
AVALIAÇÃO DE MÉTODOS DE ESTIMATIVA DE TOTAIS DIÁRIOS DE HORAS DE FRIO, PARA SANTA MARIA-RS
}

\author{
ARNO BERNARDO HELDWEIN
}

Orientador: PAULO LEONEL LIBARDI

Dissertação apresentada à Escola Superior de Agricultura "Luiz de Queiroz", da Universidade de São Paulo, para obtenção do título de Mestre em Agronomia - Área de Concentração - Agrometeorologia.

$P|R A C| C A B A$

Estado de São Paulo - Brasil

Fevereiro, 1983 
A meus pais e irmãos, DED ICO

A minha esposa, Elfrida Selma, razão de minha labuta, OFEREÇO ESTE TRABALHO 
A Universidade Federal de Santa Maria e á Escola Superior de Agricultura "Luiz de Queiroz", pela oportunidade de realização do Curso.

Ao Prof. Assistente Doutor Paulo Leonel Libardi, pela orientação e amizade.

Ao Plano Institucional de Capacitação Docente da CAPES, pelo auxilio financeiro.

Aos colegas do Dept? de Fitotecnia do CCR-UFSM, especialmente à Ailo V.Saccol, Flävio M.Schneider, Paulo A.Man fron e Galileo A.Buriol pelo incentivo e por assumirem minhas atividades didáticas possibilitaram meu afastamento da UFSM Pa ra a realização do Curso.

Ao Prof. Assistente Luiz Roberto Angelocci pela colaboração, apoio, incentivo e amizade.

Aos Professores do Curso de Agrometeorologia da ESALQ/USP, que pelo seu esforço, experiência e amizade, contri buiram para a minha formação.

Aos funcionários do Dept? de Física e Meteorologia da ESALQ/USP e do Depto de Fitotecnia da UFSM, pela colabo ração e amizade.

A Ana M.P.Gonzales, Antonio J.P. de Carvalho, En gler J.V. Lobato, Hugo J.Braga, Paula: P.Padovese e demais cole gas do Curso, pelo convíveo sadio, amizade, apoio e incentivo.

A todos que de uma forma ou de outra contribuiram para a realização deste trabalho. 
SUMMARY $\ldots \ldots \ldots \ldots \ldots \ldots \ldots \ldots \ldots \ldots \ldots \ldots \ldots \ldots \ldots \ldots \ldots$

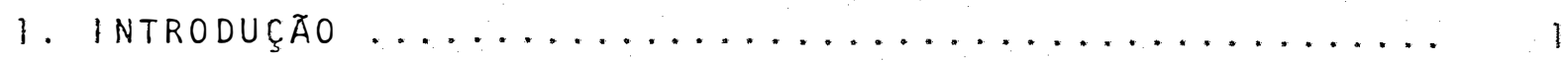

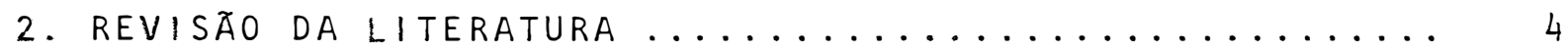

3. MATERIAL E METODOS .......................... 1

4. RESULTADOS E DISCUSSÃO ..................... 19

5. CONCLUSOES ................................ 93

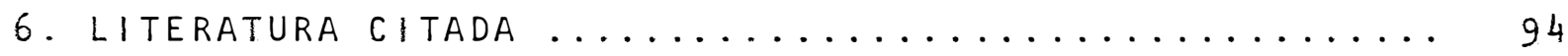




\section{AVALIAÇÃO DE METOdOS DE ESTIMATIVA DE TOTAIS DIÁRIOS DE} HORAS DE FRIO, PAFA SANTA MARIA-RS

Autor: Arno Bernardo Heldwein

orientador: Paulo Leonel Libardi

RESUMO

O presente trabalho teve como objetivos: (a) selecionar um ou mais métodos de estimativa de totais diários de horas de frio, com a finalidade de fazer estimativas regulares com boa precisão e possibilitar a superação de falhas nos registros termográficos, e (b) selecionar os métodos que permi tem minimizar os custos operacionais de obtenção dos dados, sem comprometer em demasia a precisão das estimativas, para Santa Maria-RS.

Foram analisados 16 métodos de estimativa dos to tais diários de horas de frio com temperatura base superior de $7^{\circ} \mathrm{C}$ e $13^{\circ} \mathrm{C}$, para os sete meses mais frios do local. Um dos métodos constou de oito equações analiticas, derivadas dos padrões diários de variação da temperatura do ar adotados, nas quais são empregadas as leituras instantâneas das temperaturas mínimas, máximas e das 21 horas, sendo cada equação representa tiva de um caso específico da relação entre esses dados e a tem peratura base considerada.

Os demais métodos constaram de equações de regres são simples ou mültiplas, obtidas pelo método dos quadrados mí nimos, considerando-se como variáveis independentes os dados diärios de temperatura mínima ( $T m$ ), temperatura do aràs 9 horas $\left(T_{g}\right)$, temperatura do ar às 21 horas do dia anterior $\left(T_{2 l}\right)$ e 
e a relaçāo das amplitudes tērmicas (RA), dada pela expressão: $R A=24(T B-T m) \cdot\left(\bar{T}_{M A X}-T m\right)^{-1}$, onde TB é a temperatura base e $\bar{T}_{\text {MAX }}$ ê a média entre as temperaturas máximas ocorridas no dia anterior e no dia em questão.

Utilizando-se a transformação $z(r)$ do coeficiente de correlação entre as estimativas e as observações diärias, em cada més, comparou-se os métodos pelo teste $t$, além de con siderar-se tambēm a variância dos parâmetros angulares das equações de regressão e a dispersão dos totais diários de horas de frio observados e estimados ao longo da linha $1: 1$, para cada mês. A grande maioria dos métodos apresentou a tendência de proporcionar estimativas mais precisas nos meses menos frios.

O método analítico foi significativamente o melhor para estimar totais diários de horas de frio com temperatura abaixo de $13^{\circ} \mathrm{C}$. Considerando-se a temperatura base de $7^{\circ} \mathrm{C}$, tal método proporcionou a obtenção dos maiores coeficientes de correlação entre valores estimados e observados, porém não sig nificativamente melhores, em seis dos meses analisados. Entretanto, por tratar-se de um método analítico, sugere-se a opção pelo mesmo para estimar totais diários de horas de frio com temperatura abaixo de $7^{\circ} \mathrm{C}$, para Santa Maria-RS.

Dos métodos de análise de regressão, o métodoque utiliza unicamente a relação das amplitudes térmicas (RA) como variävel independente e o método que emprega somente "RA" e temperatura mínima como variáveis independentes, mostraram-se como a melhor opção para diminuir os custos operacionais de um estudo a nivel meso-climático, por necessitar-se somente de termómetros de mínima e de máxima para o levantamento dos dados, enquanto que o método de regressão que utiliza somente a temperatura mínima como variável independente, mostrou-se ace tável apenas para estimar totais diários de horas de frio com temperatura abaixo de $7^{\circ} \mathrm{C}$. 
EVALUATION OF ESTIMATION METHODS OF DAILY CHILLING HOURS, FOR THE REGION OF SANTA MARIA (RS), BRAZIL

Author: Arno Bernardo Heldwein Adviser: Paulo Leonel Libardi

\section{SUMMARY}

The objectives of this work were: (a) to select methods of estimation of daily chilling hours in order to make regular and more precise estimations and also to overcome failures of thermalgraphic records, and (b) to select those methods that minimize the operational expenses of data aquizition without much influence on the precison of the estimates, for Santa Maria (RS) region.

Sixteen estimation methods of daily chilling hours, with temperature below $\quad 7$ and $13^{\circ} \mathrm{C}$, for the seven colder months of the local, were analysed. One of the methods consisted of eight analytical equations derived from the adopted air temperature variation daily standards, in which ins tantaneous readings of minimum and maximum temperatures, and also of the 21 hours, were utilized. Each equation is representative of a specific case of the relation among these data and the considered base temperature. The other methods consisted of simple and multiple regression equations, obtained by the minimum square method, by considering as independent variables the daily data of minimum air temperature (Tm), air temperature at 9 a.m. ( $T_{9}$ a.m.); air temperatura at 9 p.m. of the preceding day ( $T_{g}$ p.m) and the relation of the thermal amplitudes (RTA), given by the expression: $R T A=24(T B-T m) \cdot\left(\bar{T}_{M A X}-T m\right)^{-1}$, where $T B=$ base temperature and $\bar{T}_{M A X}=$ mean temperature of the maxi- 
viii.

mum temperatures ocurred in the preceding day and in the day in question.

Using the $z(r)$ transformation of the correlation coefficient between daily estimation and daily observations, in each month, the methods were compared by the t test. Besides, the variance of the angular parameters of the regression equations and the dispersion of the observed and estimated daily chilling hours along the $1: 1$ line, for each month, were also considered. The majority of the methods presented a tendency of providing more precise estimations during less cold months.

The analytical method was the better significantly, to estimate daily chilling hours with temperature below $13^{\circ} \mathrm{C}$. Considering a base temperature of $7^{\circ} \mathrm{C}$ such a …… method yielded of greater correlation coefficients between estimated and observed values, but not significantly better, in six out of the analysed months. However, being a analytical method, it is suggested its utilization to estimate the daily chilling hours with temperature below $7^{\circ} \mathrm{C}$, for the region of Santa Maria (RS).

From the regression analysis methods, the one that utilizes only the relation of the thermal amplitudes(RTA) as independent variable, and the one that utilizes only RTA and minimum temperature as independent variables, showed to be the better option to decrease the operational expenses of an study at meso-climatic level, because they need only minimum-maximum thermometers for the survey of the data, whereas the regression method that utilizes only the minimum temperature as independent variable showed to be acceptable only to estimate daily chilling hours with temperature below $7^{\circ} \mathrm{C}$. 
I. INTRODUÇ $\tilde{A} O$

O estado de "repouso" das frutiferas criófillas, que segundo SAMISH (1954) é determinado por fatores internos daplan ta, é interrompido naturalmente pela ação benéfica do frio invernal, desde que este se manifeste em quantidade suficiente para satisfazer as exigências destas plantas.

Durante o repouso não há crescimento vegetativo visível, porēm a atividade fisiolögica continua lentamente, preparando a planta para as fases vegetativa e reprodutiva subsequen tes (CHANDLER, 1937; MARKUS, 1952 e SAMISH, 1954).

Em certas regiões temperadas e nas regiões subtropicais, sujeitas a invernos mais amenos e muitas vezes com intensidade variável de ano para ano, o frio invernal pode ser insu ficiente para satisfazer as exigências destas espécies para pro mover á quebra normal da dormência.

As anomalias fenológicas e fisiológicas decorrentes da insuficiência de frio nesta fase para a quebra da dormência, são claramente enumeradas e caracterizadas entre outros, por CHANDLER et azii (1937); HIDGON (1950); LEDESMA (1950); WEINBERGER (1950 e 1954); SAMISH (1954); ABBOTT (1962); PASCALE e AS PIAZUं (1965); TABUENCA (1965); EREZ e LAVEE (1971), MASIP et alii (1976) e PETRI e PASQUAL (1982). 
Do ponto de vista agronōmico, as consequéncias mais drásticas da insuficiência de frio para determinada cultivar, são: dificuldade nos tratamentos fitossanitários, devida a desuniformidade de desenvolvimento dos frutos; queda na qualidade e quantidade da produção de frutos; diminuição do vigor e da longevidade da planta. LEDESMA (1950), encontrou coeficientes de correlação linear, de 0,73 e de 0,81 , significátivos ao nível de $5 \%$ de probabilidade, entre o total de horas de frio registrado em Buenos Aires e a entrada subsequente de maçãs e de peras, respectivamente, no mercado na região macroclimática do Delta do Paraná, Argentina. Isto evidencia que o frio invernal é um dos principais fatores que condicionam a fruticultura de cli ma temperadó em uma localidade.

Sob o ponto de vista agroclimático, a quantificação da disponibilidade local e da exigência das variedades criófilas em frio, geralmente é efetuada através do parâmetro "total de horas de frio", que consiste na contabilização do tempo em horas em que a temperatura do ar permanece abaixo de certa temperatura base, num periodo considerado. Esta avaliaçãoserve tam bém, de apoio aos melhoristas na obtenção de variedades que melhor se adaptam ao local ou na obtenção de variedades combrota ção tardia com o objetivo de diminuir os danos causados por pos siveis geadas primaveris.

o total de horas de frio ocorridas num período pode ser computado diretamente dos registros do termógrafo, ou, com precisão aceitável, a partir dos valores de observações horárias de temperatura do ar, sendo uma tarefa simples, porém mui to trabalhosa, principalmente quando se fazem necessārias corre ções nos registros da temperatura do ar dos termogramas.

observações horárias de temperatura do ar são raras no Brasil. Já o registro em termogramas, embora mais frequente; é efetuado em uma rede de estações geralmente insuficiente para atender as exigências dos estudos de regionalização de frutí feras criófilas e muitas vezes esta dificuldade è aumentada com 
as falhas ou falta de registros, causados por problemas operacionais. Para contornar esses problemas é comum recorrer-se a estimativas do total de horas de frio de um periodo determinado relacionando este parâmetro com os dados das observações conven cionais da temperatura do ar, que são realizadas regularmente numa rede maior de estações e com menores falhas. Soma-se a essa vantagem a diminuição do tempo gasto na cotação e dos erros de cálculos, pela possibilidade de realizar o processamente dos dados num sistema de computação eletrônica.

o presente trabalho foi realizado com o intuito de se lecionar, para cada mês, equações confiāveis que permitam a esti mativa do total diário de horas de frio, com a finalidade de pos sibilitar a recuperação de dados e simplificar o estudo e a ela boração de um zoneamento, em escala meso-climātica, para frutíferas criófilas, na região de Santa Maria-RS. 
A estimativa do total de horas de frio de um determi nado período pode ser possivel a partir de valores de leituras diretas de temperatura do ar efetuadas regularmente nas estaçōes meteorológicas, pois deve existir uma interrelação entre o parámetro e o elemento meteorológico citados.

os valores instantāneos da temperatura do ar, obti dos regularmente a intervalos de tempo fixos, fazem parte da curva que representa a variação diäria desse elemento meteorológico e, portanto, mostram uma relação intima com o tempo em que a temperatura permanece abaixo ou acima de um determinado limite térmico. Da mesma forma, para períodos mais longos, um raciocínio semelhante é vālido e resultados práticos podem ser obtidos quando são correlacionados os valores médios :mensais das temperaturas médias, mäximas ou mínimas, com o total men sal de horas de frio.

Correlação é a tendência de duas (ou mais) variáveis estarem relacionadas de uma maneira definida, sendo que o grau de ajuste dos dados das variāveis relacionadas é medido pelo coeficiente de correlação, "r". Para saber se o grau de ajuste obtido é real ou fruto do acaso, recorre-se a probabilidade de distribuição dos dados com os respectivos testes de significán 
cia (LITTLE, 1966).

SEģuño GOMES (1973), a comparação de diferentes coeficientes de correlação, pode ser feita pelos testes "t" ou "F". o teste "t" de significância é aplicado desde que se compare a transformação $z(r)$ dos dois coeficientes de correlação conside rados.

MARKUS (1952) em seu estudo estatístico dos invernos de Porto Alegre-RS, em relação às exigêncías em frio das frutíferas, relacionou o total mensal de horas de frio com temperatü ra menor que $7^{\circ} \mathrm{C} \quad\left(H F<7^{\circ} \mathrm{C}\right)$ com a média mensal das temperaturas mínimas, obtendo um coeficiente de correlação de $-0,8039$.

WEINBERGER (1956) encontrou um coeficiente correlação signigicativo de $-0,95$ entre a temperatura média dos dois meses mais frios, dezembro e janeiro, e o total de horas de frio ( HF $<7^{\circ} \mathrm{C}$ ) acumulado neste período, na Georgia, E.E.U.U.

MOTA (1957). estudou os invernos de Pelotas-RS, em relação às exigências em frio das frutíferas criófilas. Verificou que muitas vezes o total diário de horas de frio apresentava-se pequeno em relação a temperatura mínima mui to baixa e em outras ocasiōes, mesmo com temperatura minima alta, observou um total diário de horas de frio bastante grande. Em função desta observação correlacionou o total mensal de horas de frio ( $H F<7^{\circ} \mathrm{C}$ ) com a temperatura média mensal dos cinco meses mais frios, obtendo um coeficiente de correlação linear de $-0,8640$ e um coeficiente de correlação quadrática de -0,8641. Utilizou a equação de regressão linear, obtida pelo método dos quadrados mínimos, para estimar as horas de frio para esta loca lidade. Da mesma forma, com os dados publicados por MARKus(1952), obteve um coeficiente de correlação de $-0,8980$ entre a temperatura média mensal dos meses mais frios e o total mensal de horas de frio (HF $<7^{\circ} \mathrm{C}$ ), para Porto Alegre-RS. A equação desen volvida por MOTA (1957), para Pelotas-RS, foi utilizada por FER REIRA (1975), no Estado de Minas Gerais, para obter as horas de 
frio (HF< $7^{\circ} \mathrm{C}$ ), em função das temperaturas mëdias mensais normais de cada localidade, sem qualquer ajuste ou teste da equação e os valores mensaís estimados de horas de frio foram utili zados para o zoneamento de aptidão climática do Estado para a fruticultura de clima temperado.

SANTA MARIA, citado por FERREIRA (1975), avaliou alguns métodos de estimativa do número total de horas de frio $\left(H F<7^{\circ} \mathrm{C}\right)$, para certo período, em função das médias mensais da temperatura máxima, mínima e média, para diferentes localidades do México, comparando-os com o total de horas de frio obtido nos registros termográficos e com o comportamento fenológico de cultivares de frutíferas, em diferentes estações experimentais, cujas exigências em frio eram conhecidas. Verificou que a fórmu la de MOTA (1957) e o método de WEINBERGER (1967), foram os modelos mais adequados, pois apresentaram correlação significativa com o comportamento fenológico das frutiferas, tomadas como testemunhas, e com as horas de frio obtidas dos registros termo grāficos. O método de WEINBERGER (1967), baseia-se na correlação entre temperatura do ar, ou soma de horas de frio (HF< $\left.7,2^{\circ} \mathrm{C}\right)$ e a duração do período de dormência. Para a localidade de Fresno, Califórnia, WEINBERGER (1967), obteve as melhores correlações da duração do período de repouso com a média mensal das tempera turas máximas de novembro e dezembro, e com a amplitude térmica diāria média de dezembro, enquanto que com a soma de horas de frio mensal de outubro, novembro e dezembro, a correlação foi baixa. Estudando o regime de horas de frio de Buenos Aires, PAS CALE e ASPIAZO (1965), tomaram como välidos os valores estimados de horas de frio $\left(H F<7^{\circ} \mathrm{C}\right)$, em função da temperaturamédia, para cada mês, atravēs de equações de regressão linear. Utilizando os valores horários de temperatura do ar do período de 1911 à 1963, obtiveram o total de horas de frio de cada mês, cu jo coeficiente de correlação com a temperatura média foi elevado e significativo para maio, junho, julho e agosto, enquanto que para os meses de abril, setembro e outubro, foi de apenas 
$-0,220,-0,676$ e 0,508 , respectivamente. Também relacionaram o total de horas de frio do período de repouso das ameixeiras (01/04 à 31/08), com a temperatura média de cada mês, encontrando a melhor correlação com a temperatura média do mês de jultho $(r=-0,75)$.

PEDRO JUNIOR et atii (1979), obtiveram o total de ho ras de frio com temperatura abaixo de $7^{\circ} \mathrm{C}$ e de $13^{\circ} \mathrm{C}$ através da cotação dos termogramas do período de 1964 à 1973 , de 12 localidades do Estado de São Paulo. Correlacionaram o total médio mensal de horas de frio, cotados para cada local, com as respectivas médias mensais das temperaturas minimas, com as tempe raturas médias de julho e com a média das temperaturas mínimas absolutas mensais, pelo método dos quadrados mínimos. obtiveram melhor correlação entre o total médio de horas de frio e as temperaturas médias do mês de julho, com coeficientes de cor relação linear significativos ao nível de $1 \%$, iguais a $-0,88$ e - 0,93, respectivamente, para horas de frio com temperatura abaixo de $7^{\circ} \mathrm{C}$ e com temperatura abaixo de $13^{\circ} \mathrm{C}$. Com as respect vas equações de regressão obtidas, estimaram o total de horas de frio, para as demaís localidades, traçando então as isolinhas de horas de frio nas cartas geogräficas que serviram de base para a regionalização da fruticultura de clima temperado no Estado.

A relação da diferença entre a temperatura base e a temperatura mínima com a amplitude térmica de um período consi derado de "t" horas, $[t(T B-T m) \cdot(T M-T m)-\bar{T}$, pode ser também utilizada como uma variävel independente na obtenção de equações de estimativa pelo método dos quadrados mínimos, desde que alguns cuidados sejam observados. A obtenção de valores super-estimados nos periodos muito frios ou de valores negativos nos periodos mais quentes são os maiores problemas verificados quando da sua utilização. ARON (1975), em uma primeira a nâlise, incluiu todos os dados disponíveis de temperatura máxí ma e temperatura mínima médias mensais, quando da obtenção de 
suas equações de estimativa por regressão para a Califórnia. observou que nos meses muito frios as equações poderiam propor cionar super-estimativa do total mensal de horas de frio, enquanto que nos meses mais quentes, em que a média mensal das

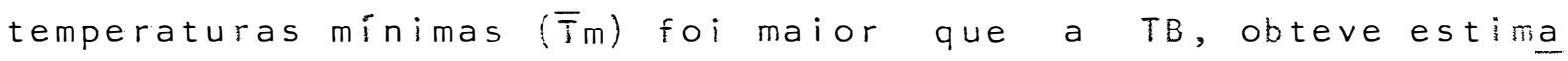
tivas de totais mensais de horas de frio menores que zero. Des ta forma, usando um processo repetitivo ("iterative"), eliminou todos os dados com os quais previa a estimativa de valores negativos ou superestimados, obtendo bom ajuste pará suas equa ções.

ARON (1975), usando a técnica dos quadrados mínimos, ajustou equações de regressão lineares e equações polinomiais por "tentativa passo a passo" ("stepwise") a diversos elementos climäticos, com a finalidade de estimar o total mensal de ho ras de frio ( $H F<45^{\circ} \mathrm{F}$ ), na Califörnia. Paratanto, corrigiu os valores dos elementos climáticos incluídos na análise para meses de 30 dias.

Na obtenção das equaçöes pelo método "stepwise", em cada passo incluiu uma nova variável independente, desde que a mesma incrementasse o coeficiente de determinação $\left(r^{2}\right)$ em pé 10 menos 0,003. Após os referidos ajustes, as melhores equações empíricas de estimativa resultaram em:

$\mathrm{HF}<45^{\circ} \mathrm{F}=801+0,2523 \mathrm{~B}+7,574 \times 10^{-4} \mathrm{~B}^{2}-6,51 \times 10^{-10_{B}^{4}}-11,44 \overline{T m}_{\mathrm{m}}$

$$
-3,32 \overline{T M}
$$

$H F<45^{\circ} F=665,5+0,152 B+6,734 \times 10^{-4} B^{2}-7,64 \times 10^{-10} B^{4}+8,08 \overline{T M}-$

$$
-30,22 G+5,2 \text { UR }
$$

$H F<45^{\circ} F=676,2+0,2856 B+7,713 \times 10^{-4} B^{2}+7,63 \times 10^{-10_{B}^{4}}-13,21 E+$

$$
+6,96 C
$$

onde:

$\mathrm{HF}<45^{\circ} \mathrm{F}=$ total mensal de horas de frio com temperatura menor que $45^{\circ} \mathrm{F}$;

$$
B=(45-\bar{T} m) \cdot(\bar{T} H-T m)^{-1} \cdot H \cdot D \cdot ;
$$


$\bar{T}_{m}=$ média mensal das temperaturas mínimas $\left({ }^{\circ} \mathrm{F}\right)$;

$\bar{T} M=$ média mensal das temperaturas mäximas ( $\left.{ }^{\circ} \mathrm{F}\right)$;

$H=$ nümero de horas em um dia (24h/dia);

D = nümero de dias do período (30 dias);

$G=$ média mensal da temperatura do termômetro de bulbo úmido $\left.{ }^{\mathrm{O}} \mathrm{F}\right)$;

$U R=$ média mensal da umidade relativa do ar;

$E$ = média mensal da temperatura do ar das 4:00 horas, hora lo cal $\left({ }^{\circ} \mathrm{F}\right)$;

$c=$ média mensal da cobertura de nuvens, em décimos.

Para a equação "A", que inclui somente dados de temperatura máxima e mínima, o coeficiente de determinação ( $\left.r^{2}\right)$ foi de 0,959. Para a equação "B", obteve um $\mathrm{r}^{2}$ igual 0,978 e para a equação "c", obtida para locais onde não sefaz medidas de umi dade do ar, obteve um $r^{2}$ igual a 0,976 .

Entretanto, segundo DAMÁRIO (1969), as equações de regressão propiciam estimativas essencialmente locais, podendo a sua aplicação extender-se somente a localidades com condições climáticas muito similares quanto a intensidade e amplitude da temperatura em cada mês e no ano. A aplicação de uma mesma equa ção a localidades geogräficas vizinhas pode produzir erros gros seiros de estimativa. Mesmo considerando que a metodologia empregada foi diversa, a grande diferença no total mensal de horas de frio (HF $\left.<7^{\circ} \mathrm{C}\right)$ estimados por PEDRO JUNIOR et alii(1979) e por FERREIRA (1975), no limite entre os estados de são Paulo e Minas Gerais, parece evidenciar a afirmativa de DAMARIO(1969). Em função desta constatação, alguns autores desenvolveram outros métodos de estimativa de "horas de frio". DAMARlo (1969), desenvolveu um método grä́fico para estimar as horas de frio $\left(H F<7^{\circ} \mathrm{C}\right)$ a partir dos valores médios mensais normais de tempe ratura mínima dos cinco meses mais frios e da temperatura média anual das mínimas, para a Argentina. Valores estimados, para 1 
gumas localidades anteriormente não incluidas na elaboração do seu método, comparados aos valores obtidos por outros autores, mostraram apenas pequenas diferenças, permitindo ao autor garan tir a utilização deste método na Argentina, embora somente para fins climatológicos, uma vez que os dados de temperatura utilizados são valores normais. Para localidades com altitude superior a $1.000 \mathrm{~m}$ acima do nível médio do mar a utilização do méto do não foí considerada välida. 0 autor pressupõe que seu método poderia ser aplicado em outras regiões relativamente pla nas, desde que se façam os devidos ajustes.

ANGELOCCI et alii (1979) desenvolveram uma metodologia para a estimativa do total diārio de horas de frio abaixo de de terminada temperatura base para 5 locais no Estado de Sãopaulo, através de equaçōes matemáticas derivadas do padrão de variação diārio da temperatura do ar. As equações utilizam apenas os va lores diārios de observação de temperatura mäxima, mínima e das 21 horas, hora local, como variáveis que governam a marcha diária da temperatura do ar. Testando as equações para cinco localidades do Estado de São Paulo, obtiveram correlação elevada e significativa $(0,88$ à 0,97$)$ entre os valores diários de horas de frio estimados e os observados nos termogramas, tomando como temperatura base os valores de $7^{\circ} \mathrm{C}$ e $13^{\circ} \mathrm{C}$. Verificaram que as equações obtidas, de um modo geral, superestimaram os valores de horas de frio quando estes eram baixos e subestimaram os mes mos quando o total diário de horas de frio era superior à 12 ho ras e à 8 horas, respectivamente, para as temperaturas base de $13^{\circ} \mathrm{C}$ e $7^{\circ} \mathrm{C}$. A correlação entre as somas mensais de horas de frio estimadas e as observadas foi de 0,99, mostrando que o método é válido para a estimativa do total de horas de frio do período diário e torna-se ainda melhor, se considerada a soma mensal dos valores diários. Os autores sugerem que o modelo utilizado seja aplicável a outras localidades no estado e sirva para outros Estados do Brasil, por basear-se no padrão de variação diário da temperatura do ar, podendo as equações serem testadas e utilizadas desde que se façam os devidos ajustes. 


\section{MATERIAL E METODOS}

Para a elaboração desse trabalho foram utilizados os dados das leituras diárias regulares de temperatura do ar e as cópias dos termogramas semanais, dos anos de 1968 à 1972 e de 1975 à 1982, obtidos na Estação Climatológica Principal de Santa Maria, pertencente ao 8: Distrito de Meteorologia do Instituto Nacional de Meteorologia e localizada no Campus da UFSM (Lat. $=29^{\circ} 42^{\prime} \mathrm{S} ;$ Long. $=53^{\circ} 42^{\prime} \mathrm{W} ; \mathrm{Alt} .=95 \mathrm{~m}$ acima do N.M. M.).

" O clima local, segundo a classificação climática de W.Koeppen, é do tipo cfa, isto é, clima subtropical ümido.

o processamento estatistico dos dados foi efetuado em um computador IBM 1130, locado no Departamento de Matemá tica e Estatistica, pertecente a ESALQ/USP.

A anälise dos dados dos anos considerados foi efe tuada para cada més do período mais frio do ano, excluindo-se do estudo os meses de novembro a março, nos quais a ocorréncia de temperaturas menores do que $13^{\circ} \mathrm{C}$ é pouco frequente no local.

Nestes meses foram selecionados os dados dos dias em que a temperatura mínima do ar foi menor ou igual a $13^{\circ} \mathrm{C}$. Pa ra esses dias foram coletados e tabulados os dados diários de temperatura mínima do ar (Tm), temperatura máxima do ar do dia 
anterior ( $T M_{1}$ ), temperatura mäxima do ar do dia em questão( $\left.T M_{2}\right)$, temperatura do ar das 9 hs, hora local ( $T_{g}$ ), temperatura do ar das 15 hs, hora local ( $T_{15}$ ), temperatura do ar das 21 hs do dia anterior, hora local ( $\left.\mathrm{T}_{2}\right)$, horärio de ocorrência da "Tm" (hTm), horário de ocorrência da "TM 2 " (hTM 2 ), total de horas de frio com temperatura menor que $7^{\circ} \mathrm{C}(H F<7)$ e total diärio de horas de frio com temperatura menor que $13^{\circ} \mathrm{C}(\mathrm{HF}<13)$.

O horário de ocorréncia das temperaturas máxima e minima foi obtido somente dos termogramas nos quais havia o registro da correção horäria, nos dias em que $T m \leqslant 13^{\circ} \mathrm{C}$.

Com base no estudo da distribuição do horārio de ocorrência das temperaturas mínimas e máximas diārias de cada mês, o total diário de horas de frio abaixo de determinada tem peratura base $(H F<T B)$ de cada dia ( $n$ ) foi computado a partir dos termogramas, considerando-se o intervalo entre 15 horas do dia anterior $(n-1)$ e 15 horas do dia $(n)$ em questão.

Sempreque necessário, foram consideradas as corre çöes de temperatura nos termogramas, tomando-se como referência os dados de leitura direta feita com termômetros (Tm, TM, TM 2 , $T_{9}, T_{15}$ e $T_{21}$ ). Porém, sempre que a diferença entre ovalor da temperatura registrado no termograma e o valor medido com termô metro excedia $0,8^{\circ} \mathrm{C}$, eliminou-se os dados desse dia.

Uti lizando o método dos quadrados mínimos, para cada mês foram ajustadas equações de regressão aos dados, por correlação simples ou mültipla do total diärio de horas de frio ( HF < TB) com os valores das leituras diretas da temperatura do ar, consideradas como variáveis independentes.

0 valores de "TM,", "TMM ${ }_{2}$ e "T, 15 ", nāo foram introduzidos diretamente na anālise por correlação, porém foram utilizados na obtenção de duas variáveis independentes calcula das da seguinte forma:

a) valor médio das variāveis independentes ( $T \bar{X})$ : 


$$
T \bar{X}=\frac{\left(\frac{T M_{1}+T M_{2}}{2}\right)+T m+T_{9}+T_{15}+T_{21}}{5}
$$

b) relação das amplitudes térmicas entre TB e Tm, e entre a média das temperaturas máximas e $\mathrm{Tm}$ :

$$
R A=\frac{24(T B-T m)}{\left(\frac{T M+T M_{2}}{2}\right)-T m}
$$

o valor médio das variáveis independentes

foi proposto com a finalidade de substituir o valor médio da temperatura do ar no período considerado ( 15 horas do dia "n-1" às 15 horas do dia "n"). Entretanto, num teste preliminar, de correlação simples dos totais diārios de horas de frio (HF< $<B$ ), com cada uma das variáveis independentes, em dois meses escolhi dos ao acaso, a variável "TX" apresentou baixa correlação com "HF < TB" nos dois meses, sendo a mesma eliminada do progra ma de análise de regressão, tendo em vista uma previsão de redú zir de aproximadamente 9 horas o tempo global de uso do computador. Desta forma, as quatro variáveis independentes efetivamente correlacionadas com os totais diärios de horas de frio co tados nos termogramas, foram "Tm", "T 9 ", "T 21 " e "RA". A tabela 3.1 mostra como essas variáveis independentes foram relacionadas às variáveis dependentes (HF 13 ou $H F<7$ ), na anàlise de regressão.

Para a obtenção das equações de regressão lineares simples ou mültiplas, com a finalidade de - estimar horas de frio com temperatura abaixo de $7^{\circ} \mathrm{C}(\mathrm{HF}<7)$, foram incluídos na análise somente os dados de "Tm", "T $g$ ", "T 21 ", "RA" e "HF< 7 ", dos dias em que observou-se a condição: $T m \leqslant 7^{\circ} \mathrm{C}$.

De acordo com a metodologia proposta por ANGELOCClet azii (1979) e considerando o horário de ocorrência da tem peratura máxima e da temperatura mínima diária, foram obtidas 
Tabela 3.1 - Diferentes combinações das variàveis independentes (Tm, T $9, T_{2 l}$ e RA), utilizadas na correlação simpies ou múltipla como total diário de horas de frio $(H F<T B *)$.

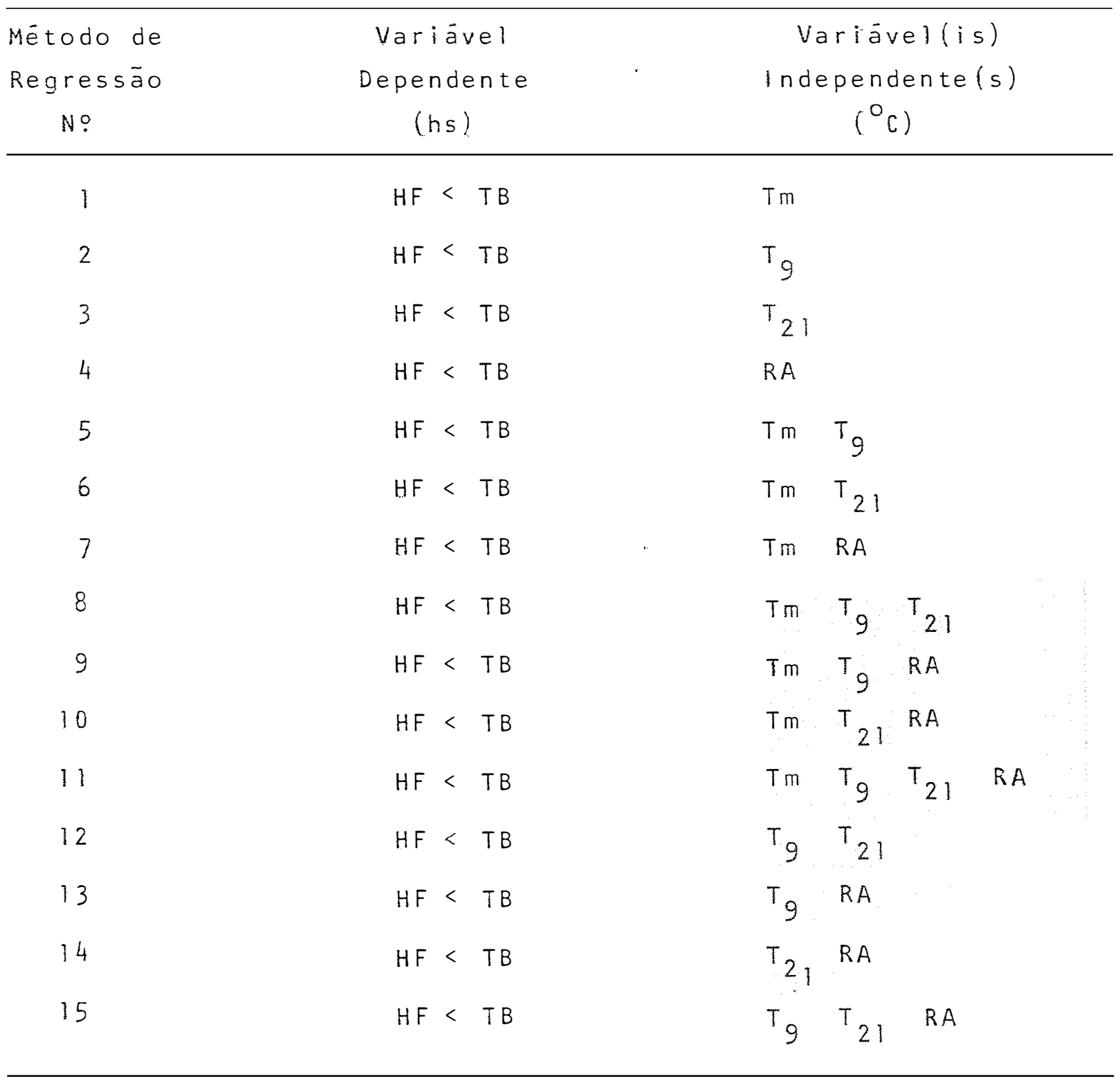

$\dot{*} \mathrm{~TB}$ corresponde às temperaturas base de $7^{\circ} \mathrm{C}$ e de $13^{\circ} \mathrm{C}$, analisadas separadamente. 
diversas equações analíticas para a estimativa do total diārio de horas de frio, conforme os padrões de variação diária da tem peratura do ar, os quais estabelecem diversas condições alternatiyas para a escolha da equação anấitica froprie para cada caso. Para tanto obteve-se o horário de ocorréncia da temperatura mínima e da temperatura máxima dos dias com "T $T_{m} \leqslant 13^{\circ} \mathrm{C}^{\prime}$, a partir dos termogra mas, desde que estes apresentassem o registro da correçãohoräria. Efetuou-se a distribuição das frequências observadas do "h $T_{m}$ " e do "h $\mathrm{T}_{\mathrm{m}_{2}}$ ", para cada mes. Com base nessa distribuição, considerando os horários de máximas frequéncias observadas, tomou-se como välido o horário das 7 horas, hora local, como sendo omomento de ocorrência da temperatura mínima diária, para todos os meses es tudados, enquanto que o período das 15 horas às 16 horas foi con siderado de temperatura constante e também como o instante de ocorréncia da temperatura máxima diária, para os 7 meses estudados. Dessa forma, o período diārio foi dividido em quatro subperíodos (15 hs às 16 hs; 16 hs às 21 hs; 21 hs às 7 hs; 7 hs às 15 hs), e as equações analíticas para as diferentes condições de va riação da temperatura do ar no decorrer do dia resultaramem:

a. para a condição de:

$$
\begin{aligned}
& T B>T m ; T B \leqslant T T_{21} ; T B<T M_{1} ; T B<T M_{2} ; \\
& H F=\frac{10(T B-T m)}{T_{21}-T m}+\frac{8(T B-T m)}{T M_{2}-T_{m}}
\end{aligned}
$$

b. para a condição de:

$T B>T m ; T B \geqslant T 21 ; T B<T M_{1} ; T B<T M_{2}:$

$$
H F=\frac{5\left(T B-T_{21}\right)}{T M_{1}-T_{21}}+\frac{8\left(T B-T_{m}\right)}{T M_{2}-T_{m}}+10 ;
$$

c. para a condição de:

$$
\begin{aligned}
& T B>T m ; T B \geqslant T M_{1} ; T B<T M_{2}: \\
& H F=\frac{8(T B-T m)}{T M_{2}-T m}+16 ;
\end{aligned}
$$


d. para a condição de:

$$
\begin{aligned}
& T B>T M ; T B \geqslant T M_{2} ; T B \geqslant T_{21}: T B<T M_{1}: \\
& H F=\frac{5\left(T B-T_{21}\right)}{T M_{1}-T_{21}}+18
\end{aligned}
$$

e. para a condição de:

$$
\begin{aligned}
& T B>T m ; T B \leqslant T T_{21} ; T B<T M_{1} ; T B>T M_{2}: \\
& H F=\frac{10(T B-T m)}{T_{21}-T m}+8 ;
\end{aligned}
$$

f. para $T B \geqslant T M_{1} ; T B \geqslant T M_{2}:$

$$
H F=24 ;
$$

g. para $T B \leqslant T m$ :

$$
H F=0 ;
$$

onde:

$\mathrm{TB}=$ temperatura base $\left(7^{\circ} \mathrm{C}\right.$ ou $\left.13^{\circ} \mathrm{C}\right)$;

Tm = temperatura mínima diària;

$T_{21}=$ temperatura das 21 horas do dia anterior;

$T M_{1}=$ temperatura mäxima do dia anterior;

$T M_{2}=$ temperatura máxima do dia;

HF = total diàrio de horas de frio com temperatura abaixo da temperatura base;

$5=$ constante de tempo em horas entre TM, e T 21 ;

$10=$ constante de tempo em horas entre T21 e Tm;

$8=$ constante de tempo em horas entre $T M_{1}$ e $T M_{2}$.

Os totais diários de horas de frio (HF $<13$ e $H F<7$ ) estimados com as equaçōes analiticas (mët. 16), foram correlacionados com os respectivos totais diärios de horas de frio cotados nos termogramas, em cada més. Procedimento igual 
foi adotado com os totais diários de horas de frio estimadas a través de cada uma das equações de regressão (métodos 1 a 15). os coeficientes de correlação "r" obtidos foram utilizados para calcular os respectivos valores da transformação $z(r)$, possibilitando a aplicação de testes, quando a comparação de dois ou mais coeficientes de correlação. A transformação z(r), segundo GoMes (1973), é dada pela equação:

$$
z(r)=0,5 \ln \left(\frac{1+r}{1-r}\right),
$$

onde:

$r=$ coeficiente de correlação entre os totais diārios de horas de frio estimados e observados nos termogramas;

In = logarítmo neperiano.

A comparação dos diferentes métodos de estimativa foi efetuada em cada mês através da comparação dos respecti vos coeficientes de correlação entre os totais diàrios de horas de frio estimados e observados, pelo teste $t$, utilizando- se a transformação z $(r)$. o valor de t foi calculado em função da diferença entre os valores $z(r)$ de dois diferentes métodos em cada mês, utilizando-se a expressão:

$$
t=\frac{z(r)-z\left(r^{1}\right)}{\sqrt{z / N-3}}
$$

onde:

$N=$ nümero de totais diārios de horas de frio, observados e estimados, correlacionados em cada mês;

$z(r)$ e $z\left(r^{\prime}\right)=$ valores da transformação $z(r)$ dos coeficientes de correlação de dois métodos diferentes.

Para facilitar a tarefa de comparação dos métodos, utilizando-se o valor de $t_{v}$ para o nivel de $5 \%$ de probabi lidade $\left(t_{v}=1,96\right)$, rearranjou-se a expressão 3.11 da seguinte forma:

$$
\left|z(r)-z\left(r^{\prime}\right)\right|=1,96 \cdot \sqrt{2 / N-3},
$$


onde $\left|z(r)-z\left(r^{\prime}\right)\right|$, denominado "intervalo de tolerância", é - valor absoluto da diferença máxima entre os valores de $z(r)$ dos diferentes métodos que não apresentam diferença estatística entre si, ao nível de 5\% de probabiiidade. 
A precisão das estimativas de horas de frio efetuadas através das equações analiticas (método 16), pode ser comprometida ao se estabelecer um horário padrão como instante único de ocorrência da temperatura minima e ou da temperatura máxima, quando no local em estudo os horários reais de ocorrēn cia das temperaturas mínima (Tm) e máxima (TM) apresentam gran de variabilidade dentro do periodo diário, considerando-se os dados de cada mês. Nesse caso, o tempo em horas nos intervalos: (a) entre o momento de ocorrência da temperatura máxima do dia anterior e 21 horas do dia anterior; (b) entre 21 horas do dia anterior e o instante de ocorrência da temperatura mínima(hTm); (c) e entre este (hTm) e o momento de ocorrência da temperatura máxima do dia, não poderia ser padronizado para todos os da dos de cada mês e sua definição para cada dado diário em parti cular, tornaria o método inadequado quanto aos objetivos estabelecidos, pois haveria a necessidade de se recorrer aos regís tros de temperatura do ar nos termogramas.

As figuras 1 e 2 mostram, para cada mês, a distribuição diāria das frequências observadas do horário de ocor rência das temperaturas mínimas (hTm) e máximas (hTm), respectivamente, considerando-se apenas os dias em que se observou a condição: $\operatorname{Tm} \leqslant 13^{\circ} \mathrm{C}$. 

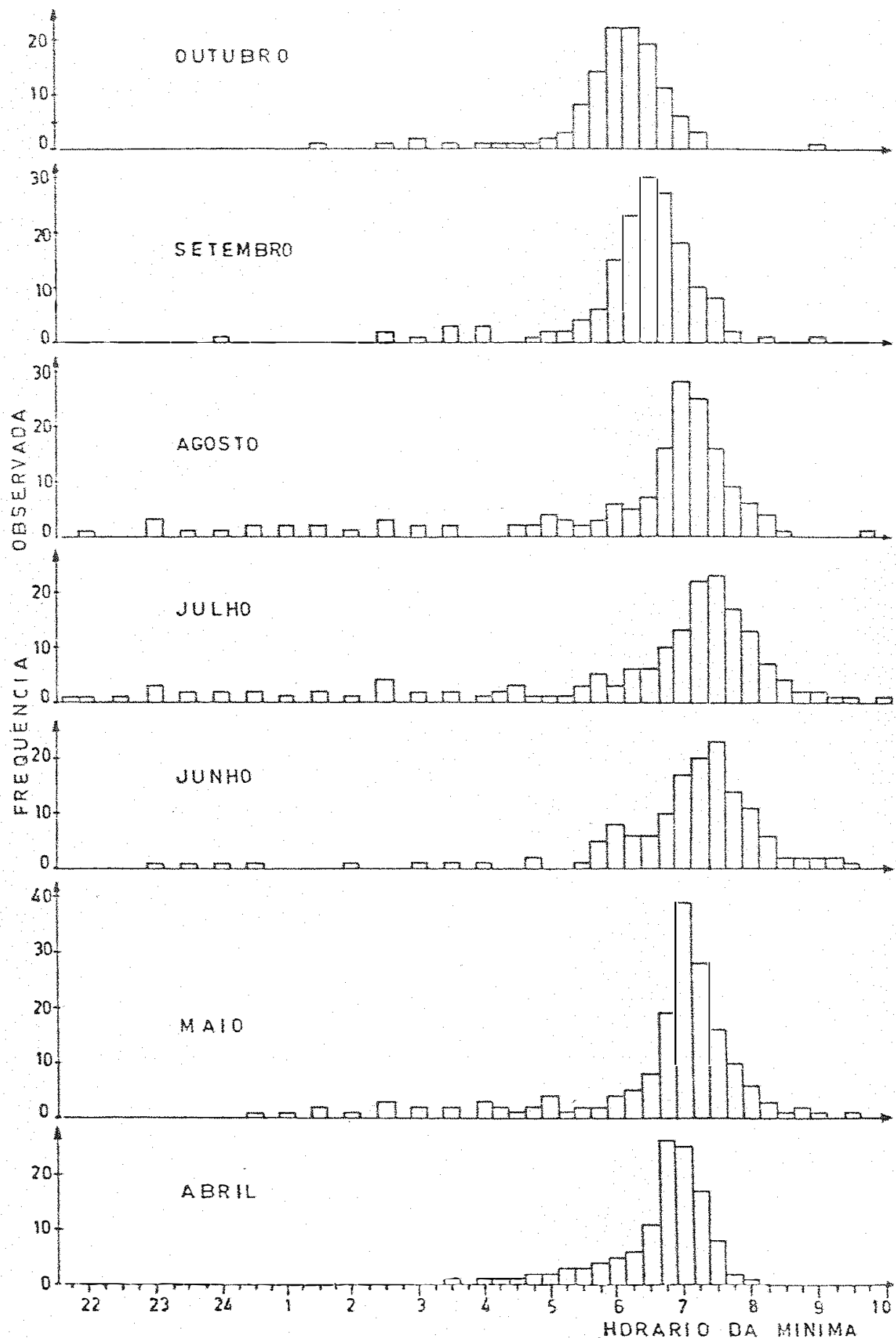

Figura 1 - Freqlência observada do horário de ocorréncia da temperatura minima nos dias com temperatura minima menor ou igual a $13^{\circ} \mathrm{C}$, para os diferentes meses, em Santa Maria - RS. 


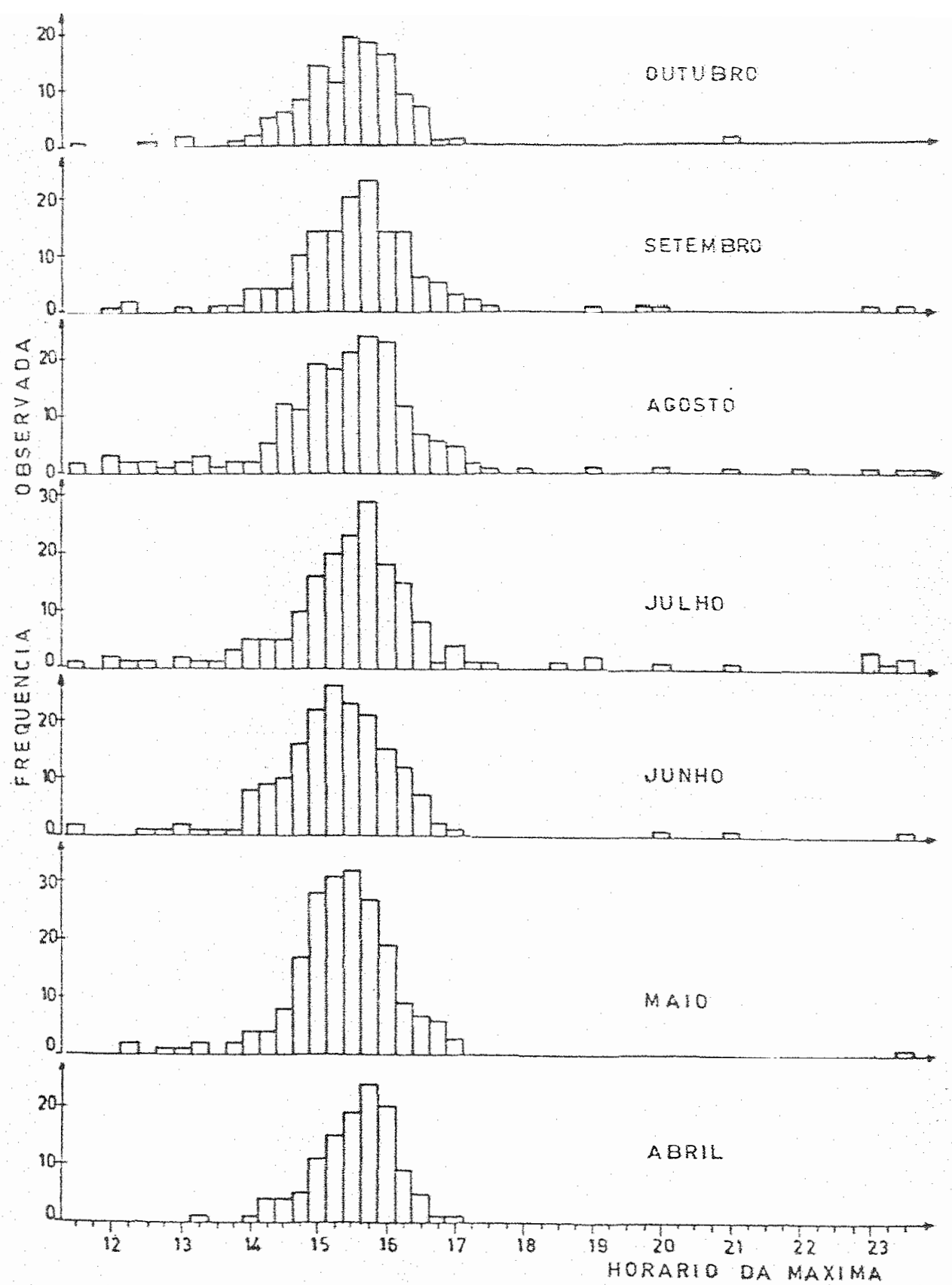

Figura 2 - Frequéncia observada do horärio de ocorrência da temperatura máxima nos dias em que a temperatura mínima foi menor ou igual a $13^{\circ} \mathrm{C}$, para os diferentes meses, em Santa Maria-RS. 
Observa-se que a distribuição das frequéncias do horärio de ocorrência das temperaturas minimas, não obedece exatamente uma distribuição normal, mostrando que não é rara a ocorrência da temperatura minima durante a madrugada, ou mesmo antes das 24 horas do dia anterior, principalmente nos meses mais frios. Entretanto, verificou-se nos termogramas que, nesses casos, após a ocorrência da temperatura mínima, a temperatura do ar se eleva muito pouco até o momento do nascer do sol, permanecendo abaixo da temperatura base em grande parte dos ca sos. Por outro lado, as superestimativas de horas de frio, decorrentes dos casos em que a temperatura do ar se eleva acima da temperatura base, porēm permanece próxima a mesma desde o momento de ocorrência da "Tm" até o momento do nascer do sol, podem ser negligenciadas quanto aos seus efeitos biológicos.

As frequências máximas dos horärios de ocor rência da temperatura mínima, observadas para Santa Maria-RS, oscilaram em torno das 7 horas, hora local, nos meses de abril, maio e agosto; para junho e julho oscilaram em torno de 7 hs: $: 15^{\prime}$ e 7 hs:30', respectivamente, enquanto que para os meses de setembro e outubro as frequéncias máximas ocorreram em torno de 6 hs: $30^{\prime}$ e 6 hs: 15', respectivamente. Considerando-se es sa pequena variação do valor mediano dos horários de ocorrēncia da "Tm" nos diferentes meses, e em função da argumentação apresentada para a variabilidade dentro de cada més, optou-se por um horário padrão, o que facilitou os cálculos pela utili zação dos mesmos parâmetros nas equações analiticas, para todos os meses estudados. Dessa forma, o horário das 7 horas, hora local, foi fixado como momento de ocorrência da temperatura mí nima para todos os dias dos meses analisados.

A figura 2 mostra que as frequências máximas dos "hTM" concentram-se entre $15 \mathrm{hs}$ e $16 \mathrm{hs}$, em todos os meses. Ve rificou-se também nos termogramas que pröximo da temperatura má xima (TM) a temperatura do ar varia muito pouco, aumentando e decrescendo muito lentamente antes e apös o momento da "TM", res 
pectivamente. Dessa forma, a temperatura do ar fol considerada constante e igual à "TM" entre às 15 hs e 16 hs, para todos os meses. Esse critério já fol adotado com bons resultados por ANGELOCCl et alì (1979), para o período das 14 hs às 15 hs, no Estado de são Paulo.

As tabelas 4.1 à 4.14 apresentam para cada més os pa rámetros linear e angulares das equações de regressão obtidas por correlação simples ou múltipla dos totais diärios de horas de frio, (HF< 13 ou HF $<$ ), com os respectivos valores de tempe ratura mínima ( $T \mathrm{~m})$, temperatura às 9 horas $\left(T_{g}\right)$, temperatura às 21 horas do dia anterior $\left(T_{2 l}\right)$ e razão das amplitudes térmi cas (RA), dada pela expressão: $R A=24(T B-T m) /(\bar{T} M-T m)$, onde TB é a temperatura base $\left(13^{\circ} \mathrm{C}\right.$ ou $\left.7^{\circ} \mathrm{C}\right)$ e $\bar{T} M$ é a média da tem peratura máxima do dia anterior $\left(T M_{1}\right)$ com a temperatura máxima do dia $\left(T_{2}\right)$. São apresentados também os respectivos valores dos coeficientes de determinação $\left(r^{2}\right)$ e de variação (c.V.) tes te F da análise da variância e teste t dos parâmetros angulares das equaçōes de regressão.

As relações gräficas entre os totais diārios de horas de frio observados e estimados atravēs dos diferentes më todos para os meses analisados, são apresentadas nas figuras 3 à 19 e nas figuras 20 à 33, respectivamente, para as tempera turas base de $13^{\circ} \mathrm{C}$ e $7^{\circ} \mathrm{C}$. Adotou-se o critērio arbitrário de não elaborar tal representação gráfica para os casosde regressão simples em que os coeficientes de determinação foram menores que 0,5800 ,ou para os casos em que as equações de regres são mültipla apresentaram pelo menos um dos parâmetros angulares não significativos ao nível de $5 \%$ de probabilidade pelo teste $t$.

A relação das ampli tudes tērmicas (RA), para um período considerado de n horas, dada pela expressão analítica $R A=n(T B-T m) \cdot(T M-T m)^{-1}$, pode ser utilizada diretamente na estimativa do total de horas de frio do periodo, porém é co 


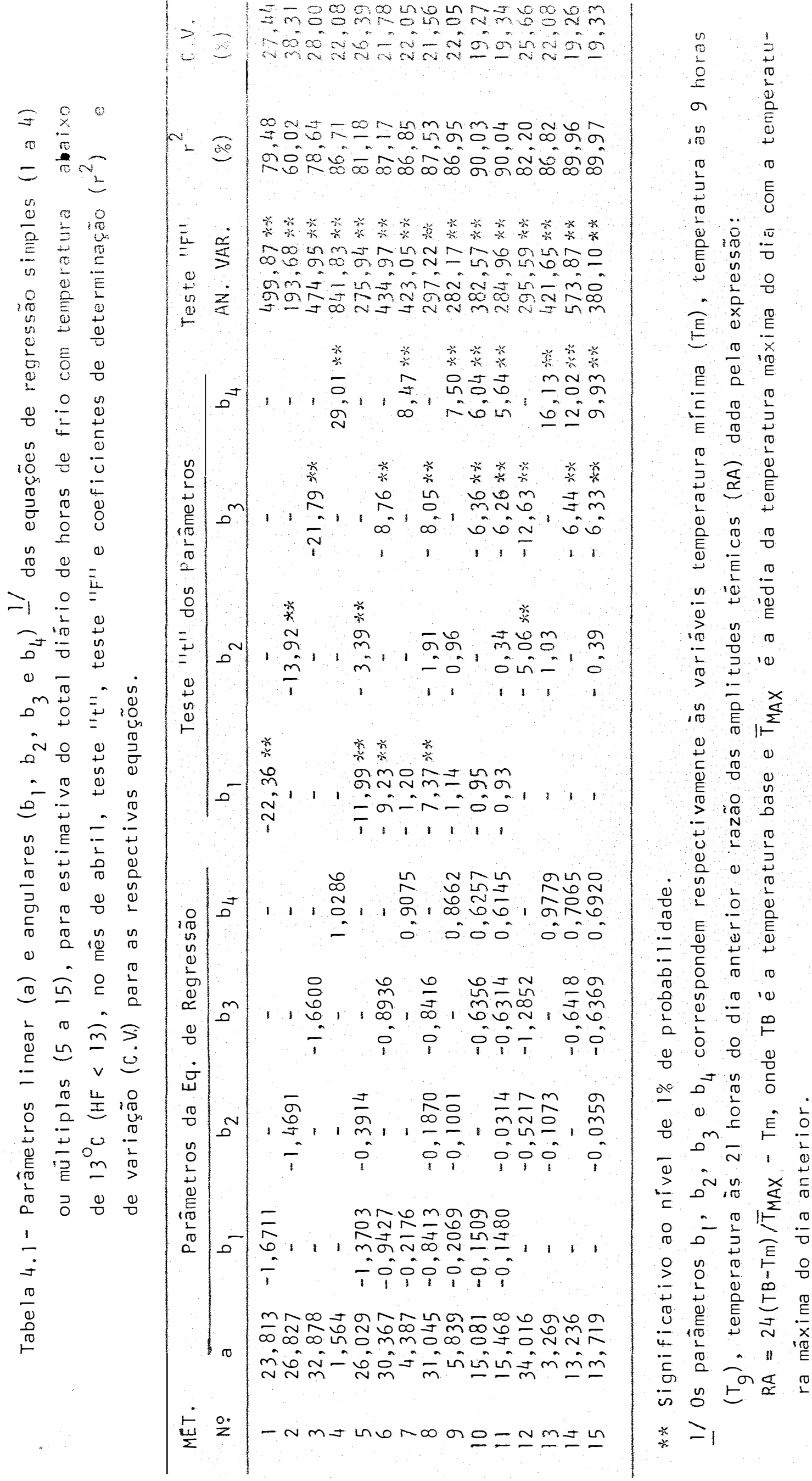




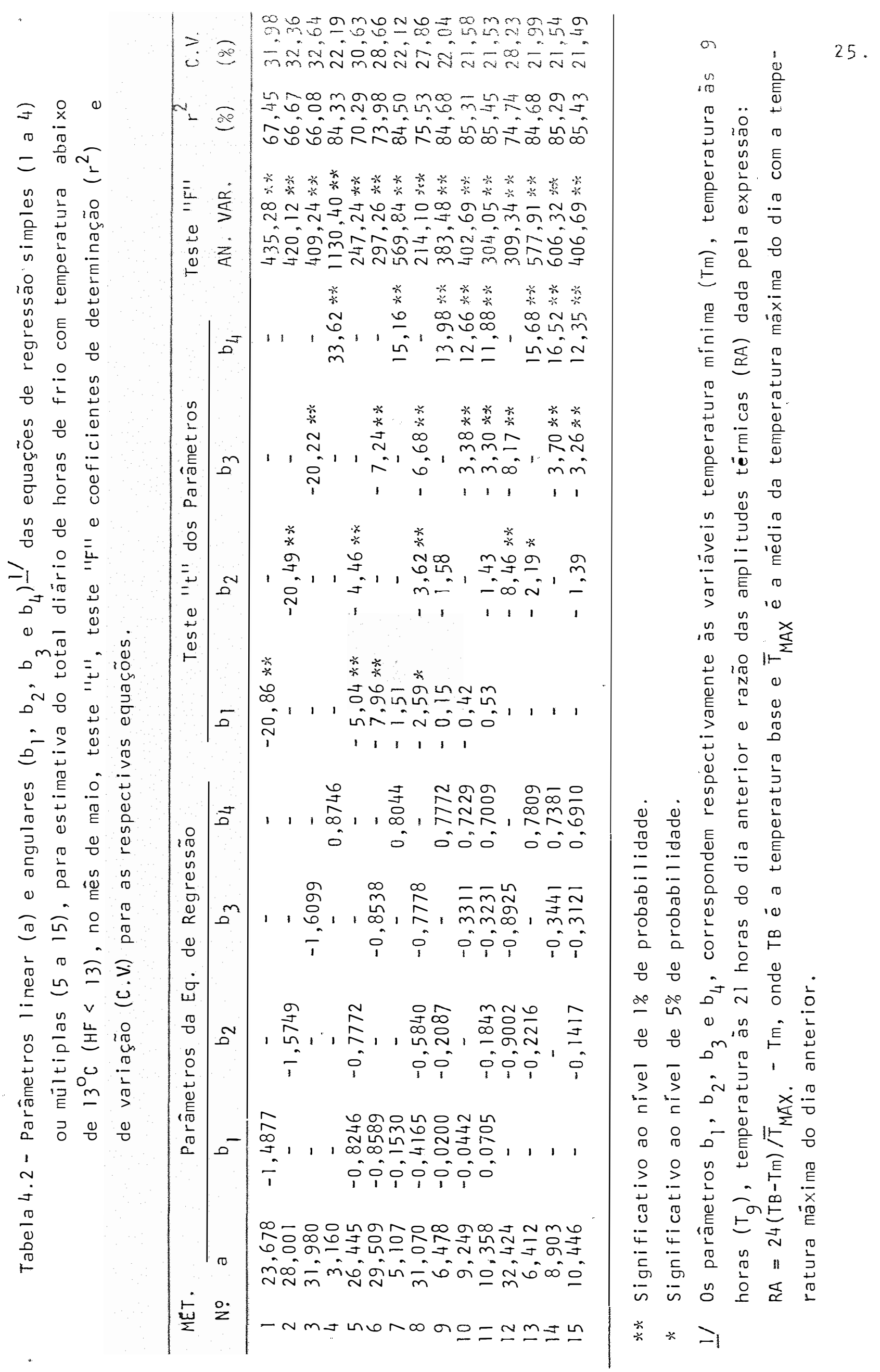




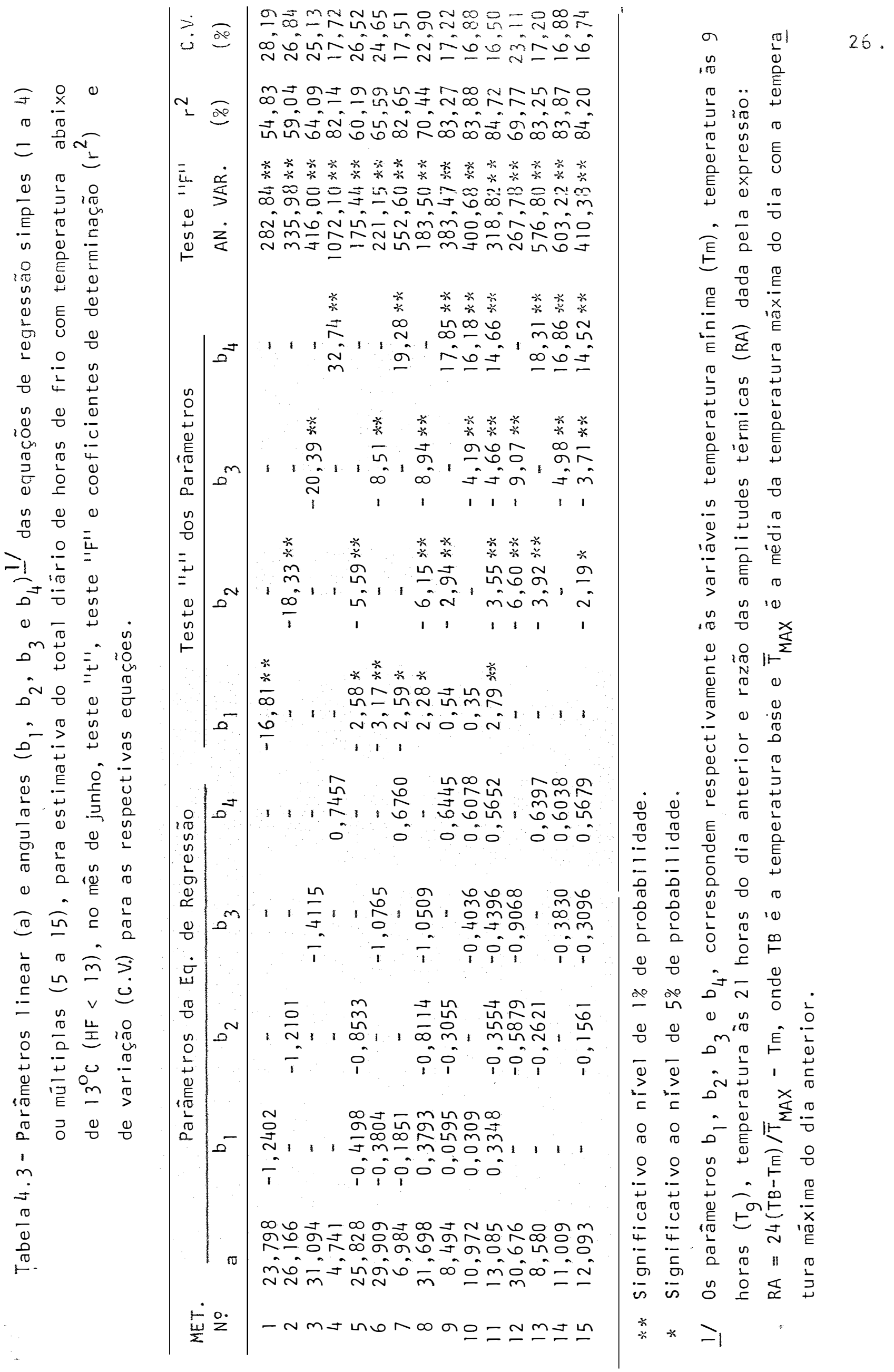




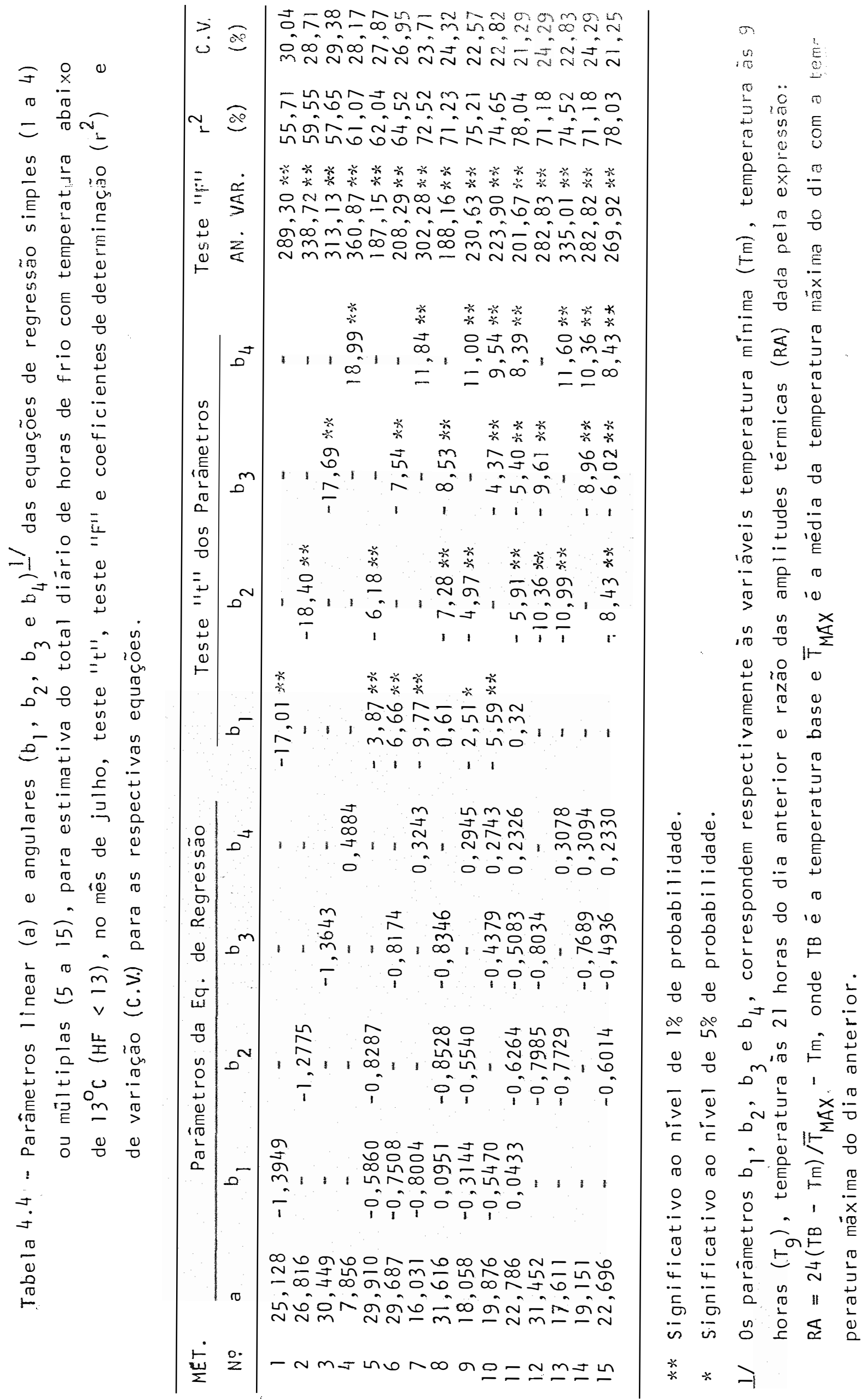

27. 

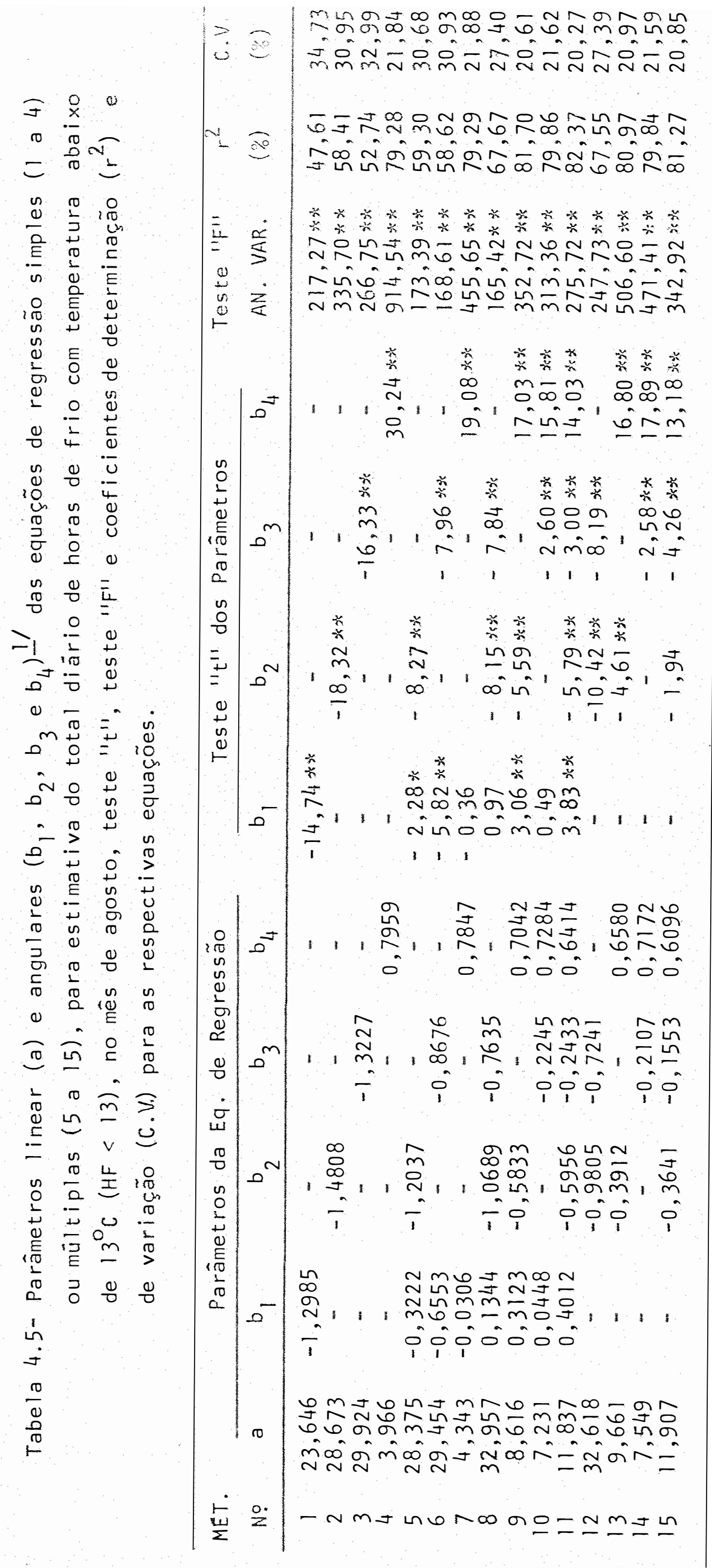


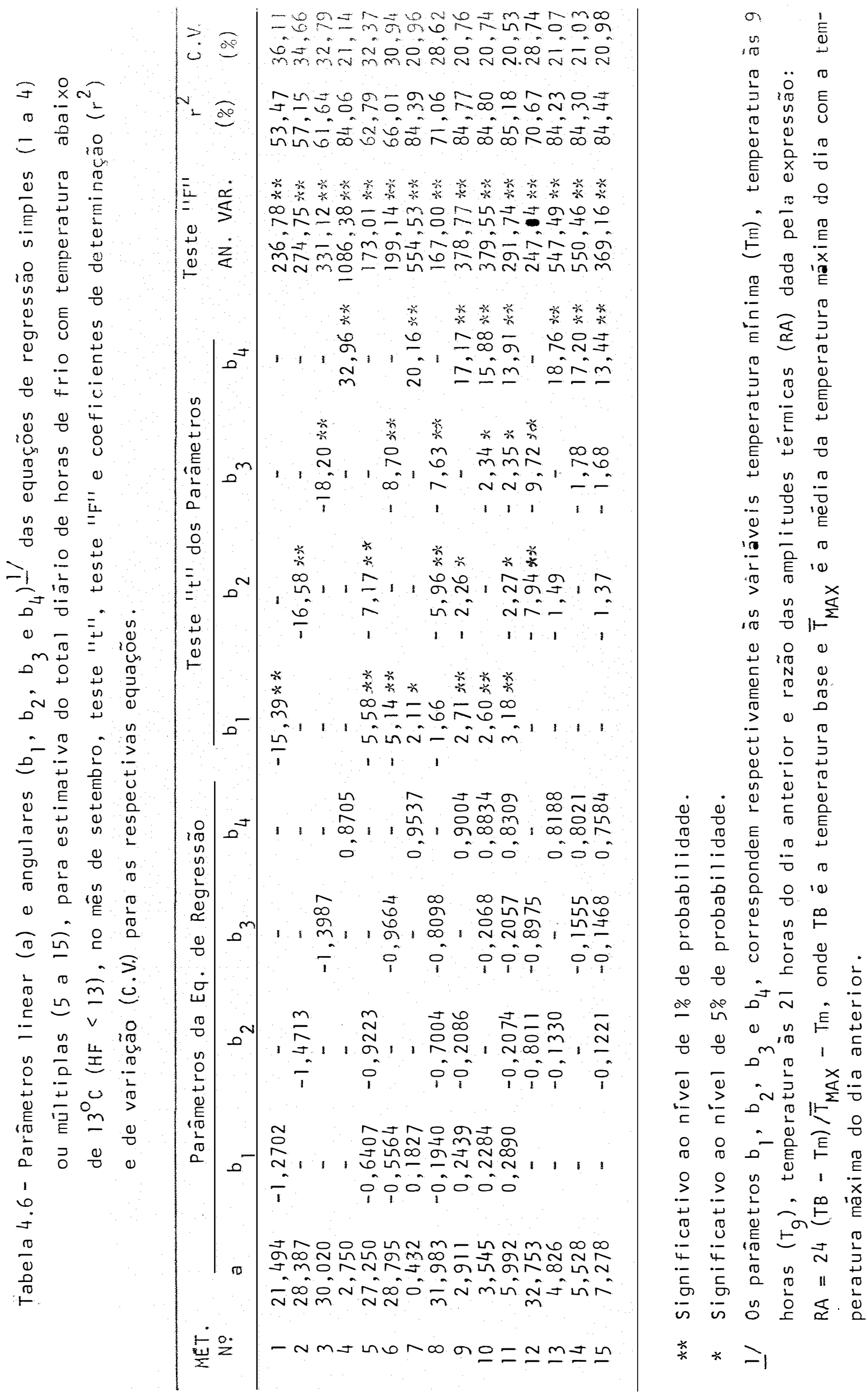




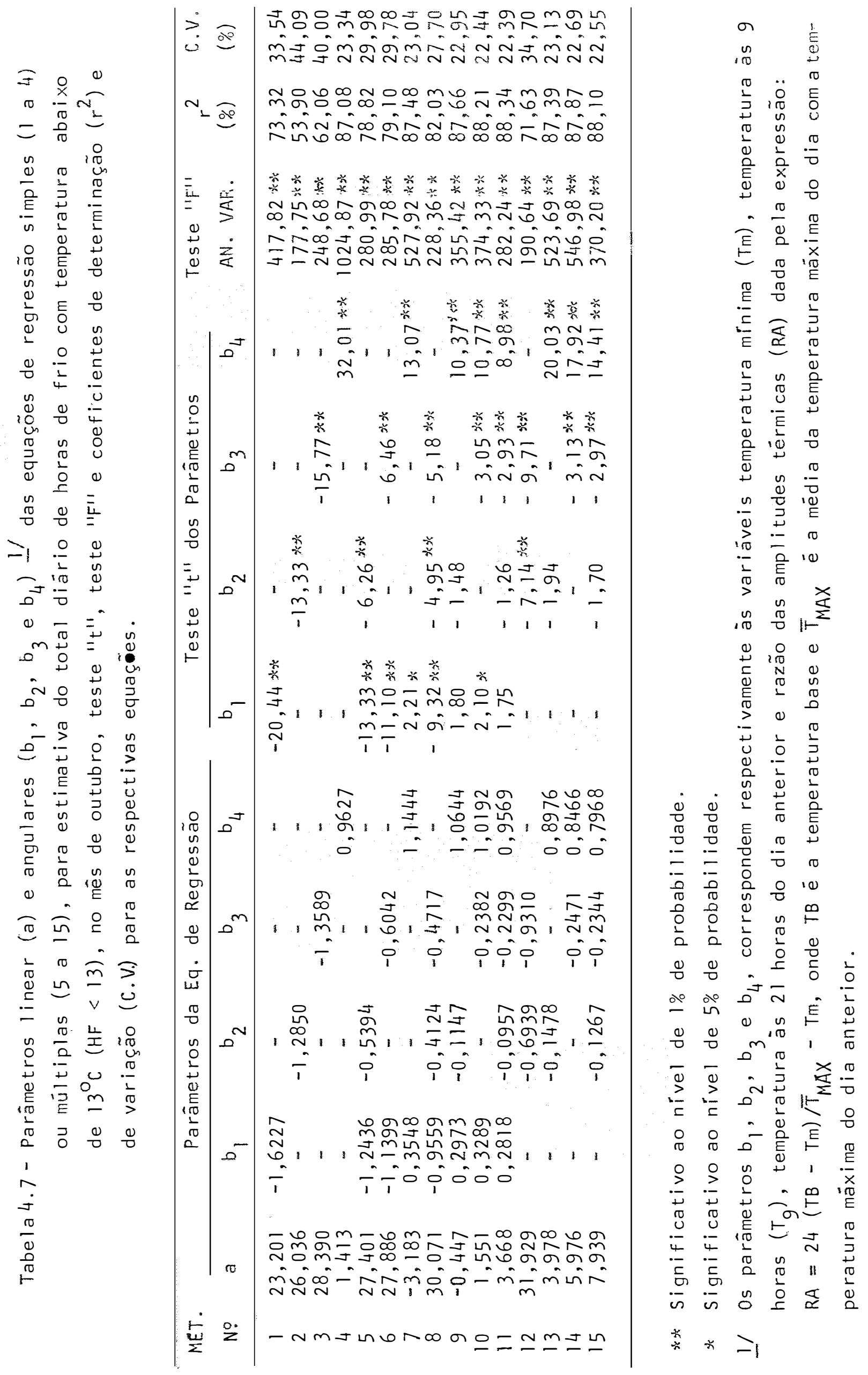



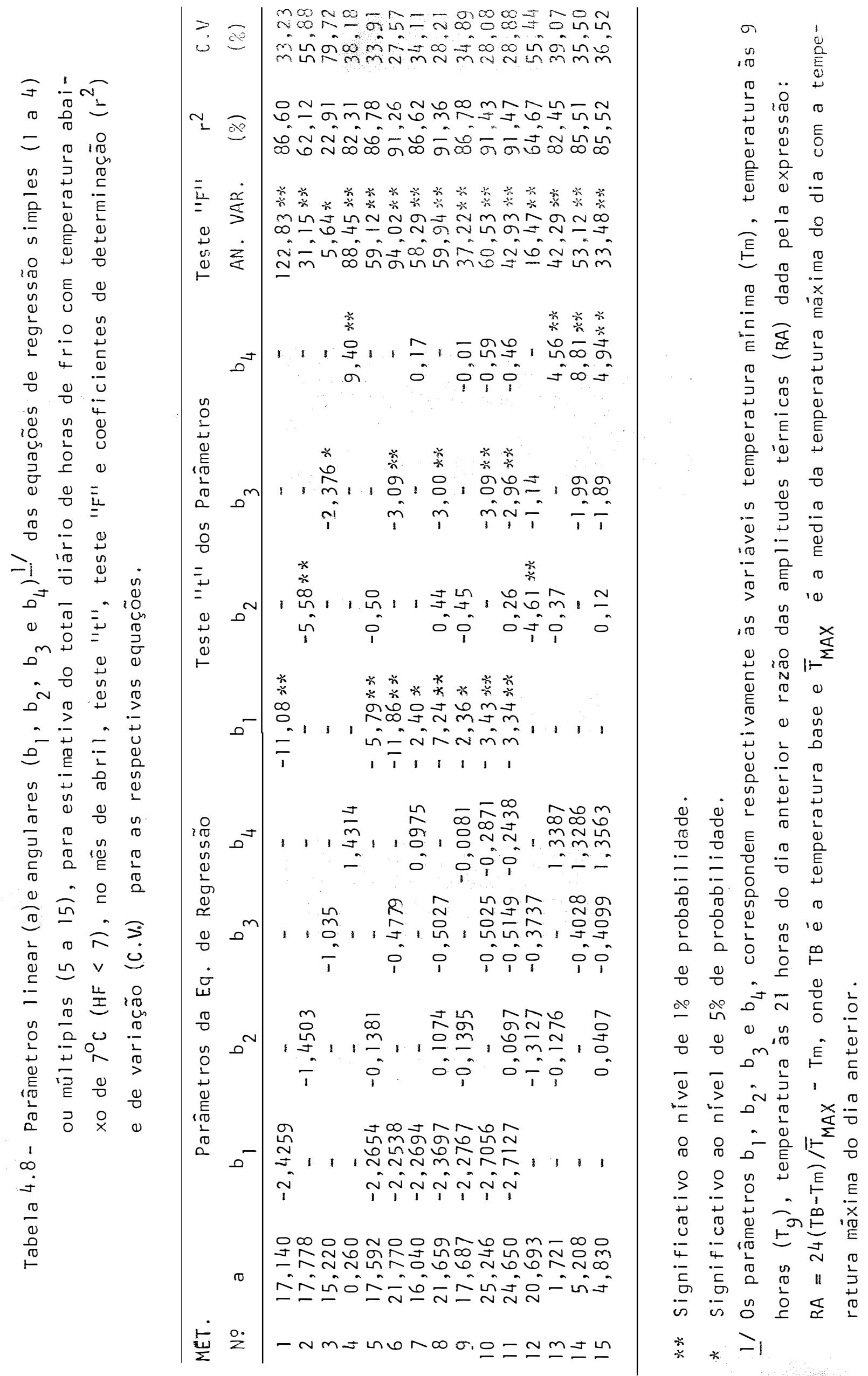


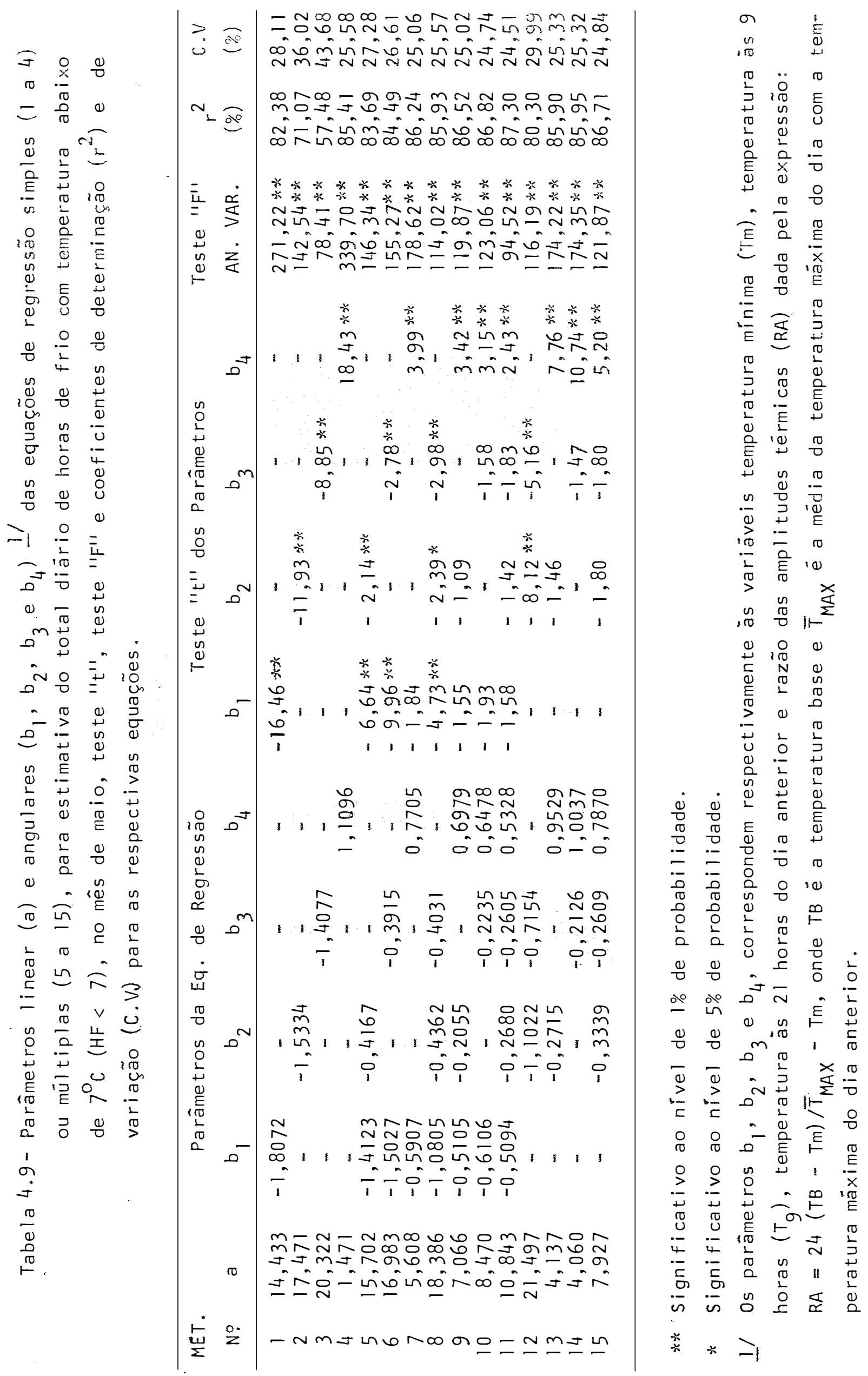




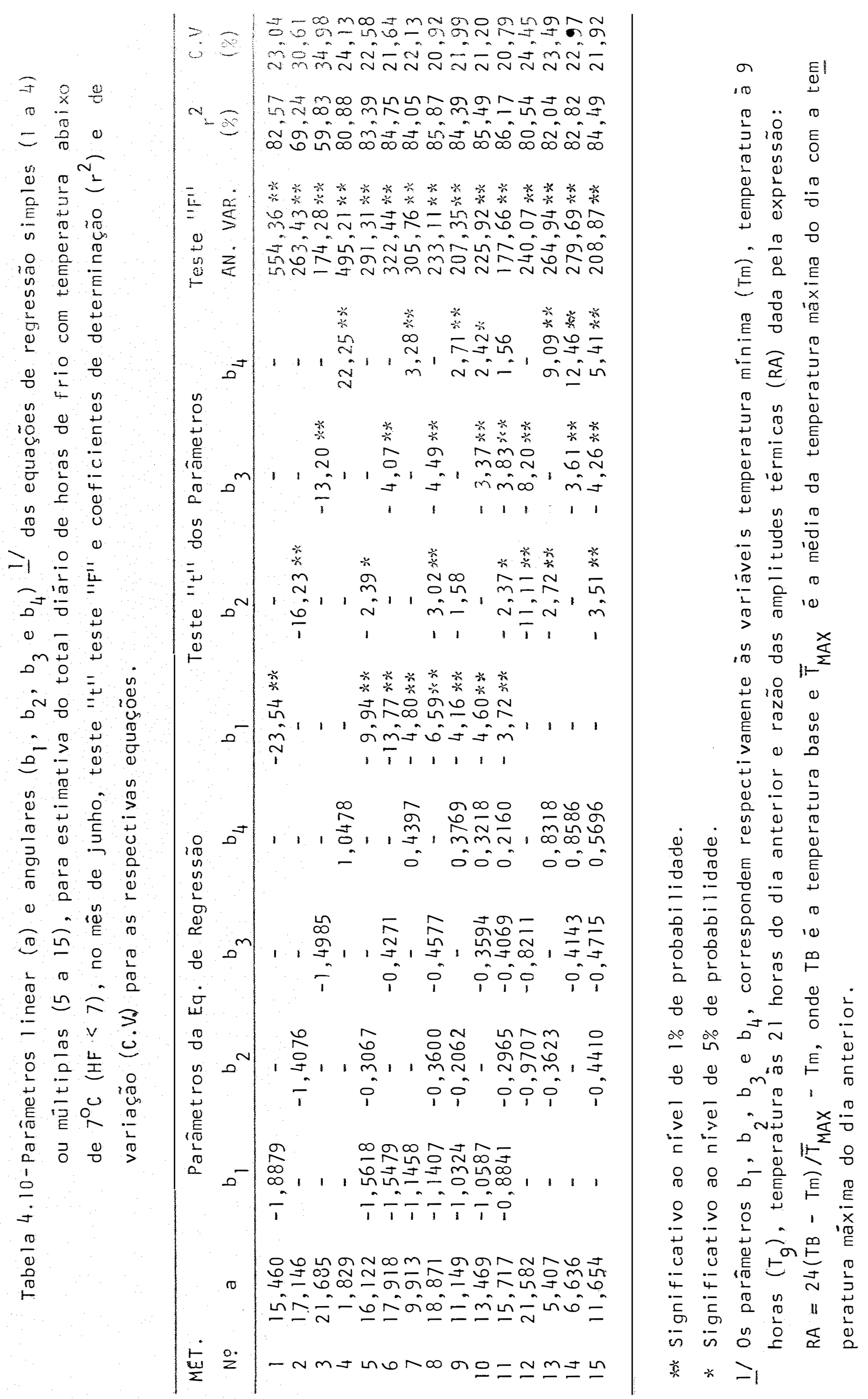




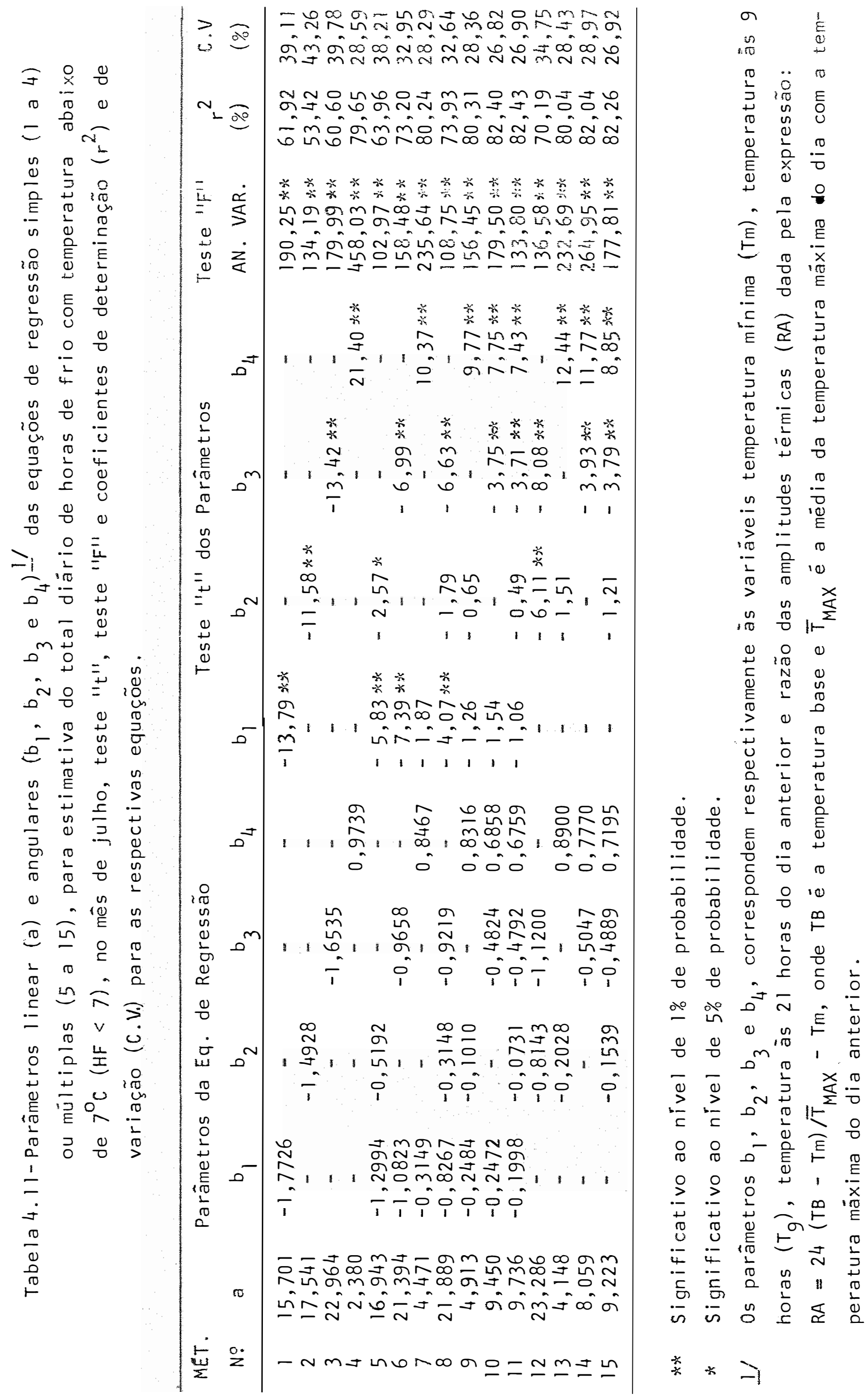




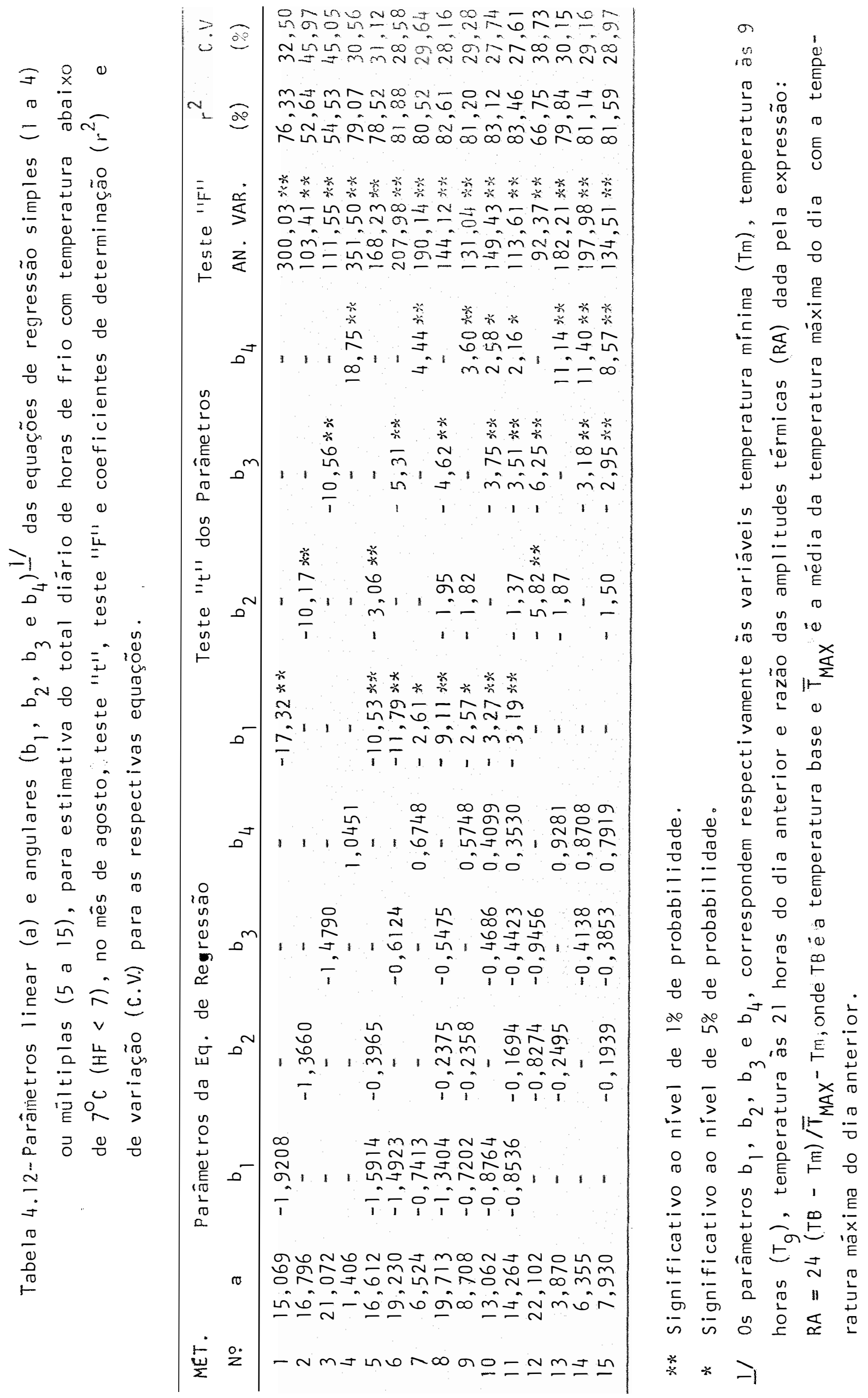




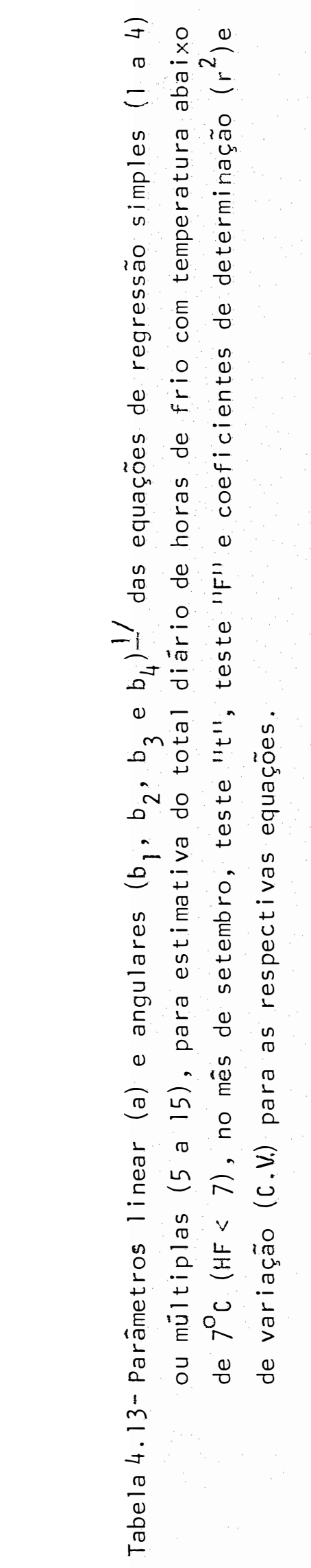

$\dot{n}_{2}$

$\begin{array}{ll}= & 0 \\ = & \frac{\alpha}{5} \\ 0 & \\ \stackrel{0}{0} & \vdots \\ 0 & \vdots\end{array}$

(m)

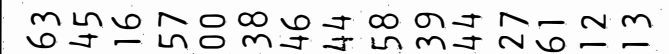
ஸि

* grmm-

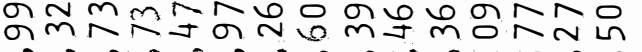

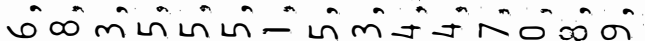
ำ

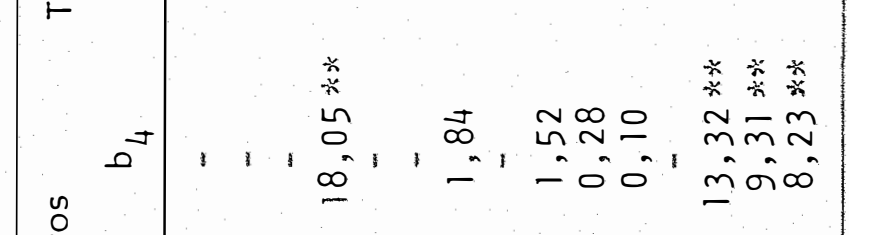

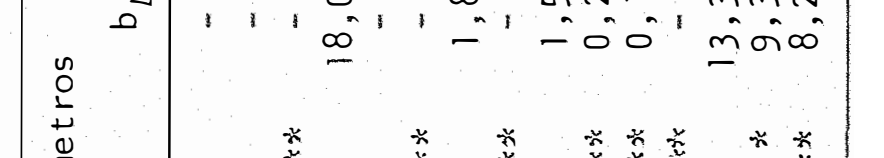

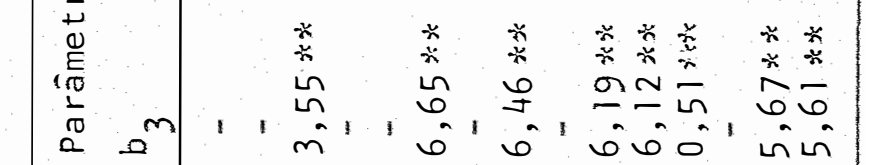

$\begin{array}{lllllllll}0 & 0 \\ n & \frac{m}{1} & 0 & 0 & 0 & 0 & 0 & 1 & 1 \\ 0 & 1 & 1 & 1 & 1 & 1 & 1\end{array}$

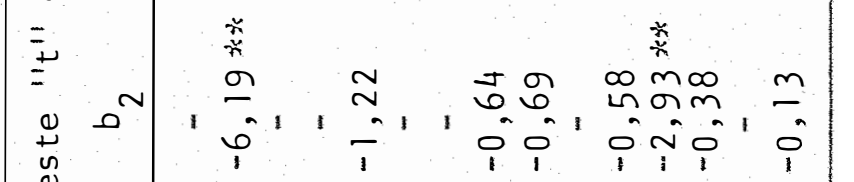
$\stackrel{0}{1}$

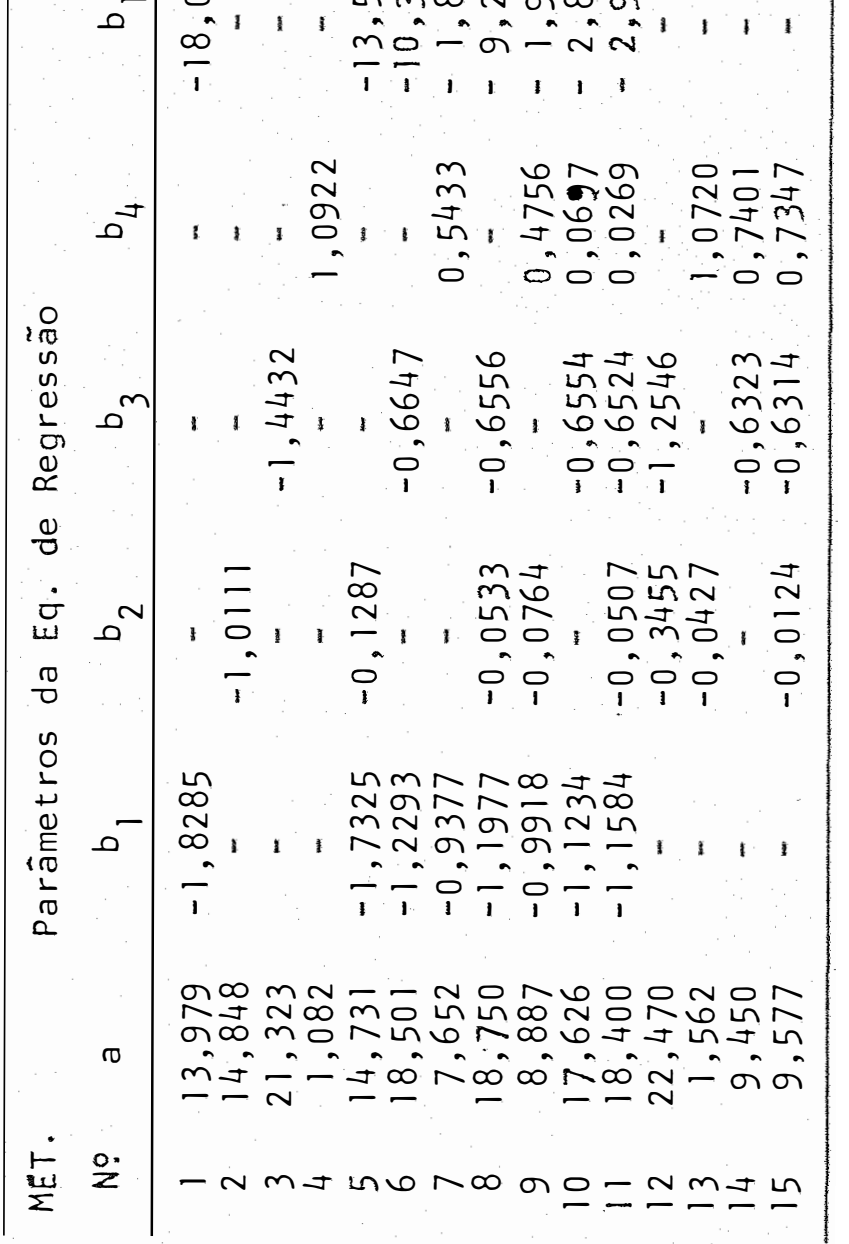

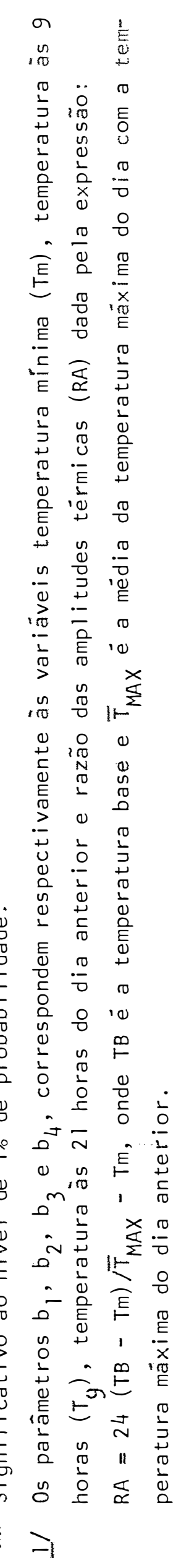




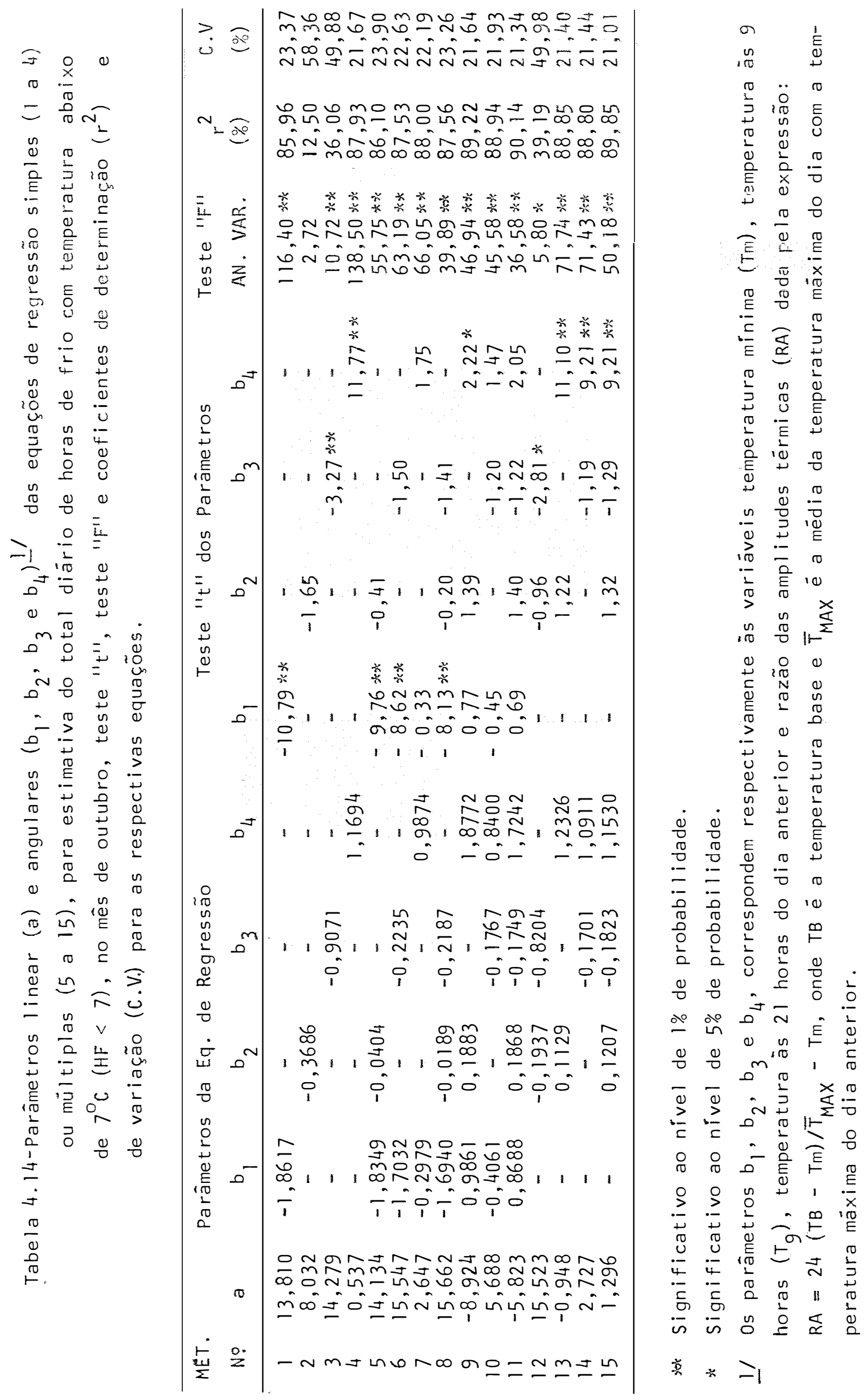



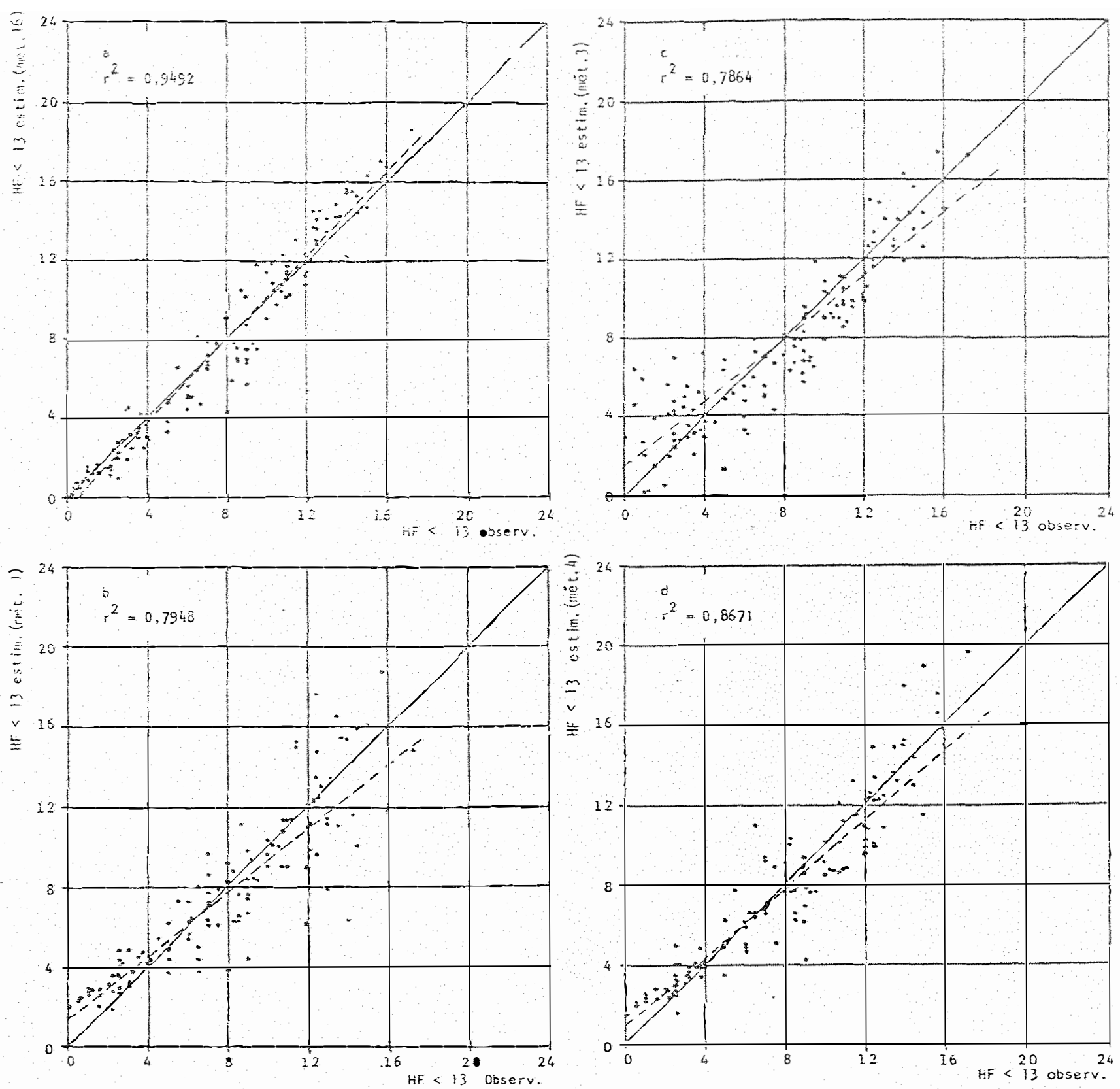

Figura 3 - Correlação entre os totais diärios observados e estimados de horas de frio com temperatura abaixo de $13^{\circ} \mathrm{C}$ ( HF $<13$ observ; HF < 13 estim.), com os respectivos coeficientes de determinação $\left(r^{2}\right)$, no mês de abril. As estimativas fei tas pelos métodos $16,1,3$ e 4, fazem parte dos valores representados nas figuras $3 a, 3 b, 3 c$ e $3 d$, respectivamente. 

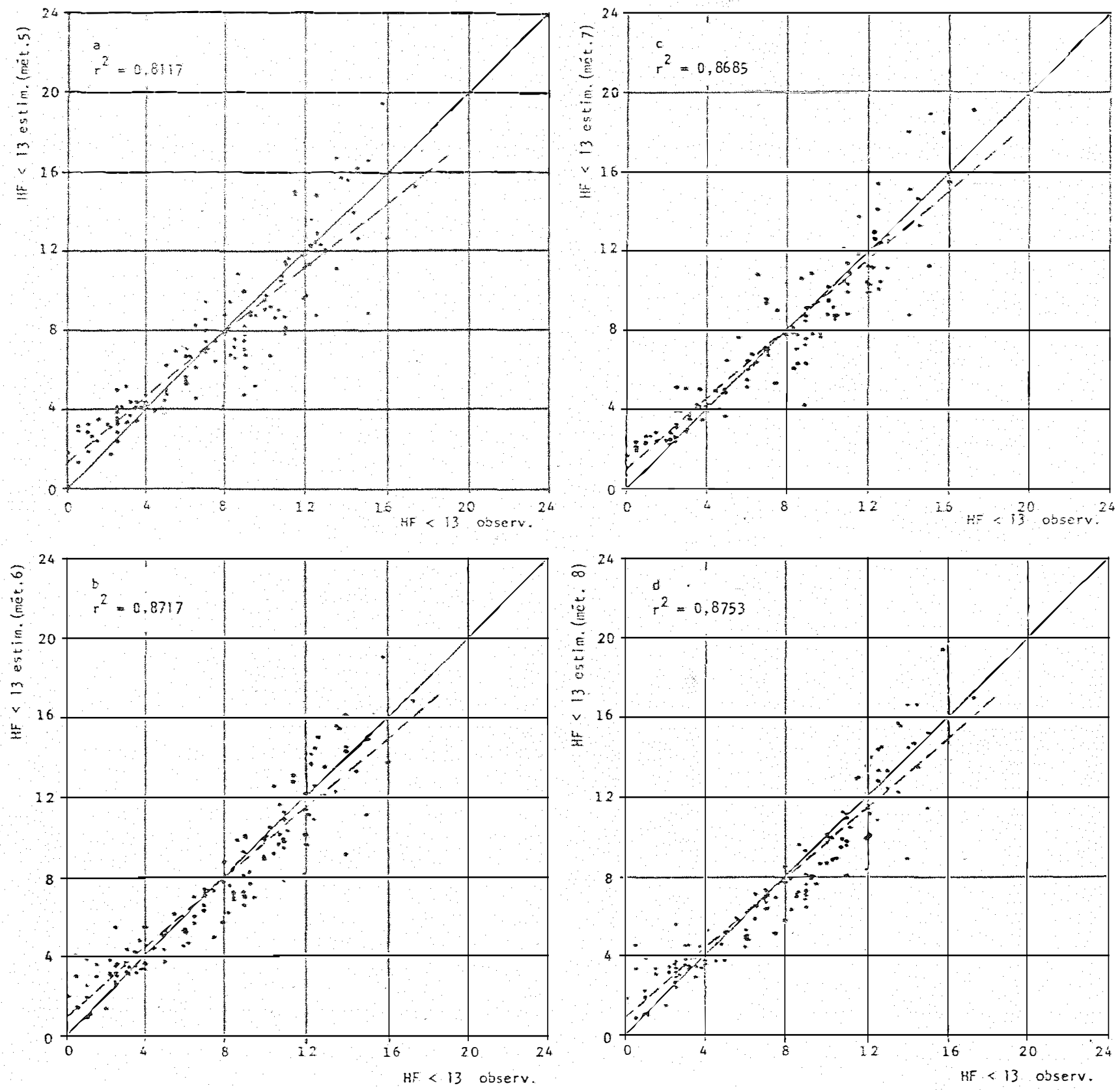

Figura 4 - Correlação entre os totais diários observados e estimados de horas de frio com temperatura abaixo de $13^{\circ} \mathrm{C}$ ( $\mathrm{HF}<13$ observ; $H F<13$ estim.), com os respectivos coeficientes de determinação $\left(r^{2}\right)$, no mês de abril. As estimativas fei tas pelos métodos $5,6,7$ e 8 , fazem parte dos valores representados nas figuras $4 a, 4 b, 4 c$ e $4 d$, respecti vamente. 

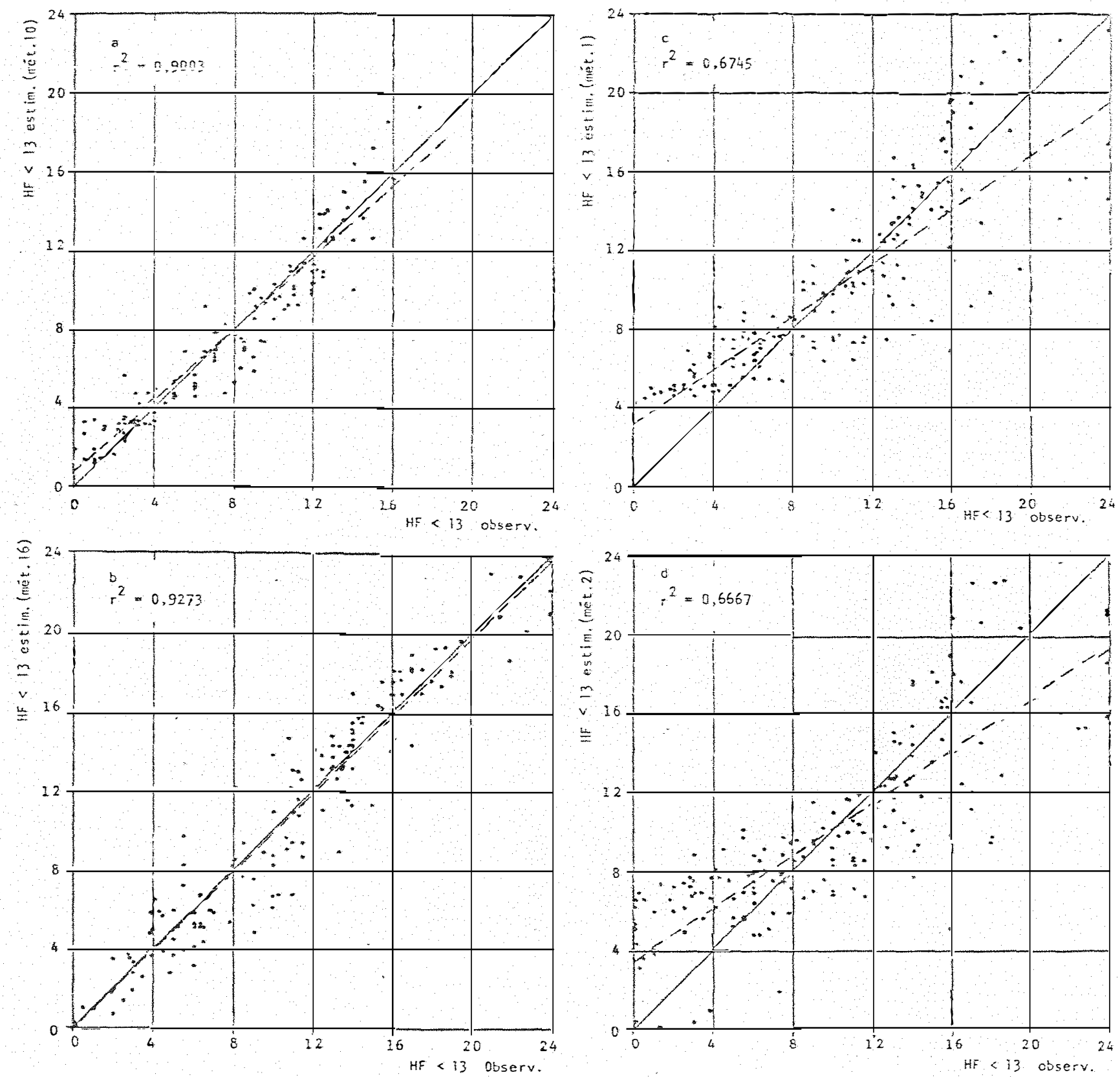

Figura 5 - Correlação entre os totais diärios observados e estimados de horas de frio com temperatura abaixo de $13^{\circ} \mathrm{C}$ ( HF $<13$ observ; $H F<13$ estim.), com os respectivos coeficientes de determinação $\left(r^{2}\right)$, nos meses de abril (fig. 5a) e maio (fig. 5b, 5c e 5d). As estimativas feitas pelos métodos 10, 16,1 e 2, fazem parte dos valores representados nas. figuras $5 a, 5 b, 5 c$ e $5 d$, respectivamente. 

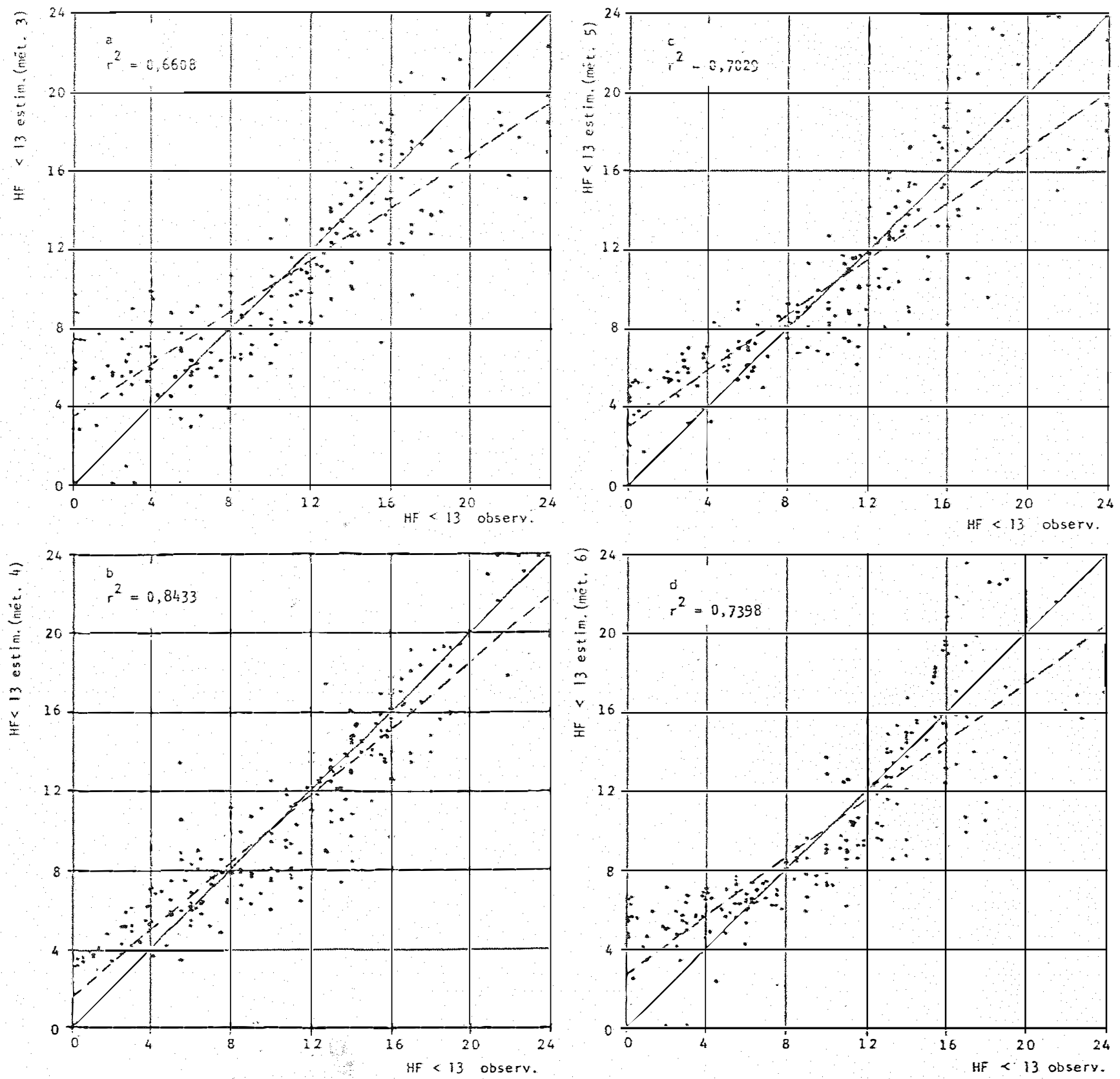

Figura 6 - Correlação entre os totais diärios observados e estimados de horas de frio com temperatura abaixo de $13^{\circ} \mathrm{C}$ ( $\mathrm{HF}<13$ observ; HF < 13 estim.), com os respectivos coeficientes de determinação $\left(r^{2}\right)$, do mês de maio. As estimativas feitas pelos métodos $3,4,5$ e 6, fazem parte dos valores representados nas figuras $6 a, 6 b, 6 c$ e $6 d$, respecti vamente. 

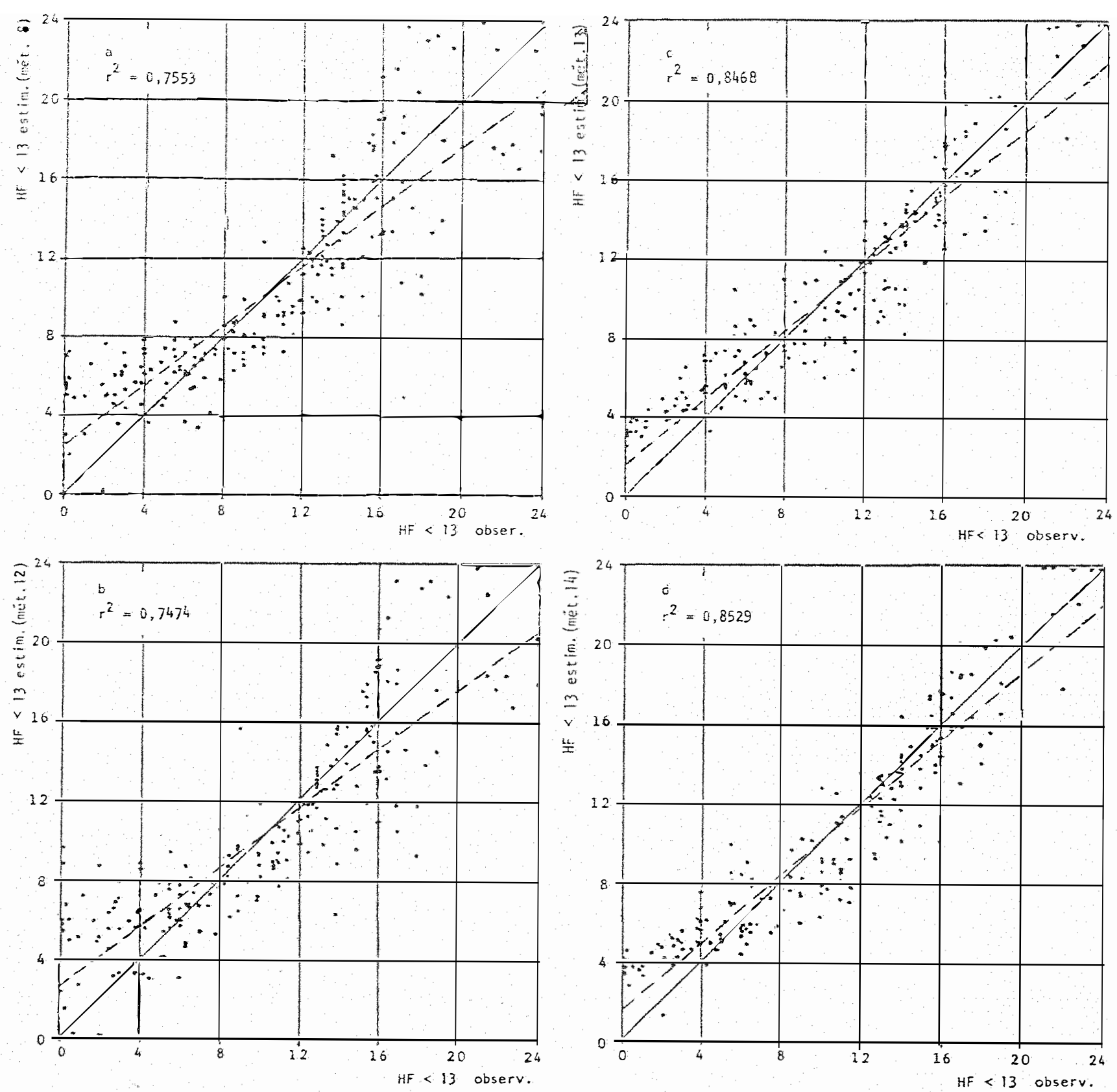

Figura 7 - Correlação entre os totais diários observados e estimados de horas de frio com temperatura abaixo de $13^{\circ} \mathrm{C}(\mathrm{HF}<13$ observ; HF < 13 estim.), com os respectivos coeficientes de determinação $\left(r^{2}\right)$, no mês de maio. As estimativas feitas pelos métodos $8,12,13$ e 14, fazem parte dos valores representados nas figuras $7 a, 7 b, 7 c$ e $7 d$, respectivamente. 

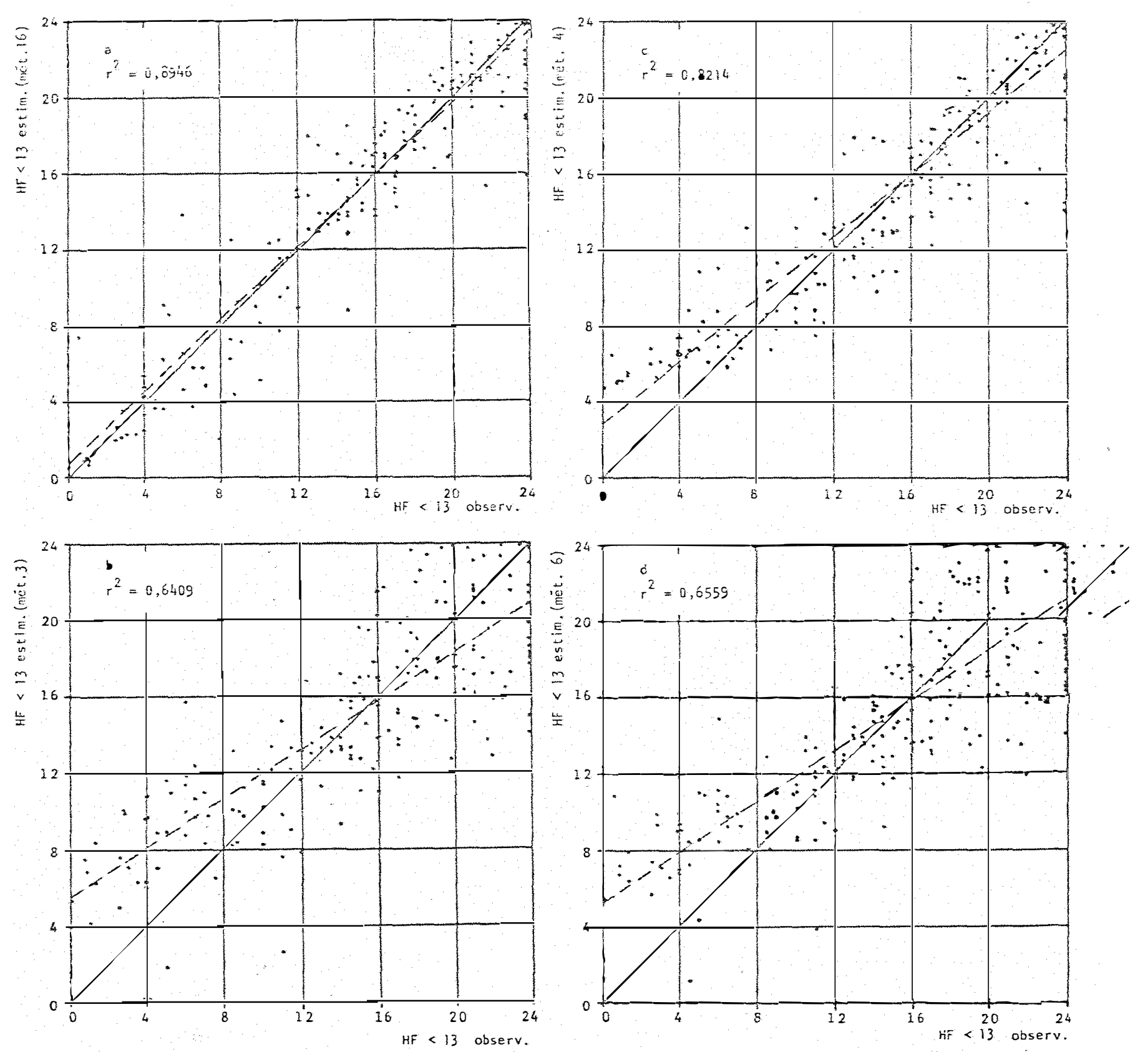

Figura 8 - Correlação entre os totais diärios observados e estimados de horas de frio com temperatura abaixo de $13^{\circ} \mathrm{C}$ ( HF $<13$ observ; HF < 13 estim.), com os respectivos coeficientes de determinação $\left(r^{2}\right)$, no mês de junho. As estimativas fei tas pelos métodos $16,3,4$ e 6 , fazem parte dos valores representados nas figuras $8 a, 8 b, 8 c$ e $8 d$, respectivamente. 

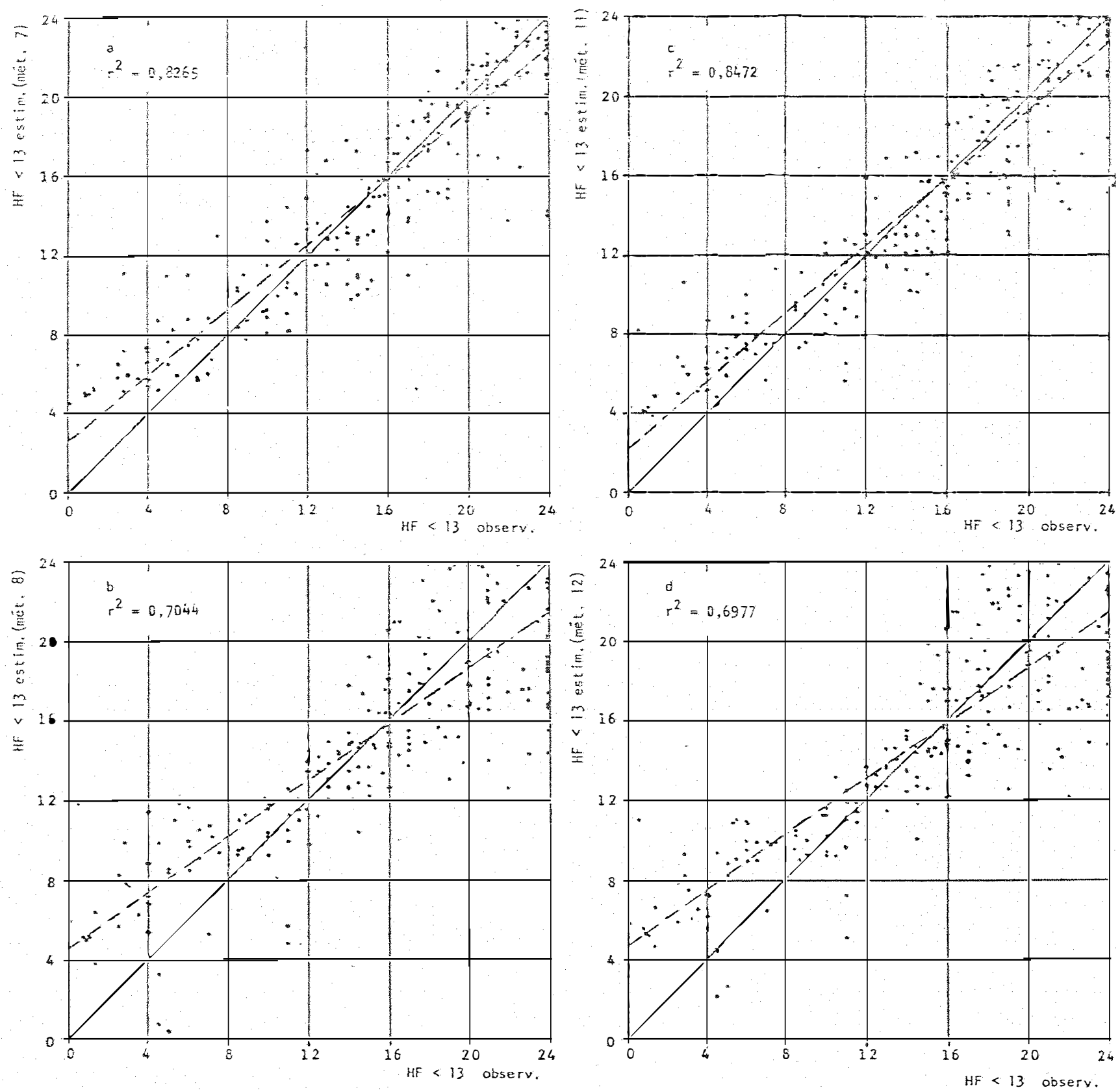

Figura 9 - Correlação entre os totais diārios observados e estimados de horas de frio com temperatura abaixo de $13^{\circ} \mathrm{C}$ ( $\mathrm{HF}<13$ observ; HF < 13 estim.), com os respectivos coeficientes de determinação $\left(r^{2}\right)$, no mês de junho. As estimativas fei tas pelos métodos $7,8,11$ e 12 , fazem parte dos valores representados nas figuras $9 a, 9 b, 9 c$ e $9 d$, respectivamente. 

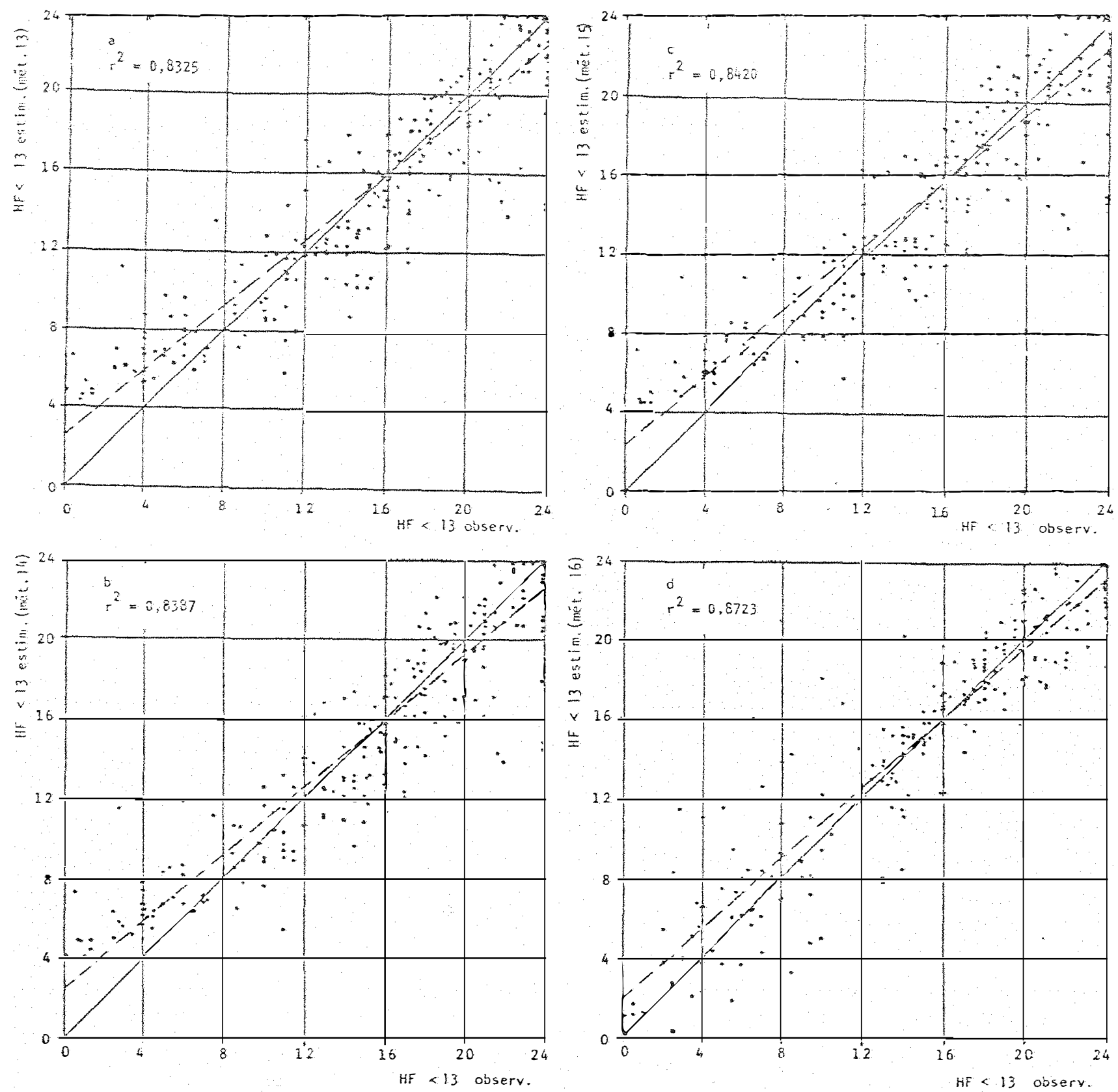

Figura 10 - Correlação entre os totais diārios observados e estimados de horas de frio com temperatura abaixo de $13^{\circ} \mathrm{C}$ ( HF $<13$ observ; HF< 13 estim.), com os respectivos coeficientes de determinação $\left(r^{2}\right)$, nos meses de junholfig. 10a, lob e 10c) e julho(fig. 10d). As estimativas feitas pelos métodos 13, 14, 15 e 16, fazem parte dos valores representados nas figuras $10 a, 10 b, 10 c$ e $10 d$ respectivamente. 

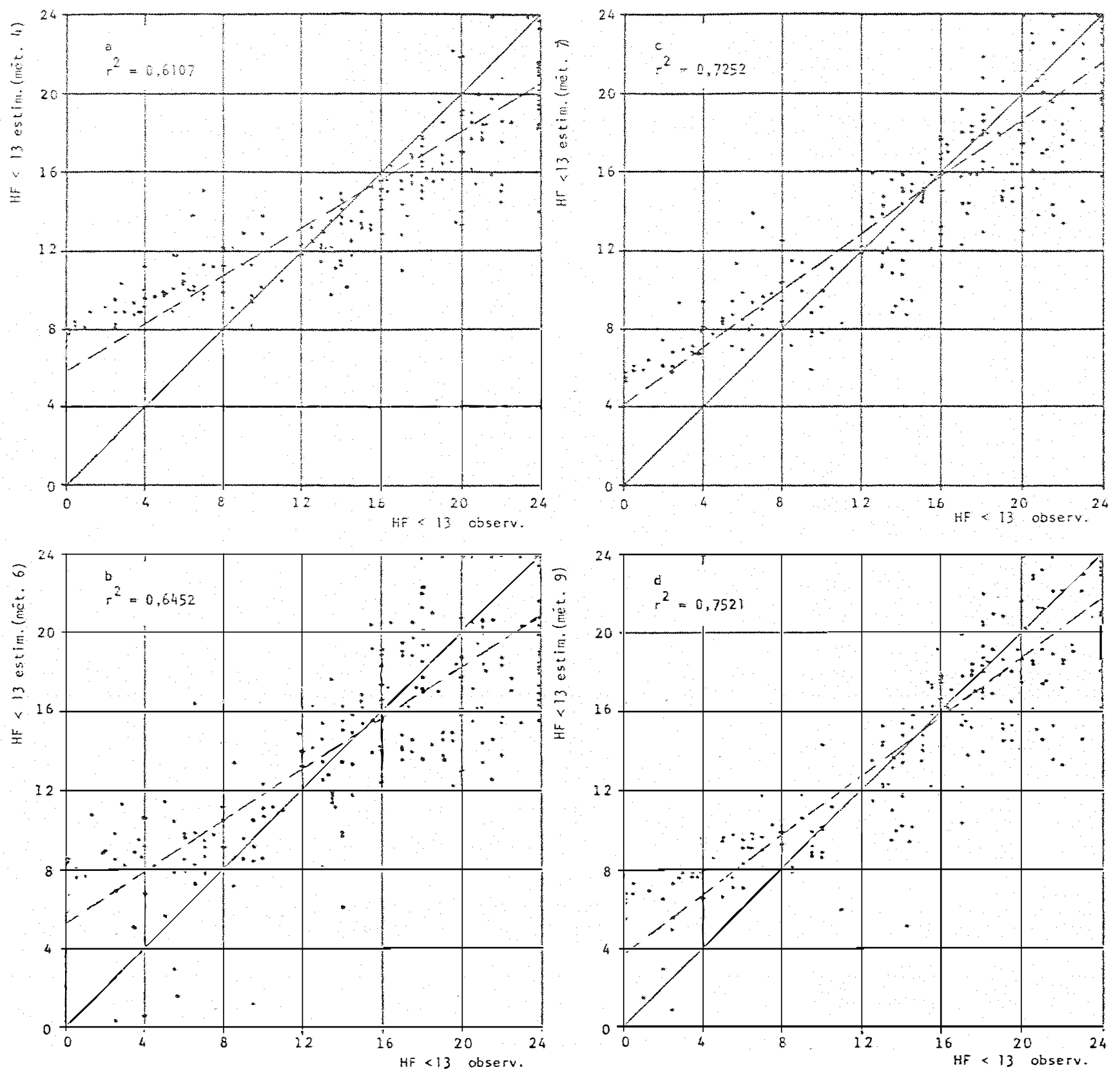

Figura 11 - Correlação entre os totais diärios observados e estimados de horas de frio com temperatura abaixo de $13^{\circ} \mathrm{C}$ (HF $<13$ observ; HF < 13 estim.), com os respectivos coeficientes de determinação $\left(r^{2}\right)$, no mês de jutho. As estimativas fei tas pelos métodos 4,6,7 e 9, fazem parte dos valores representados nas figuras lla, $11 \mathrm{~b}, 11 \mathrm{c}$ e $11 \mathrm{~d}$, respec tivamente. 

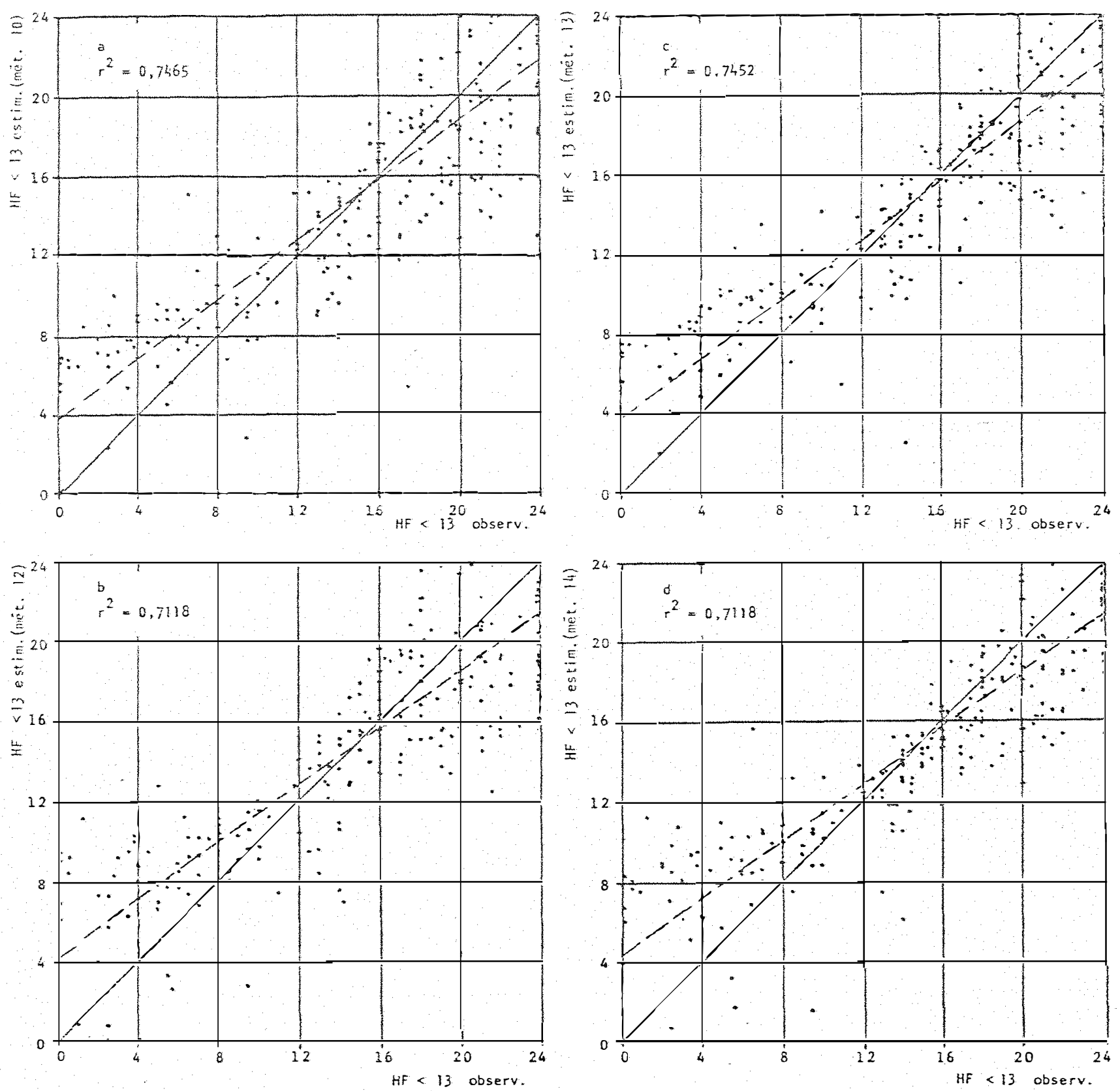

Figura 12 - Correlação entre os totais diārios observados e estimados de horas de frio com temperatura abaixo de $13^{\circ} \mathrm{C}$ ( $\mathrm{HF}<13$ observ; $H F<13$ estim.), com os respectivos coeficientes de determinação $\left(r^{2}\right)$, no mês de julho. As estimativas fei tas pelos métodos 10, 12, 13 e 14, fazem parte dos valores representados nas figuras $12 a, 12 b, 12 c$ e $12 d$, respec tivamente. 

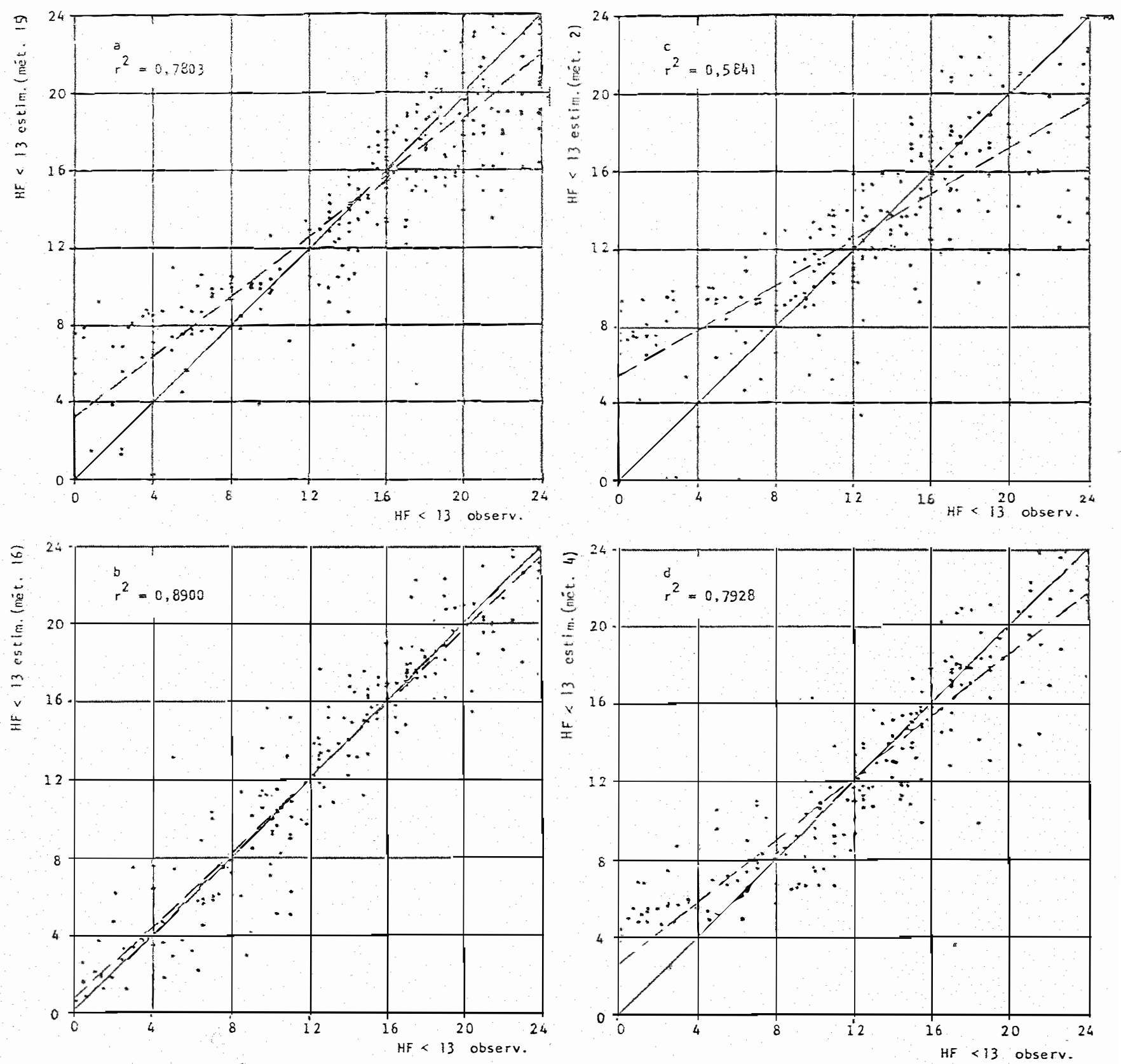

Figura 13 - Correlação entre os totais diärios observados e estimados de horas de frio com temperatura abaixo de $13^{\circ} \mathrm{C}$ (HF $<13$ observ; HF < 13 estim.), com os respectivos coeficientes de determinação $\left(r^{2}\right)$, nos meses de julho ( $\left.f i g .13 a\right)$ e agosto (fig. 13b, 13c, 13d). As estimativas feitas pelos métodos $15,16,2$ e 4, fazem parte dos valores representados nas figuras $13 a, 13 b, 13 c$ e $13 d$, respectivamente. 

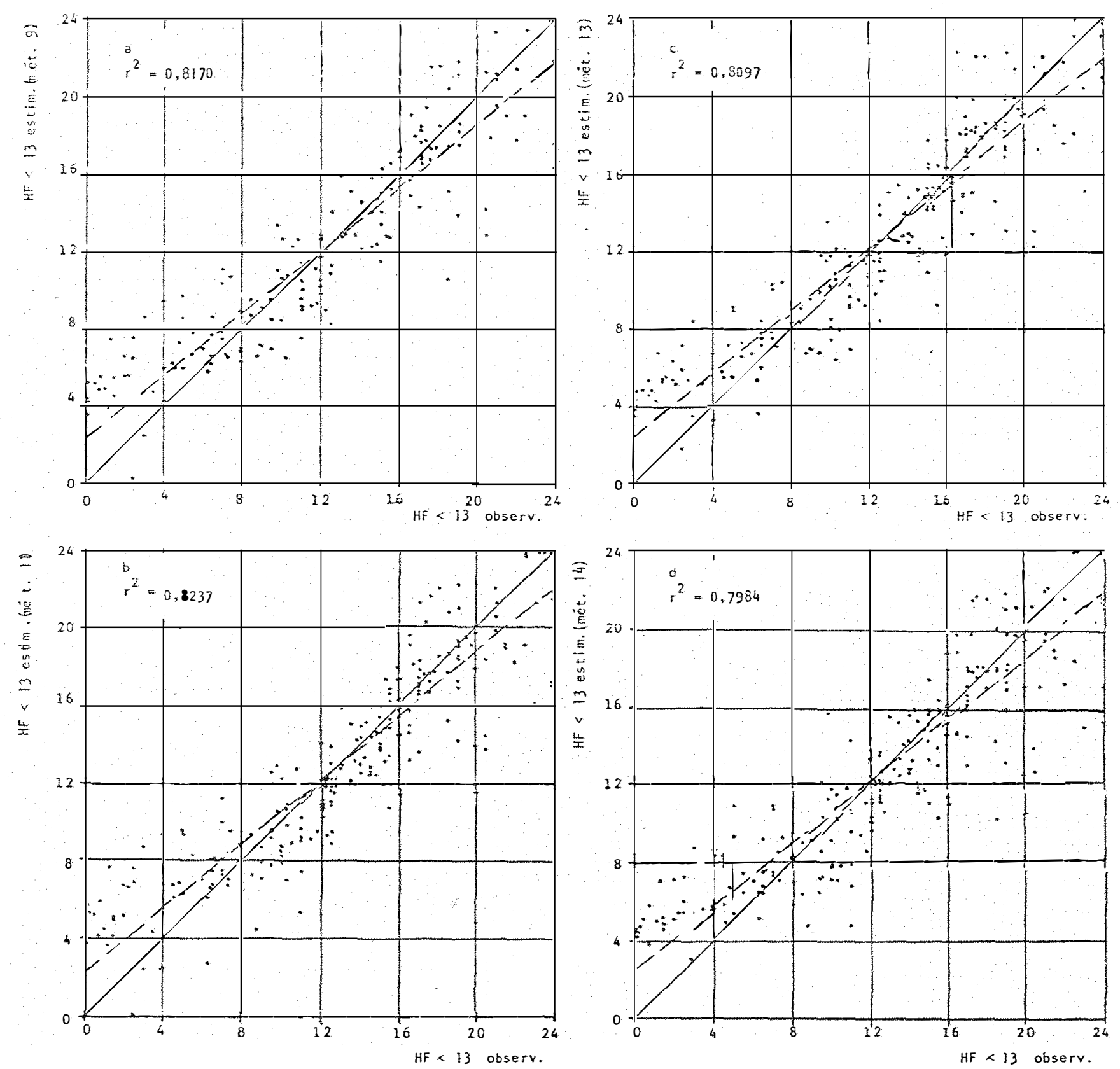

Figura 14 - Correlação entre os totais diários observados e estimados de horas de frio com temperatura abaixo de $13^{\circ} \mathrm{C}$ ( HF $<13$ observ; $H F<13$ estim.), com os respectivos coeficientes de determinação $\left(r^{2}\right)$, no mês de agosto. As estimativas fei tas pelos métodos 9, 11, 13 e 14, fazem parte dos valores representados nas figuras $14 a, 14 b, 14 c$ e $14 d$, respectivamente. 

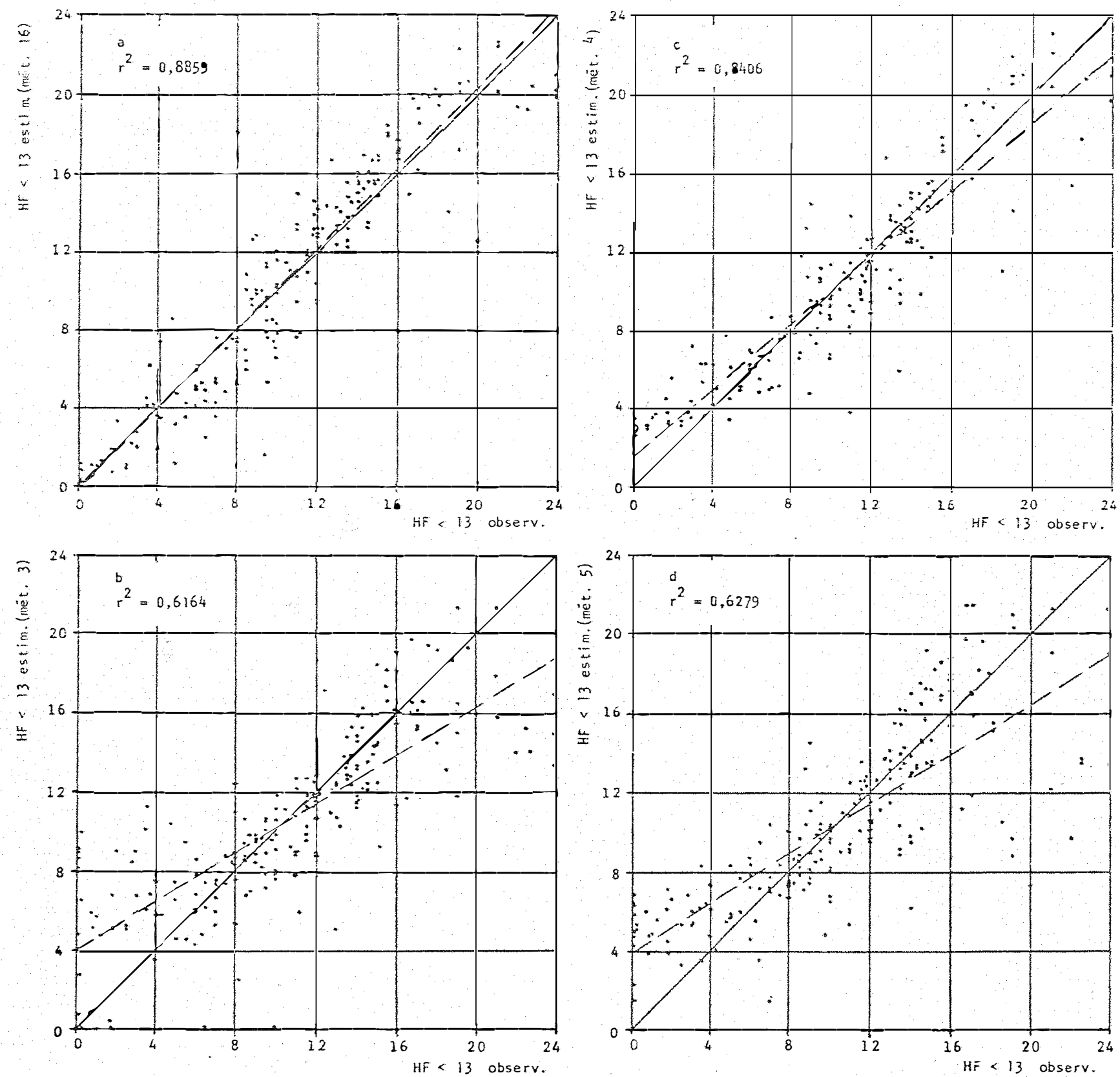

Figura 15 - Correlação entre os totais diärios observados e estimados de horas de frio com temperatura abaixo de $13^{\circ} \mathrm{C}$ ( $\mathrm{HF}<13$ observ; $H F(13$ estim.), com os respectivos coeficientes de determinação $\left(r^{2}\right)$, no mês de setembro. As estimativas feitas pelos métodos $16,3,4$ e 5 , fazem parte dos valores representados nas figuras $15 a, 15 b, 15 c$ e $15 d$, respectivamente. 

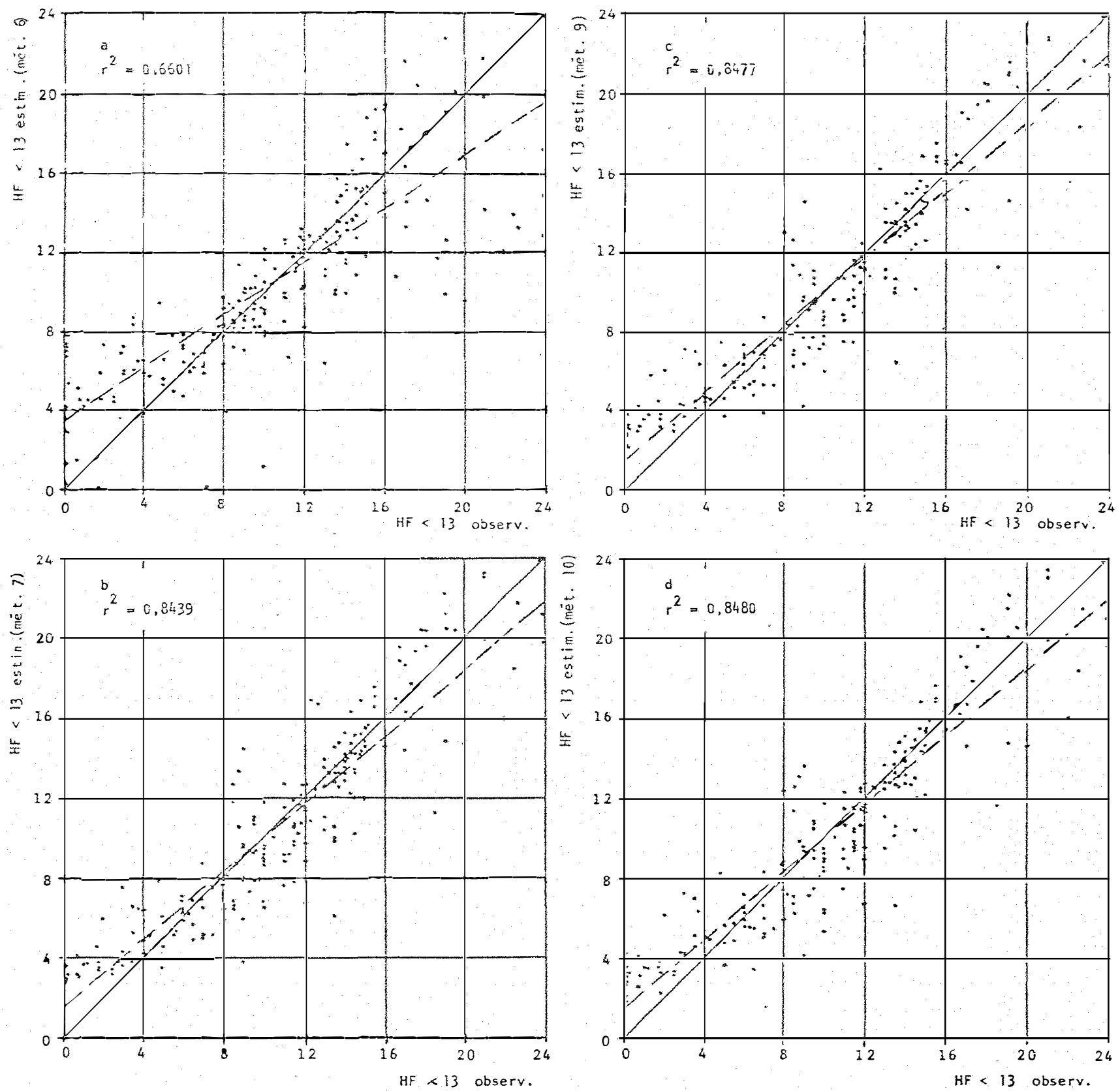

Figura 16 - Correlação entre os totais diărios observados e estimados de horas de frio com temperatura abaixo de $13^{\circ} \mathrm{C}$ ( $\mathrm{HF}<13$ observ; $H F<13$ estim.), com os respectivos coeficientes de determinação $\left(r^{2}\right)$, no mês de setembro. As estimativas fei tas pelos métodos $6,7,9$ e 10, fazem parte dos valores representados nas figuras 16a, 16b, 16c e 16d, respectivamente. 

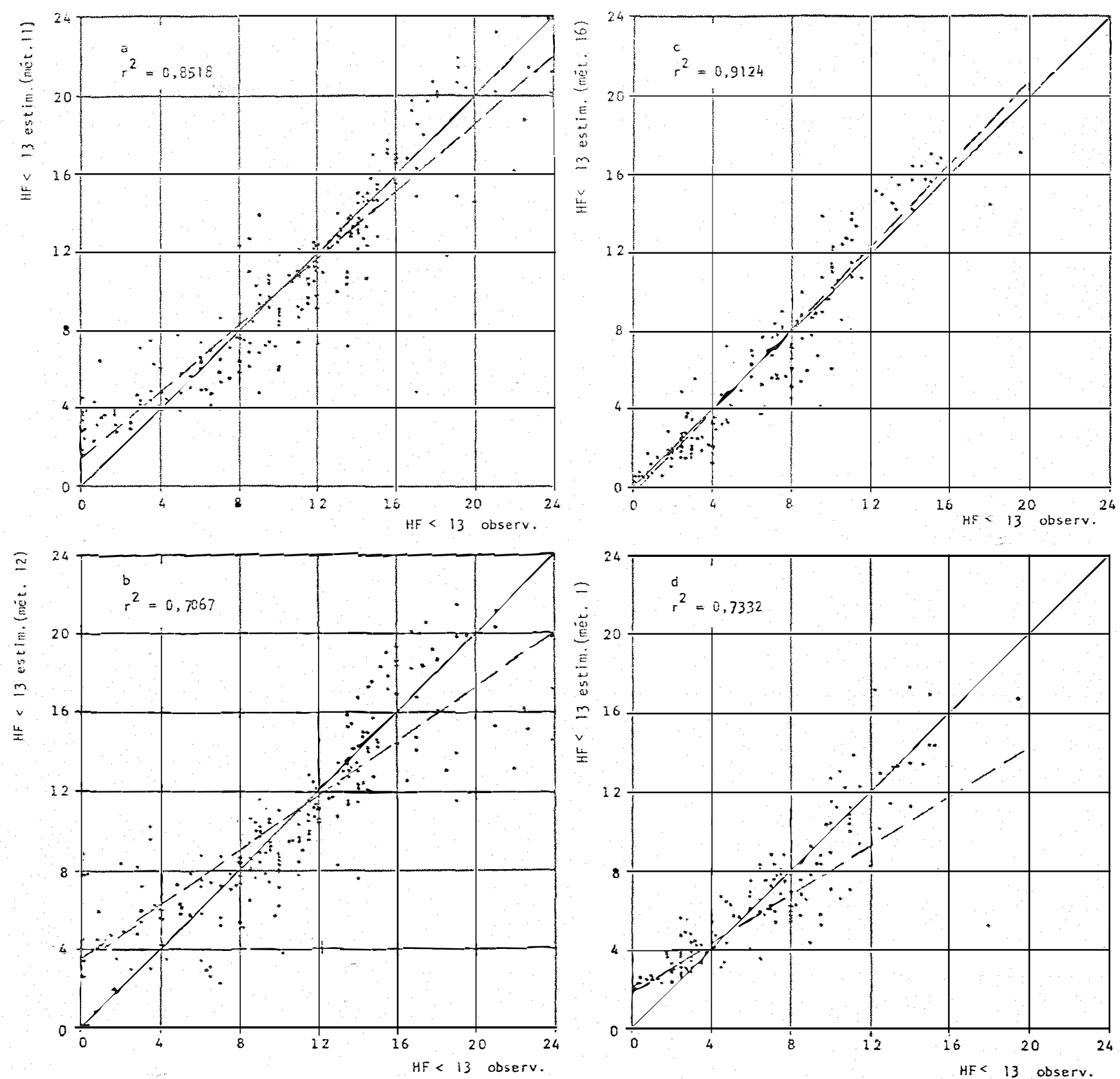

Figura 17 - Correlação entre os totais diārios observados e estimados de horas de frio com temperatura abaixo de $13^{\circ} \mathrm{C}(\mathrm{HF}<13$ observ; $H F<13$ estim.), com os respectivos coeficientes de determinaçāo $\left(r^{2}\right)$, nos meses de setembro (fig. 17a e 17b) e outubro (fig. 17c e 17d). As estimativas feitas pe los métodos 11, 12, 16 e 1, fazem parte dos valores repre sentados nas figuras $17 a, 17 b, 17 c, 17 d$, respectivamente. 

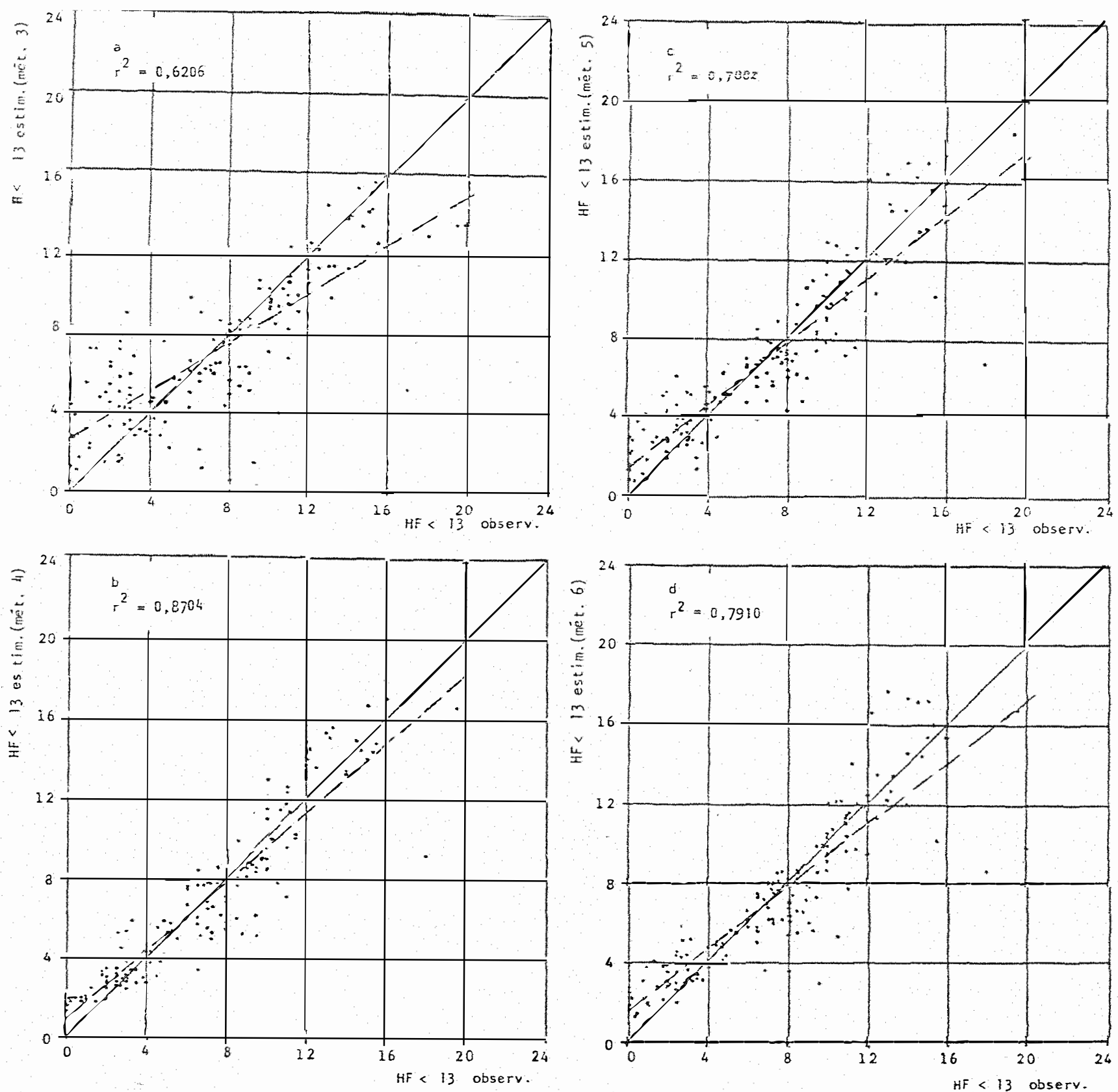

Figura 18 - Correlação entre os totais diärios observados e estimados de horas de frio com temperatura abaixo de $13^{\circ} \mathrm{C}$ ( $\mathrm{HF}<13$ observ; $H F<13$ estim.), com os respectivos coeficientes de determinação $\left(r^{2}\right)$, no mês de outubro. As estimativas feitas pelos métodos 3, 4, 5 e 6, fazem parte dos valores representados nas figuras $18 a, 18 b, 18 c$ e $18 d$, respectivamente. 

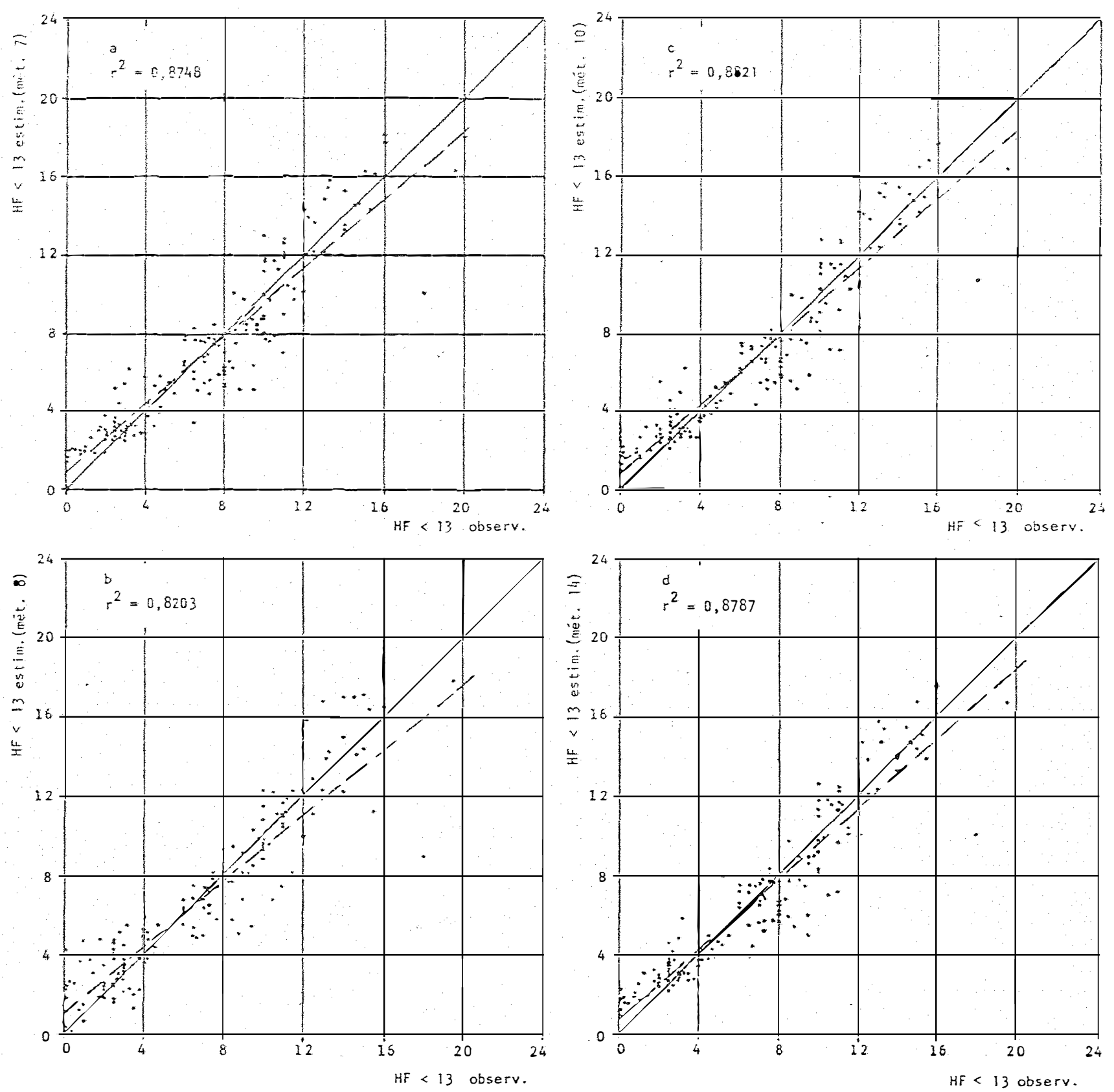

Figura 19 - Correlação entre os totais diários observados e estimados de horas de frio com temperatura abaixo de $13^{\circ} \mathrm{C}$ ( $\mathrm{HF}<13$ observ; HF $<13$ estim.), com os respectivos coeficientes de determinação $\left(r^{2}\right)$, no mês de outubro. As estimativas feitas pelos métodos $7,8,10$ e 14 fazem parte dos valores representados nas figuras 19a, 19b, 19c e 19d, respec tivamente. 

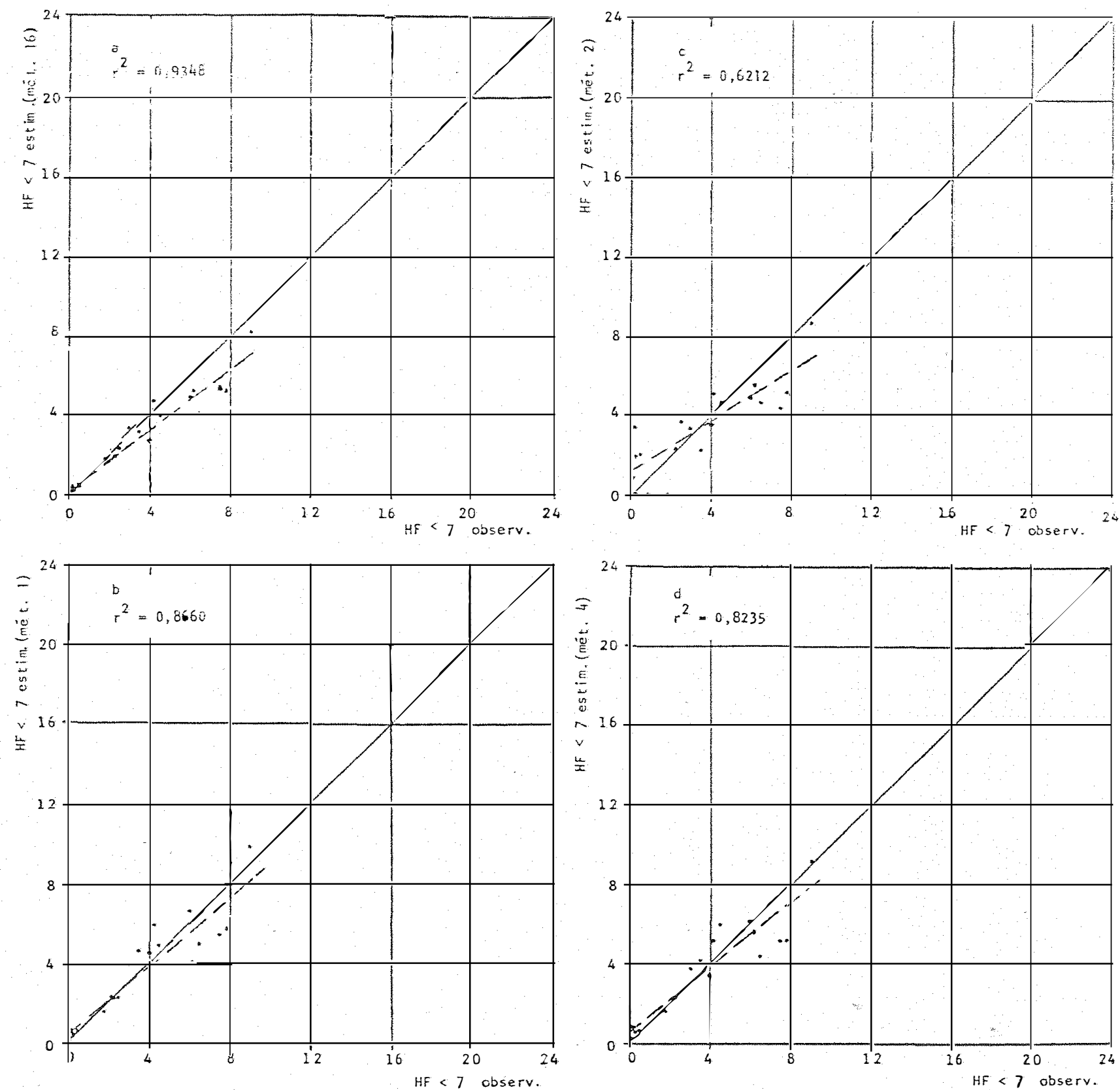

Figura 20 - Correlação entre os totais diārios observados e estimados de horas de frio com temperatura abaixo de $7^{\circ} \mathrm{C}$ ( $\mathrm{HF}<7$ observ; $H F<7$ estim.), com os respectivos coeficientes de determinação $\left(r^{2}\right)$, no mês de abril. As estimativas fei tas pelos métodos $16,1,2$ e 4 fazem parte dos valores re presentados nas figuras $20 \mathrm{a}, 20 \mathrm{~b}, 20 \mathrm{c}$ e $20 \mathrm{~d}$, respectiva mente. 

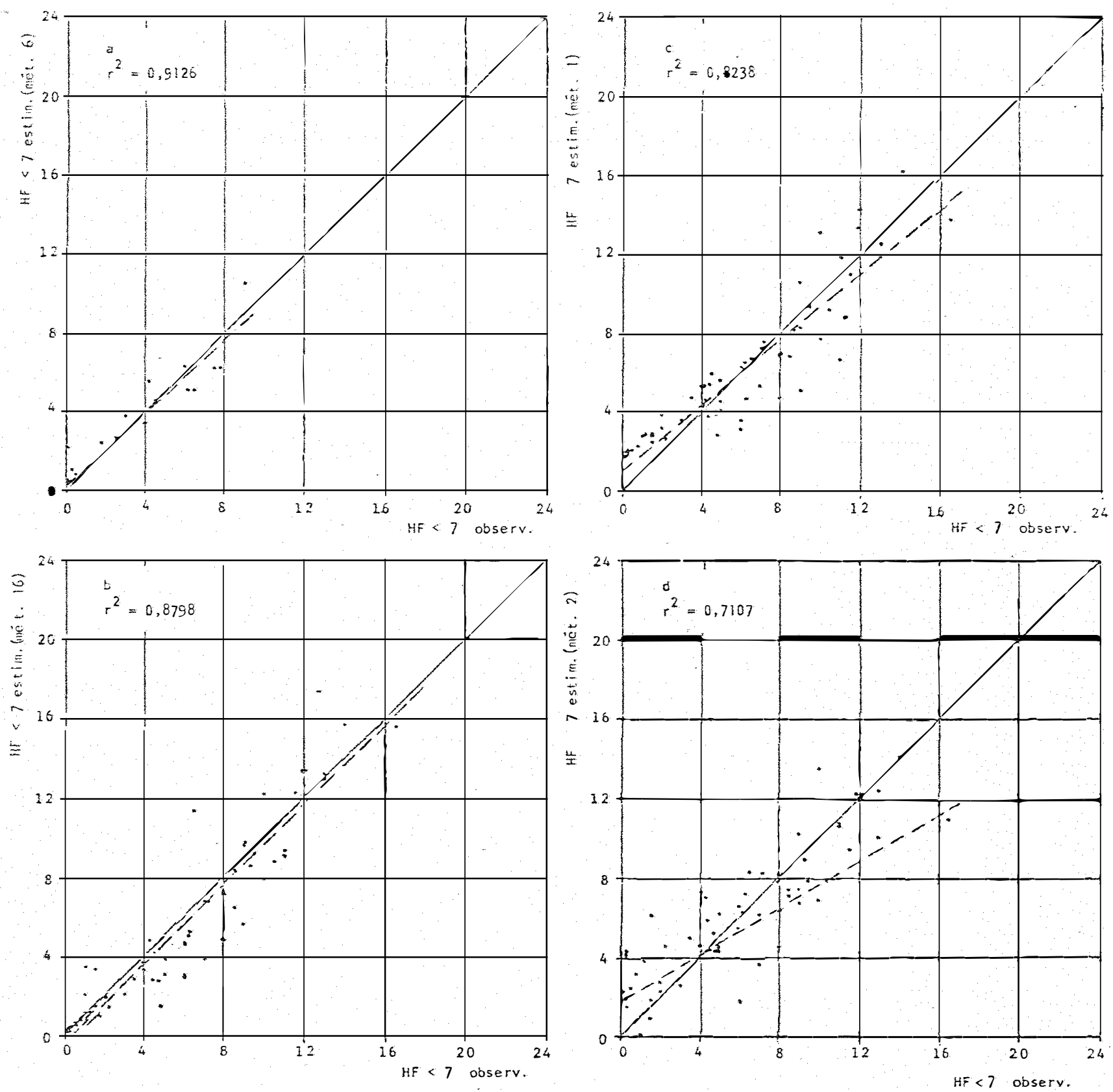

Figura 21 - Correlação entre os totais diärios observados e estimados de horas de frio com temperatura abaixo de $7^{\circ} \mathrm{C}$ ( $\mathrm{HF}<7$ observ; $H F<7$ estim.), com os respectivos coeficientes de determinação $\left(r^{2}\right)$, nos meses de abril (fig. 2la) e maio (fig. 2lb, $21 \mathrm{c}$ e $21 \mathrm{~d}$ ). As estimativas feitas pelos méto$\operatorname{dos} 6,16,1$ e 2, fazem parte dos valores representados nas figuras $21 a, 21 b, 21 c$ e $21 d$, respectivamente. 

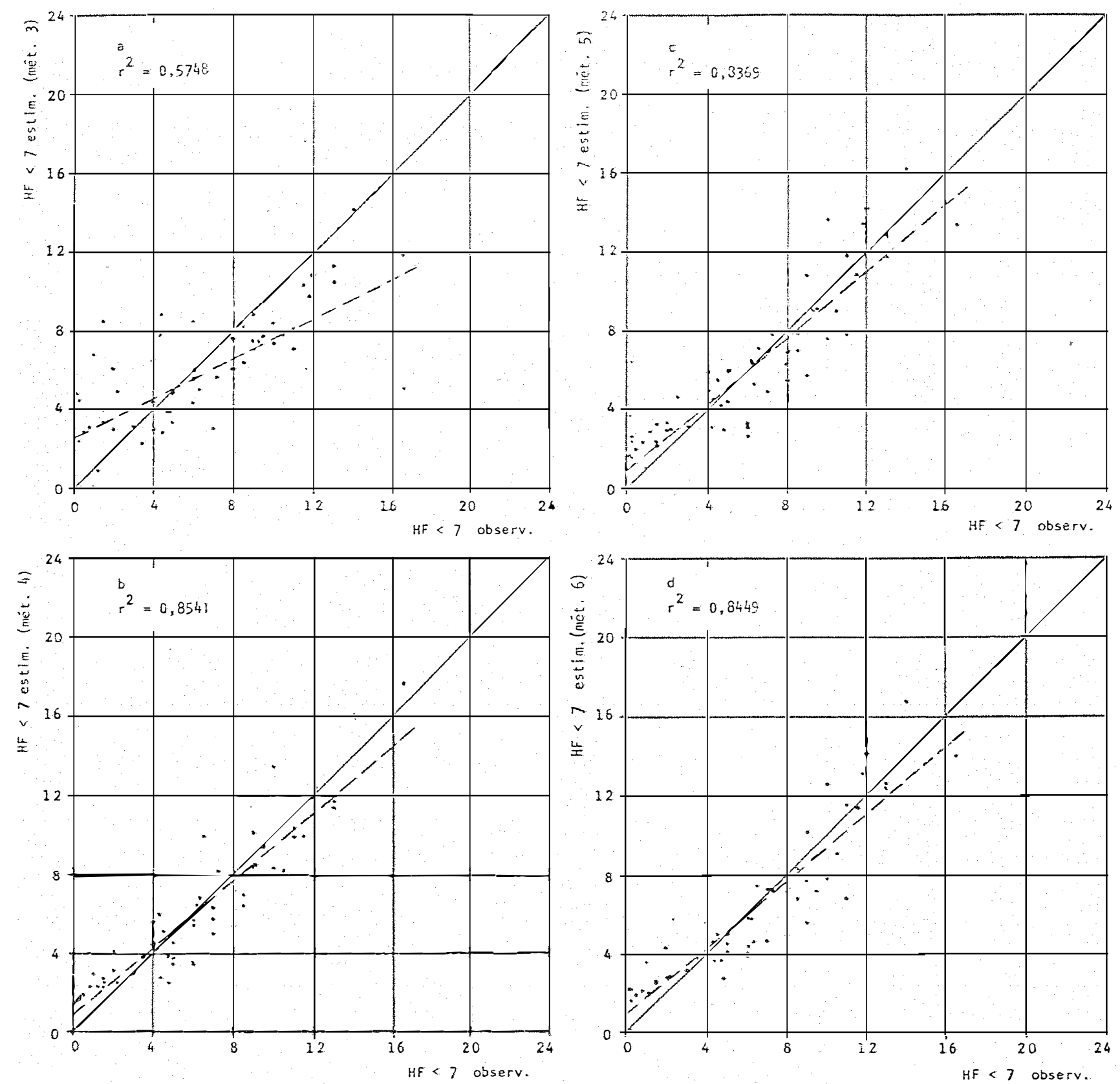

Figura 22 - Correlação entre os totais diārios observados e estimados de horas de frio com temperatura abaixo de $7^{\circ} \mathrm{C}$ ( $\mathrm{HF}<7$ observ; $H F<7$ estim.), com os respectivos coeficientes de determinação $\left(r^{2}\right)$, no més de maio. As estimativas fei tas pelos métodos $3,4,5$ e 6 , fazem parte dos valores representados nas figuras $22 a, 22 b, 22 c$ e $22 d$, respectivamente. 

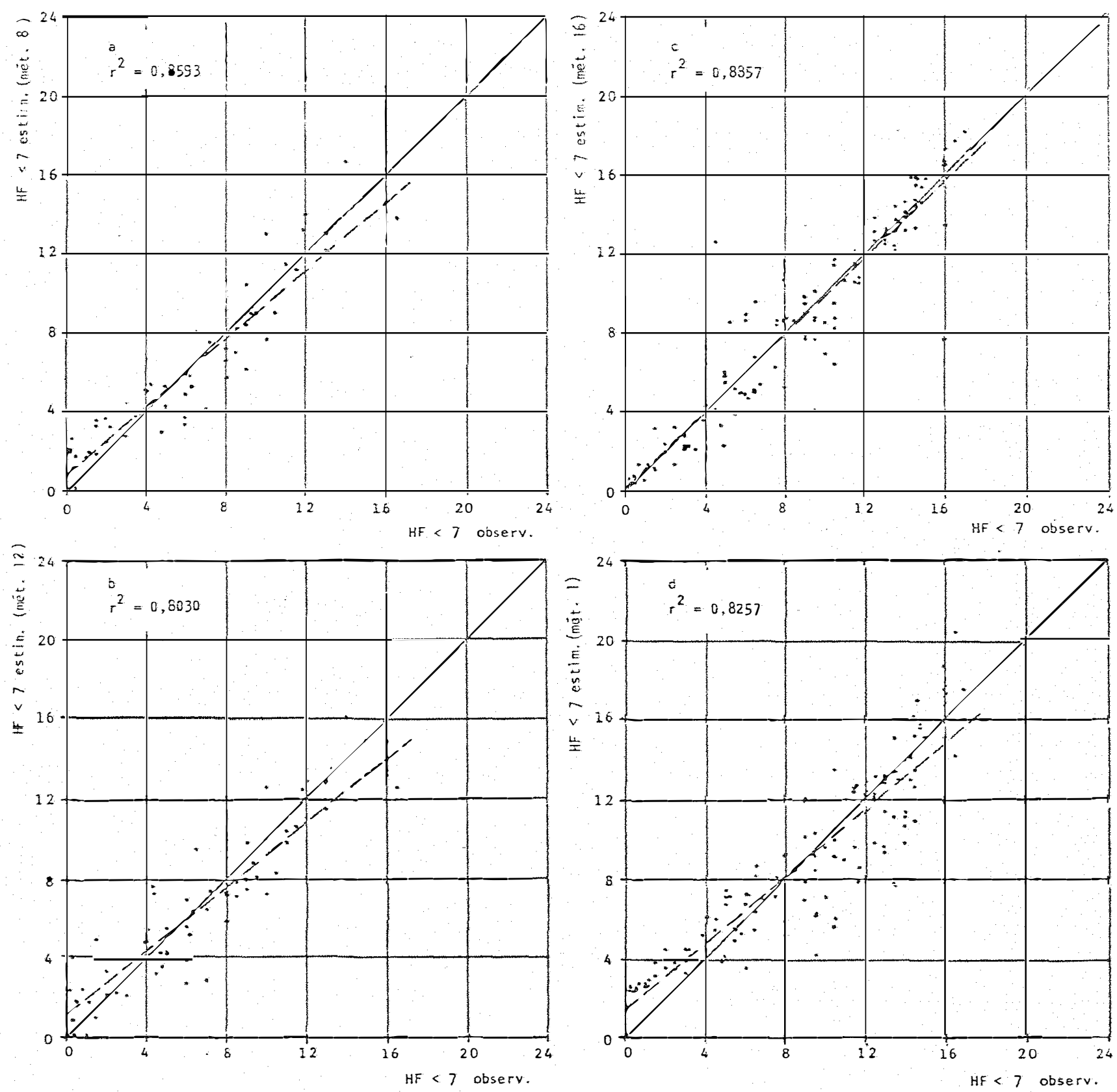

Figura 23 - Correlação entre os totais diārios observados e estimados de horas de frio com temperatura abaixo de $7^{\circ} \mathrm{C}$ ( $\mathrm{HF}<7$ observ; $H F<7$ estim.), com os respectivos coeficientes de determinação $\left(r^{2}\right)$, nos meses de maio (fig. 23a e 23b) e junho (23c e 23d). As estimativas feitas pelos métodos $8,12,16$ e 1, fazem parte dos valores representados nas figuras $23 a, 23 b, 23 c$ e $23 d$, respectivamente. 

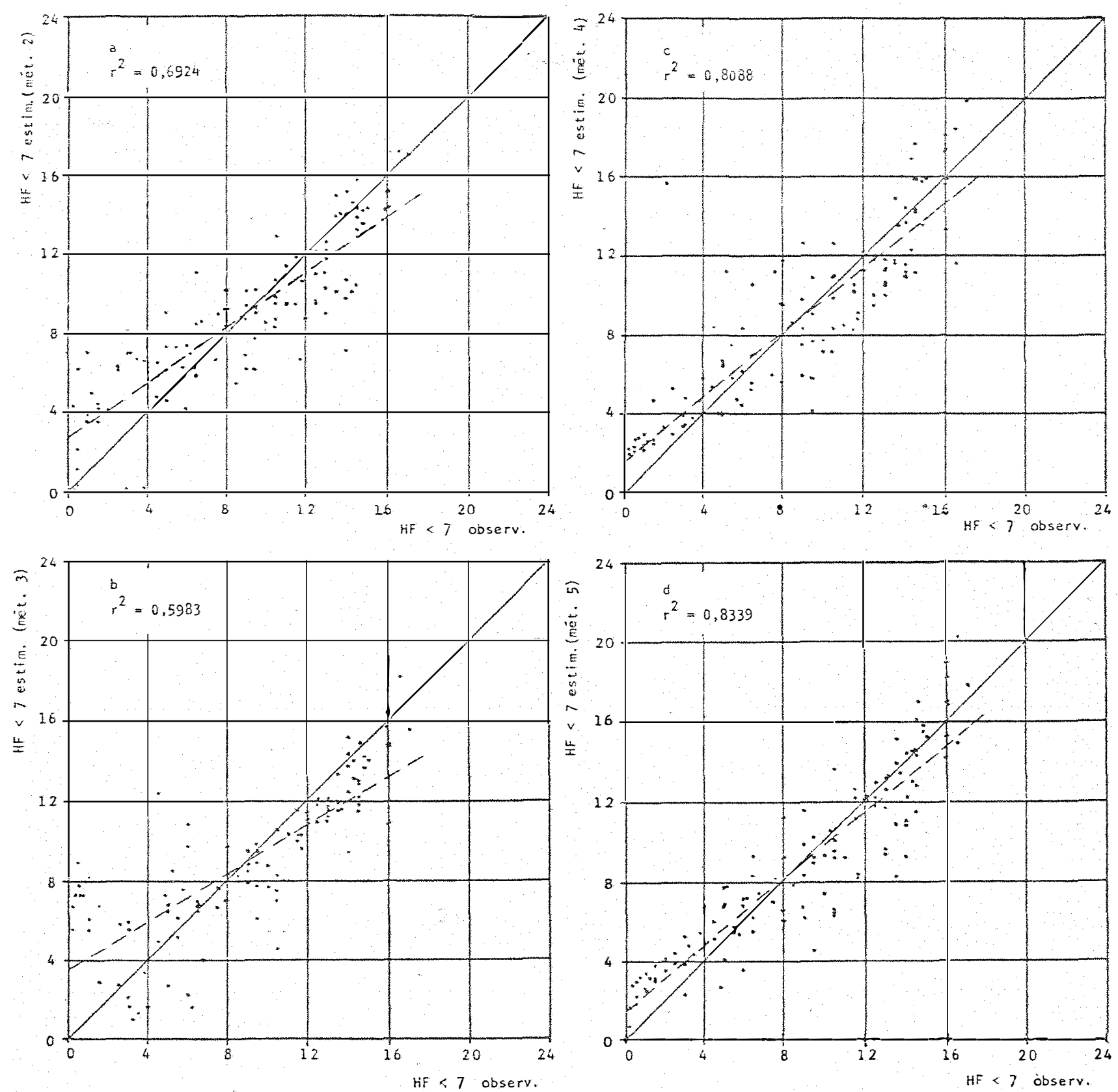

Figura 24 - Correlação entre os totais diários observados e estimados de horas de frio com temperatura abaixo de $7^{\circ} \mathrm{C}$ ( $\mathrm{HF}<7$ observ; $\mathrm{HF}<7$ estim.), com os respectivos coeficientes de determinação $\left(r^{2}\right)$, no mês de junho. As estimativas fei tas pelos métodos $2,3,4$ e 5 , fazem parte dos valores representados nas figuras $24 a, 24 b, 24 c$ e $24 d$, respectivamente. 

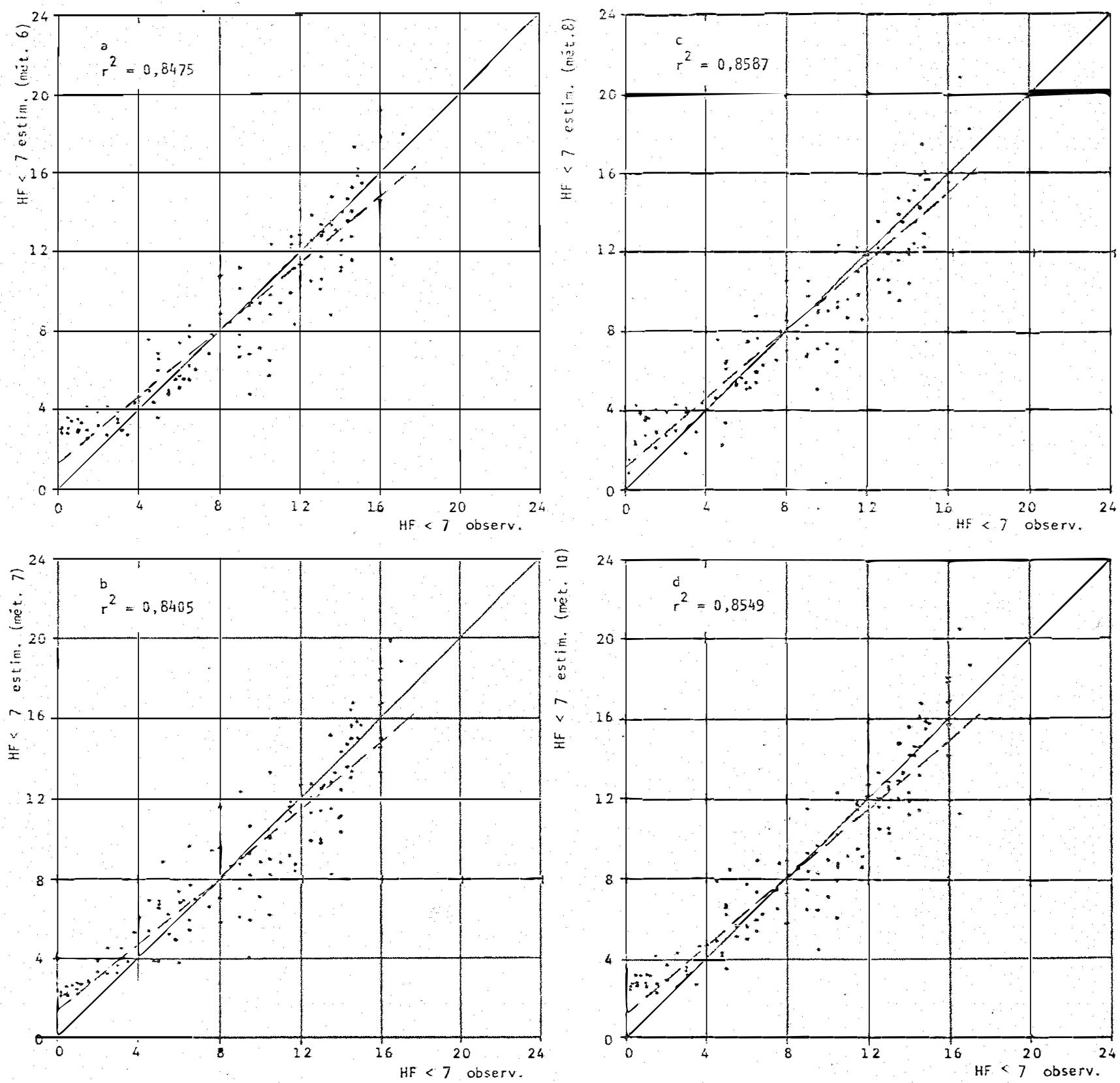

Figura 25 - Correlação entre os totais diārios observados e estimados de horas de frio com temperatura abaixo de $7^{\circ} \mathrm{C}$ ( HF $<7$ observ; $H F<7$ estim.), com os respectivos coeficientes de determinação $\left(r^{2}\right)$, no més de junho. As estimativas fé tas pelos métodos $6,7,8$ e 10, fazem parte dos valores representados nas figuras $25 a, 25 b, 25 c$ e $25 d$, respectivamente. 

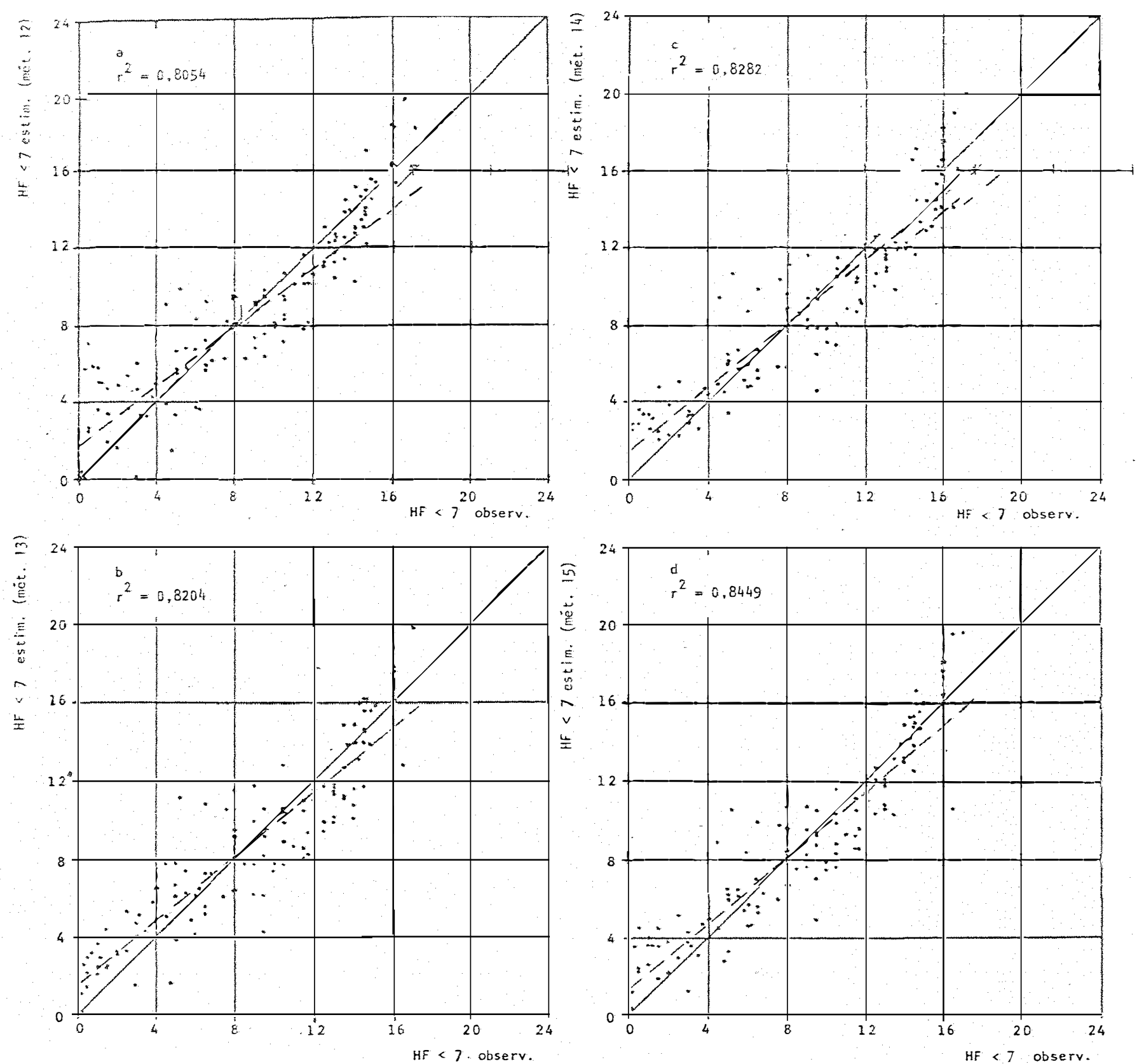

Figura 26 - Correlação entre os totais diärios observados e estimados de horas de frio com temperatura abaixo de $7^{\circ} \mathrm{C}$ ( HF $<7$ observ; HF 7 estim.), com os respectivos coeficientes de determinação $\left(r^{2}\right)$, no mês de junho. As estimativas fe tas pelos métodos 12, 13, 14 e 15, fazem parte dos valores representados nas figuras $26 a, 26 b, 23 c$ e $26 d$, respectivamente. 

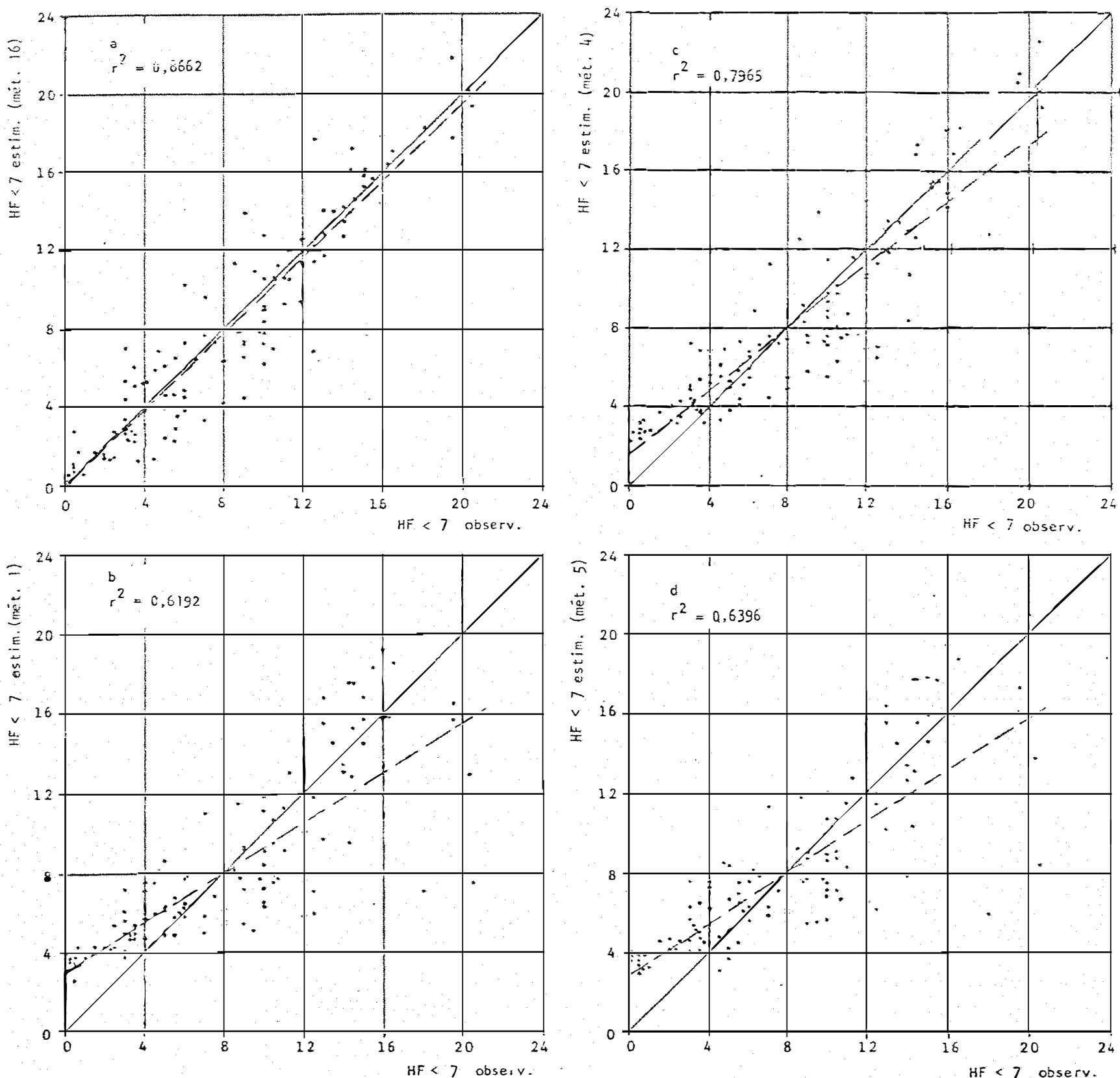

Figura 27 - Correlação entre os totais diārios observados e estimados de horas de frio com temperatura abaixo de $7^{\circ} \mathrm{C}$ ( $\mathrm{HF}<7$ observ; HF $<7$ estim.), com os respectivos coeficientes de determinação $\left(r^{2}\right)$, no més de julho. As estimativas fei tas pelos métodos 16, 1,4 e 5, fazem parte dos valores representados nas figuras $27 \mathrm{a}, 27 \mathrm{~b}, 27 \mathrm{c}$ e $27 \mathrm{~d}$, respect $\mathrm{i}$ vamente. 

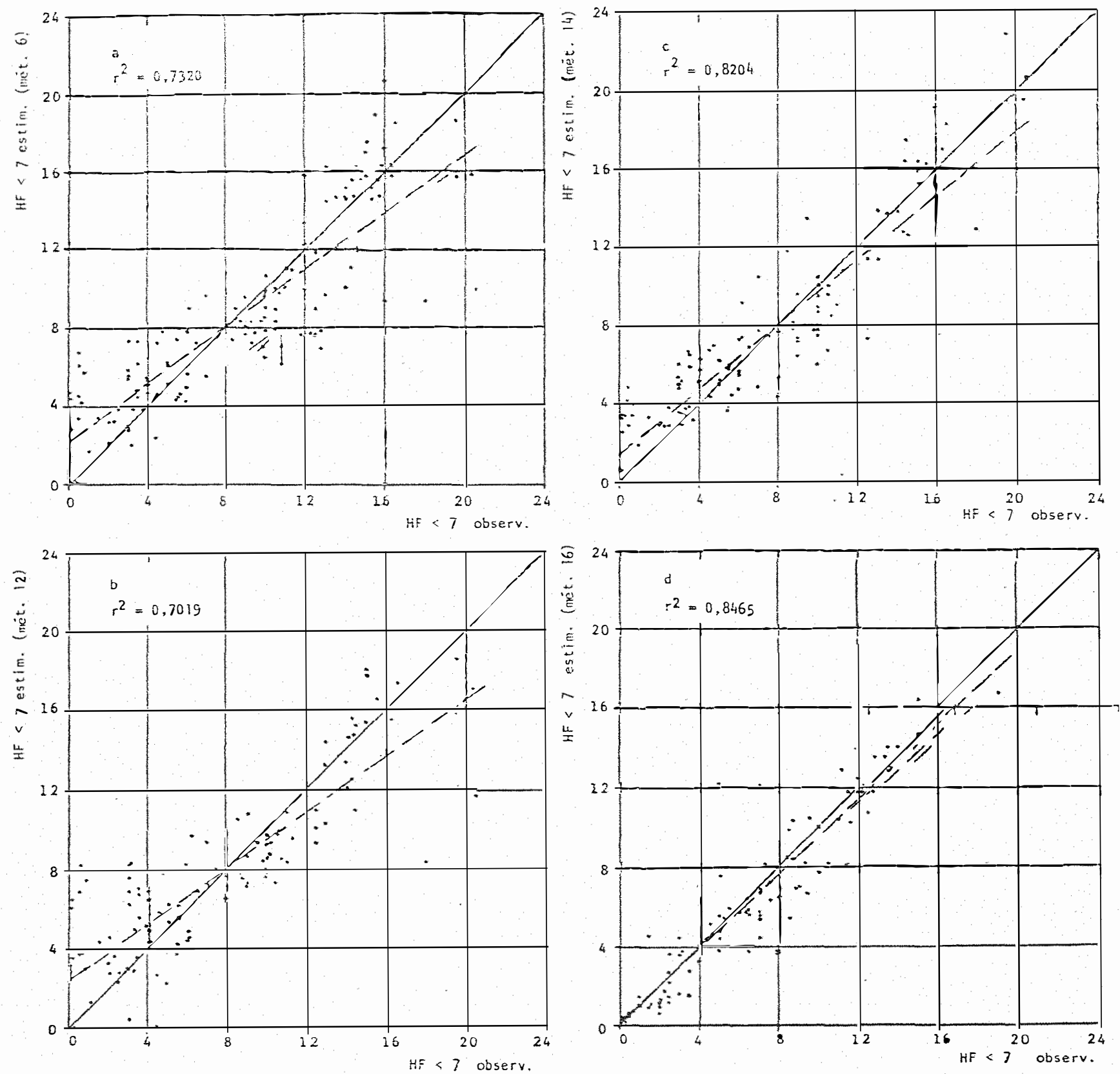

Figura 28 - Correlação entre os totais diärios observados e estimados de horas de frio com temperatura abaixo de $7^{\circ} \mathrm{C}(\mathrm{HF}<7$ observ; HF $<7$ estim.), com os respectivos coeficientes de determinaçāo $\left(r^{2}\right)$, nos meses de julho ( $f i g .28 a, 28 b$ e 28c) e agosto (fig. 28d). As estimativas feitas pelos métodos $6,12,14$ e 16, fazem parte dos valores representados nas figuras $28 \mathrm{a}, 28 \mathrm{~b}, 28 \mathrm{c}$ e $28 \mathrm{~d}$, respectivamente. 

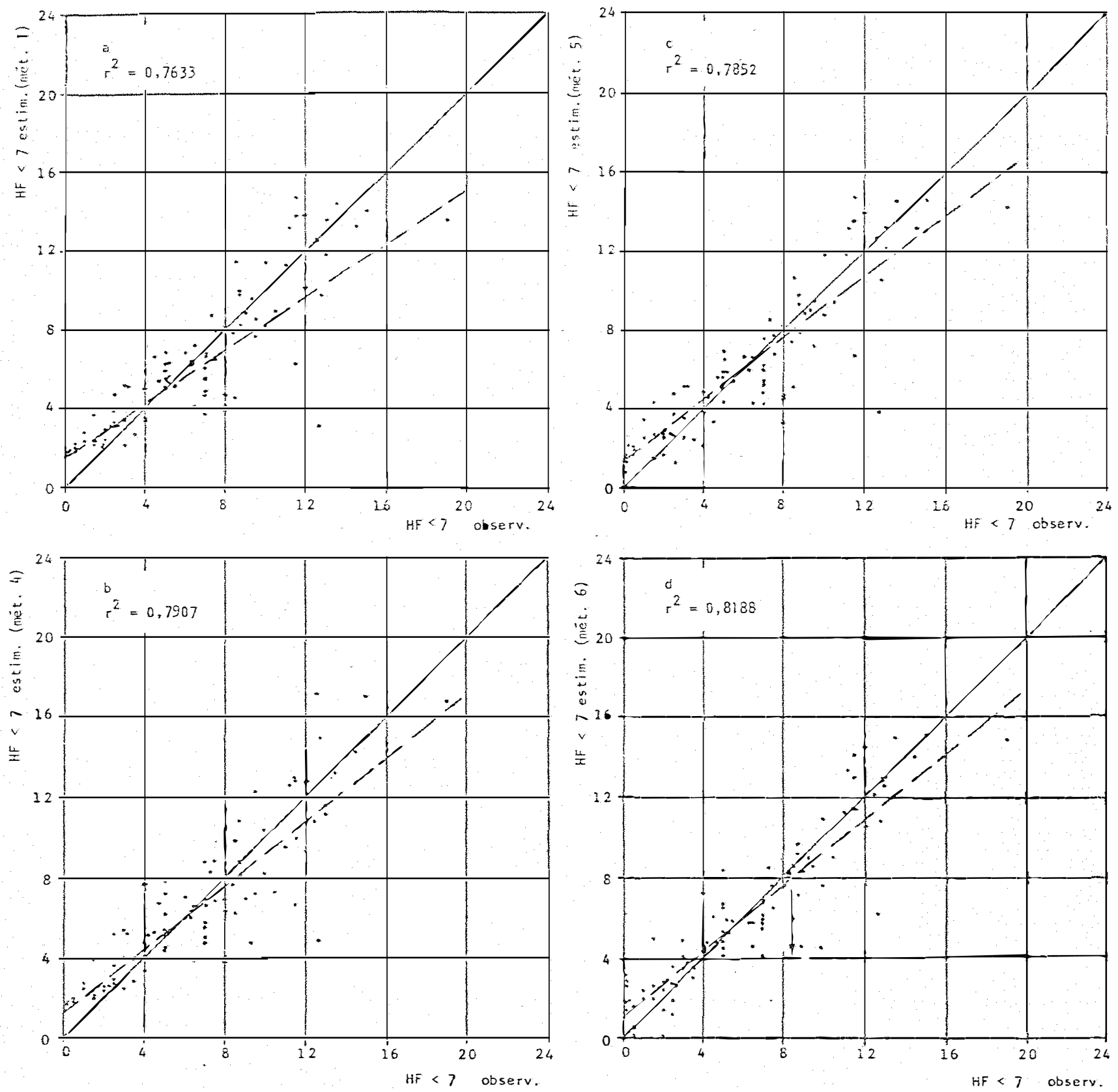

Figura 29 - Correlação entre os totais diärios observados e estimados de horas de frio com temperatura abaixo de $7^{\circ} \mathrm{C}$ ( HF $<7$ observ; HF< 7 estim.), com os respectivos coeficientes de determinação $\left(r^{2}\right)$, no mês de agosto. As estimativas fei tas pelos métodos $1,4,5$ e 6 , fazem parte dos valores re presentados nas figuras 29a, 29b, 29c e 29d, respec tivamente. 

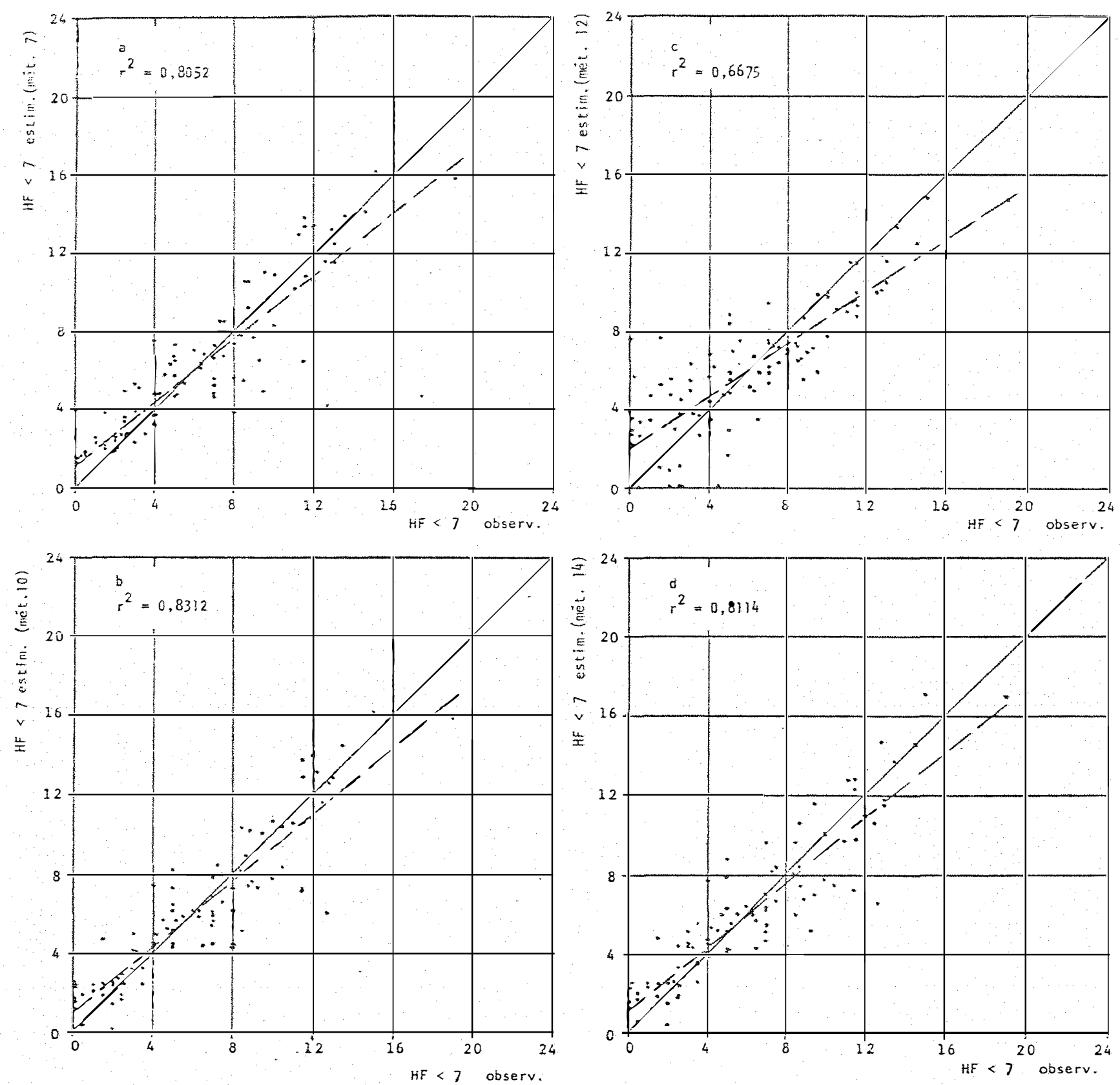

Figura 30 - Correlação entre os totais diärios observados e estimados de boras de frio com temperatura abaixo de $7^{\circ} \mathrm{C}$ ( $\mathrm{HF}<7$ observ; $H F<7$ estim.), com os respectivos coeficientes de determinação $\left(r^{2}\right)$, no mês de agosto. As estimativas fei tas pelos métodos $7,10,12$ e 14 , fazem parte dos valores representados nas figuras $30 \mathrm{a}, 30 \mathrm{~b}, 30 \mathrm{c}$ e $30 \mathrm{~d}$, respectivamente. 

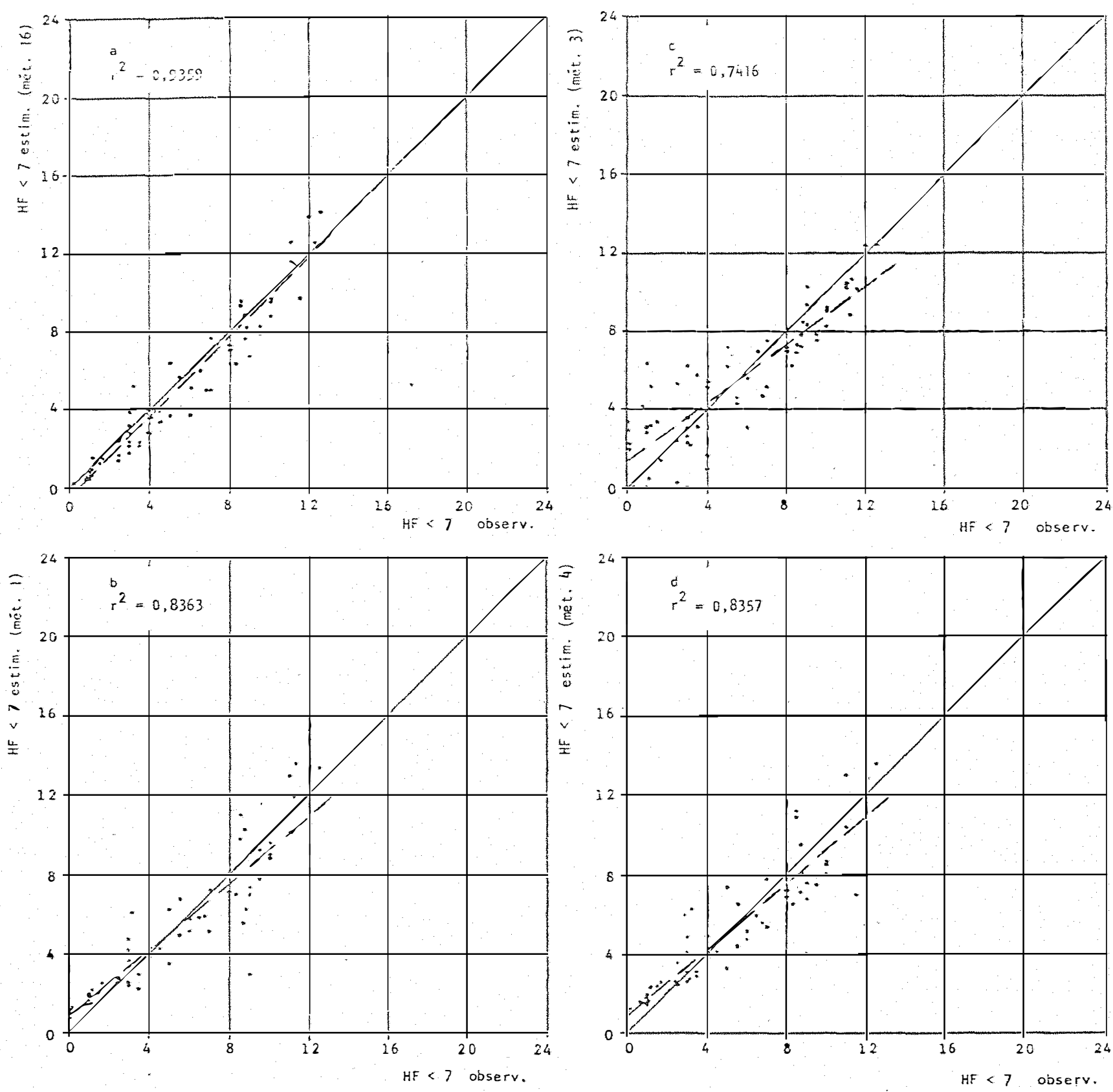

Figura 31 - Correlação entre os totais diários observados e estimados de horas de frio com temperatura abaixo de $7^{\circ} \mathrm{C} \quad$ (HF $<7$ observ; $H F<7$ estim.), com os respectivos coeficientes de determinação $\left(r^{2}\right)$, no mês de setembro. As estimativas feitas pelos métodos $16,1,3$ e 4 , fazem parte dos valo res representados nas figuras $31 \mathrm{la}, 31 \mathrm{~b}, 31 \mathrm{c}, 31 \mathrm{~d}$, respec tivamente. 

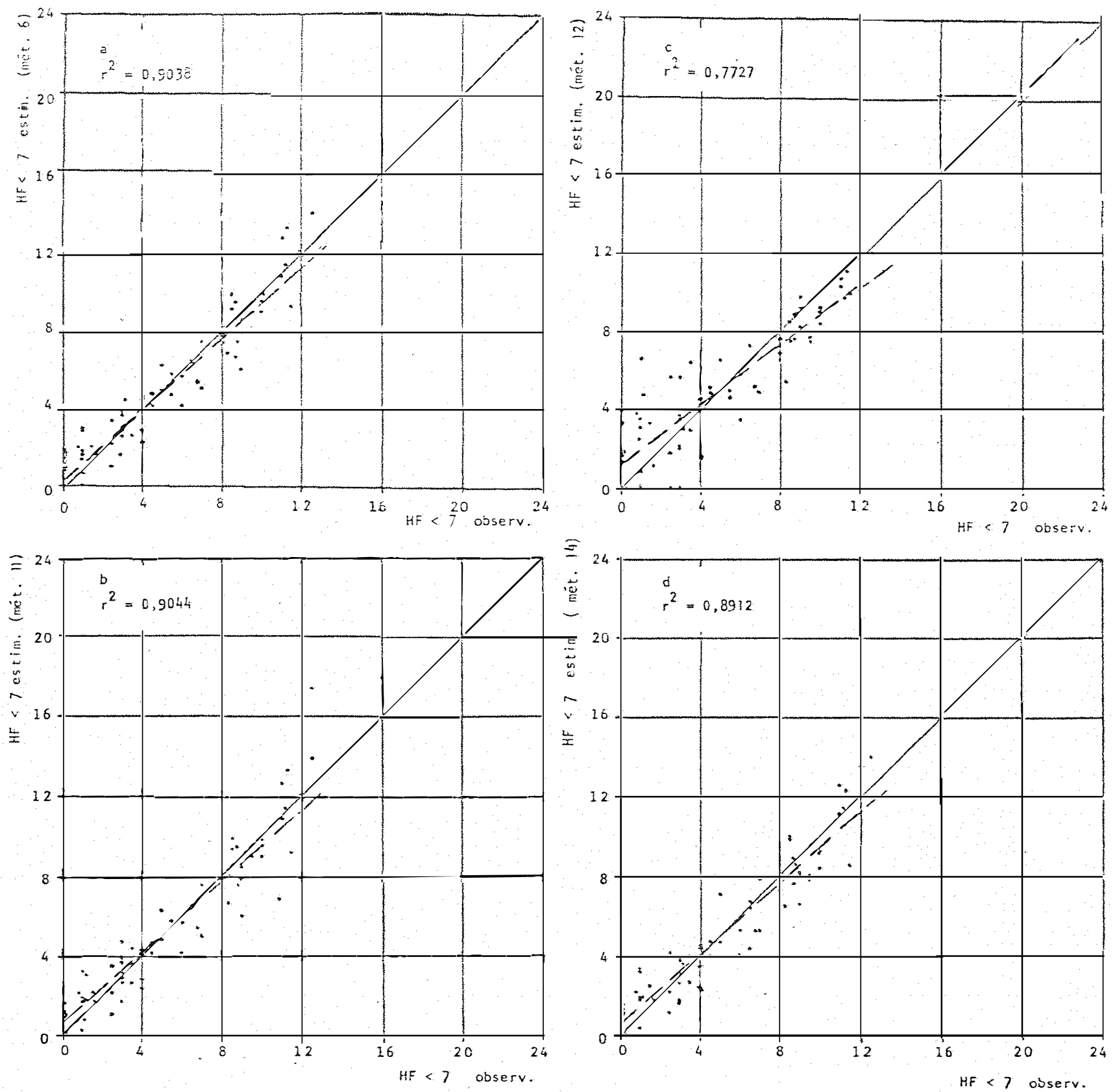

Figura 32 - Correlação entre os totais diários observados e estimados de horas de frio com temperatura abaixo de $7^{\circ} \mathrm{C}(\mathrm{HF}<7$ observ; HF $<7$ estim.), com os respectivos coeficientes de determinação $\left(r^{2}\right)$, no mês de setembro. As estimativas feitas pelos métodos $6,11,12$ e 14, fazem parte dos valo res representados nas figuras $32 a, 32 b, 32 c$ e $32 d$, respec tivamente. 

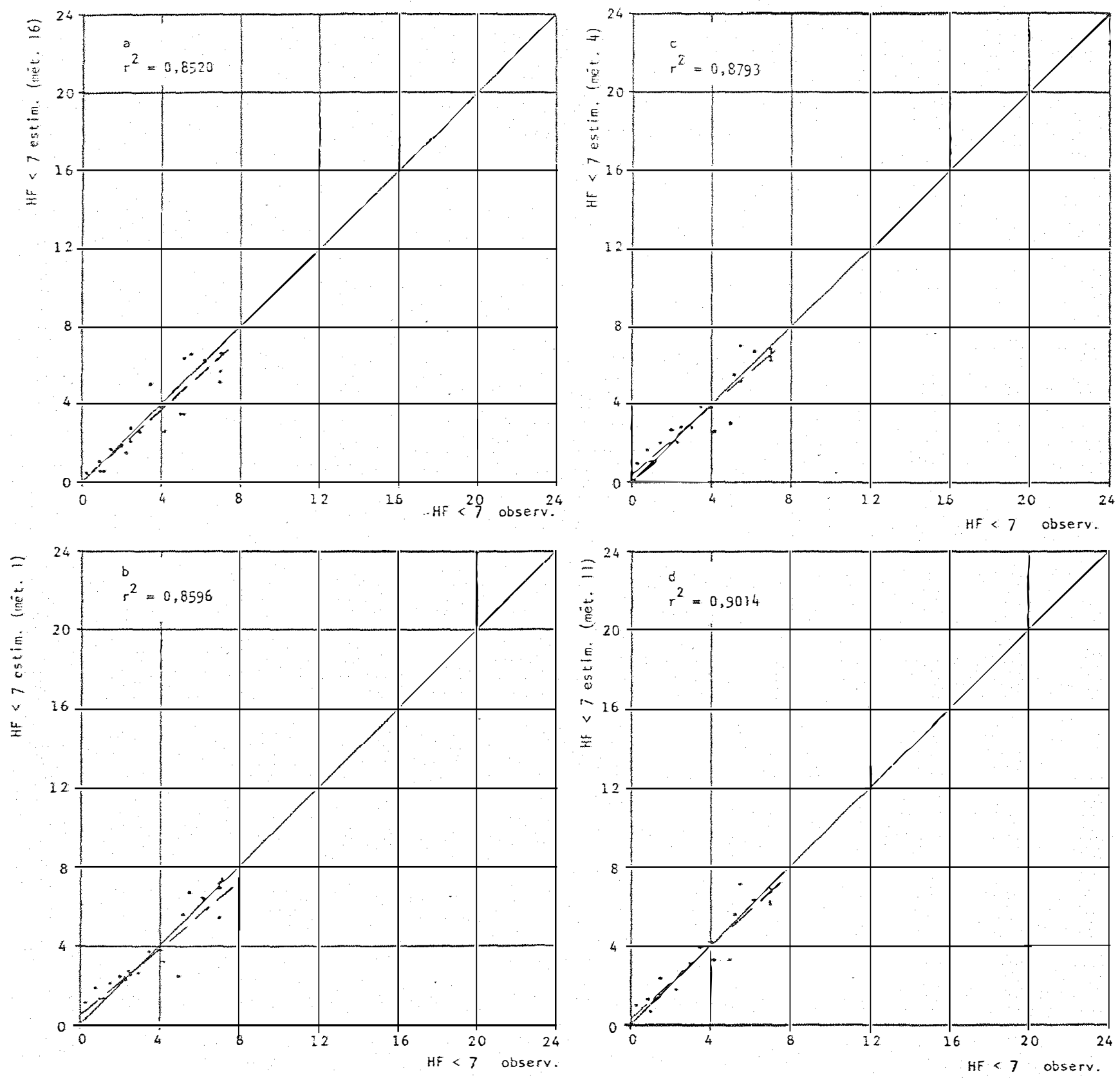

Figura 33 - Correlação entre os totais diārios observados e estimados de horas de frio com temperatura abaixo de $7^{\circ} \mathrm{C}(\mathrm{HF}<7$ observ; $H F<7$ estim.), com os respectivos coeficientes de determinação $\left(r^{2}\right)$, no mês de outubro. As estimativas feitas pelos métodos $16,1,4$ e 11 , fazem parte dos valores representados nas figuras $33 a, 33 b, 33 c$ e $33 d$, respec tivamente. 
mum a necessidade de se acrescentar um fator de ajuste à equação. Pode-se tambēm utilizá-la como uma variável independente na obtenção de equações de regressão para estimativa de horas de frio, pelo método dos quadrados mínimos. Entretanto, para os dois casos citados, alguns cuidados devem ser observados, como por exemplo, evitar a obtenção de valores de estimativa de horas de frio negativos, nos períodos com temperatura mínima maior que a temperatura base. Isso foi verificado por ARON (1975), que em uma primeira análise incluiu todos os dados de temperatura máxima e mínima médios mensais ( $\bar{T} M$ e $\bar{T} m$ ) e poste riormente teve de excluir esses dados dos meses mais quentes em que observou a condição: $\bar{T} m>T B$, para ajustar suas equações de estimativa de horas de frio para o Estado da California, E.U.A. Dessa forma justifica-se plenamente a inclusão para anälise de somente os dados diários de Santa Maria-RS, em que observou-se a condição: $T m$ < TB. Mesmo assim, nos dias em. que os valores de temperatura mínima e da temperatura base, se aproximavam da igualdade, juntamente com amplitude tērmica diá ria pequena, ou ainda com temperatura das 21 horas do dia ante rior pouco acima da "TB" (somente para o método 16), observou- se superestimativas de horas de frio pelo método 4 e, principalmente, pelo método 16 (equação analitica 3.3).

ARON (1975) comenta também que nos meses muito frios, as equaçōes de regressão teöricamente poderiam proporcionar superestimativas de totais mensais de horas de frio com valores acima do mäximo real possível para o período, o que en tretanto não se verificou nas estimativas feitas pelas suas equações de regressão para os locais analisados na California.ob servando-se a tabela 4.15 , verifica-se que foram relativamente pou cos os dias para cujos dados utilizou-se a equação analítica 3.8 , a qual serve de indicativo de que a temperaturadoar permaneceu abaixo da temperatura base (TB) durante as 24 horas do período. Considerando a temperatura base de $13^{\circ} \mathrm{C}$, alguns valores de estimativa maiores que 24 horas de frio foramobtidos por algu- 
Tabela 4.15 - Nümero de dados diärios enquadrados nos diferentes casos L-, pa ra a utilização das respectivas equações de estimativa de horas de frio com temperatura abaixo de $13^{\circ} \mathrm{C}$ e $7^{\circ} \mathrm{C}$, nos meses de abril a outubro, em 12 anos de observação, para Santa Maria-RS.

\begin{tabular}{|c|c|c|c|c|c|c|c|c|}
\hline \multirow[b]{2}{*}{ Més } & \multirow{2}{*}{$\begin{array}{c}\text { Tempe- } \\
\text { ratura } \\
\text { base } \\
{ }^{\circ} \mathrm{C}\end{array}$} & \multicolumn{2}{|c|}{ Nümero de dados } & diàrios & \multicolumn{2}{|c|}{ enquadrados nos } & diferentes & $s$ casos \\
\hline & & $\begin{array}{l}E q . \\
A n . \\
" 3.3 "\end{array}$ & $\begin{array}{l}E q . \\
A n . \\
" 3.4^{11}\end{array}$ & $\begin{array}{l}E q . \\
A n . \\
" 3.5 "\end{array}$ & $\begin{array}{l}\text { Eq. } \\
\text { An. } \\
" 3.6 "\end{array}$ & $\begin{array}{l}\text { Eq. } \\
\text { An. } \\
" 3.711\end{array}$ & $\begin{array}{c}\text { Eq. } \\
\text { An. } \\
" 3.8 "\end{array}$ & $\begin{array}{c}\text { Eq. } \\
\text { An. } \\
" 3.9 " 1\end{array}$ \\
\hline \multirow[t]{2}{*}{ Abril } & 13 & 105 & 25 & 0 & 0 & 0 & 0 & 2 \\
\hline & 7 & 17 & 0 & 0 & 0 & 0 & 0 & 4 \\
\hline \multirow{2}{*}{ Ma io } & 13 & 122 & 76 & 3 & 5 & 0 & 2 & 5 \\
\hline & 7 & 55 & 5 & 0 & 0 & 0 & 0 & 1 \\
\hline \multirow{2}{*}{ Junho } & 13 & 71 & 115 & 19 & 19 & 0 & 14 & 1 \\
\hline & 7 & 82 & 38 & 0 & 0 & 0 & 0 & 0 \\
\hline \multirow{2}{*}{ Julho } & 13 & 57 & 103 & 26 & 23 & 3 & 18 & 3 \\
\hline & 7 & 90 & 24 & 2 & 2 & 0 & 0 & 2 \\
\hline \multirow{2}{*}{ Agos to } & 13 & 98 & 106 & 15 & 12 & 3 & 6 & 5 \\
\hline & 7 & 84 & 9 & 0 & 0 & 0 & 0 & 4 \\
\hline \multirow{2}{*}{ Setembro } & 13 & 124 & 72 & 6 & 4 & 2 & 0 & 7 \\
\hline & 7 & 60 & 2 & 0 & 0 & 0 & 0 & 4 \\
\hline \multirow{2}{*}{ Outubro } & 13 & 127 & 13 & 0 & 0 & 0 & 0 & 4 \\
\hline & 7 & 21 & 0 & 0 & 0 & 0 & 0 & 0 \\
\hline
\end{tabular}

I/ Os caso a, b, c, d, e, f e g, correspondem a utilização das equações analiticas $3.3,3.4,3.5,3.6,3.7,3.8$ e 3.9 , respectivamente. 


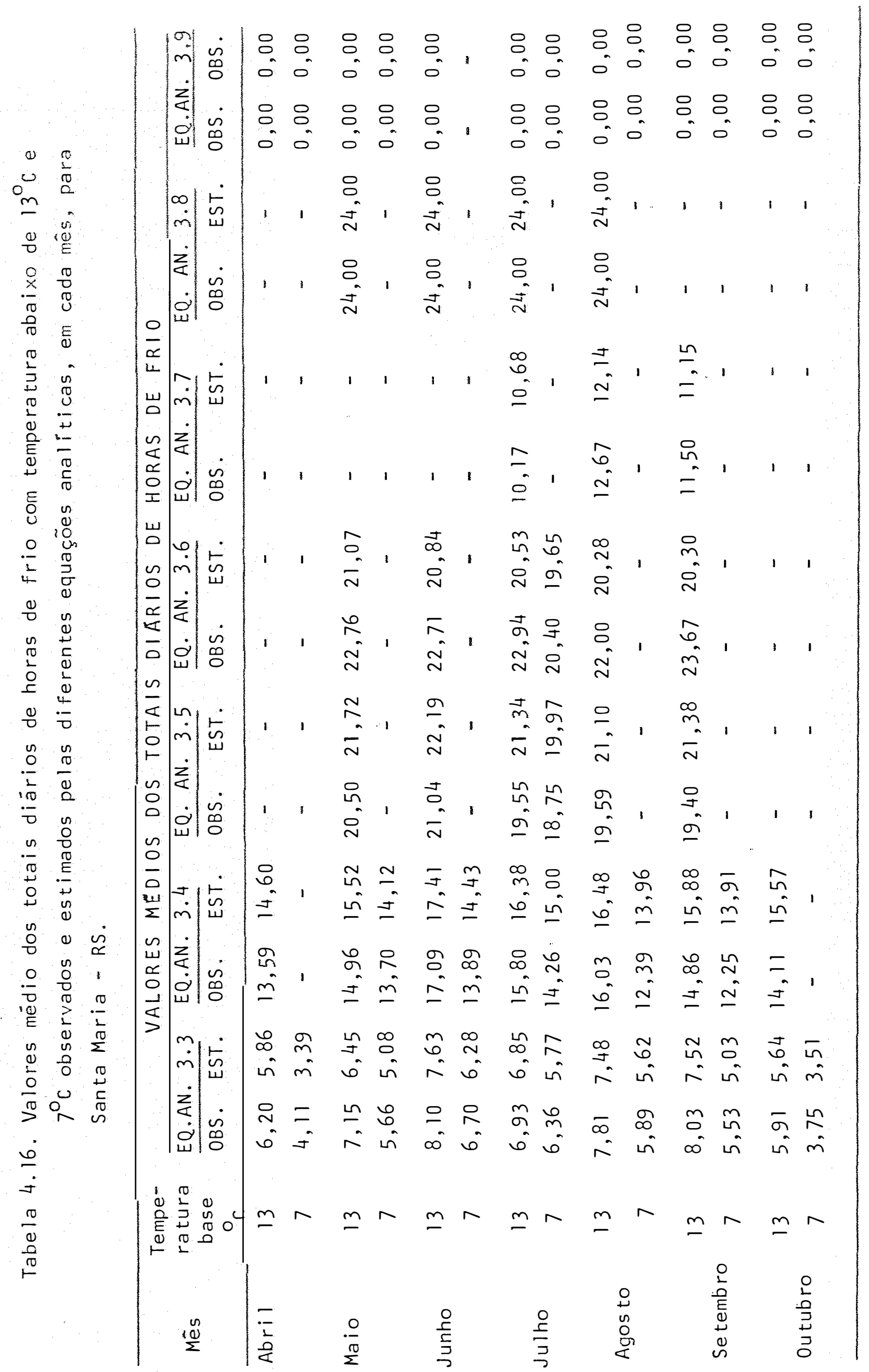

71. 
mas equações de regressão nos meses de maio, junho, julho e agosto, mas que em termos globais não proporcionaram erros significativos, tornando desnecessário sua correção. Essas superes timativas foram desprezadas quando da representação gräfica dos valores observados e estimados ao longo da linha $1: 1$ (figuras 3 à 33), para não se alterar a escala utilizada nesses gräficos, e também devido a sua pequena expressão em relação aos de mais dados.

observando-se as figuras 3 à 33 , verifica-se que, em termos mëdios, todas as equações de regressão (métodos 1 à 15), superestimaram os totais diários de horas de frio de valo res pequenos. Baseando-se nos valores dos coeficientes de determinação $r^{2}$, obtidos pela correlação entre os totais diários de horas de frio ( $H F<13$ ou HF $<7$ ), observados e estimados, para cada mês (tabelas 4.31 e 4.32) verifica-se também que as equações de regressão em que foram incluídas as variáveis independentes Tm e, ou RA (métodos 1, 4, 5, 6, 7, 8, 9, 10, 11 , 14 e 15), apresentaram a tendência de proporcionar melhores es timativas nos meses menos frios, tendência essa também verificada com as estimativas efetuadas através das equações analít cas (método 16). Entretanto, para as estimativas feitas pelas equações de regressão que incluem somente as variáveis indepen dentes "T 9 " e, ou "T 21 " (métodos 2,3 e 12), essa tendéncianão foi observada, exceto quando da estimativa de horas de friocom temperatura abaixo de $13^{\circ} \mathrm{C}$, pelo método 12 . Essa observação ge nearalizada sugere que a inclusão adicional das variáveis $T_{9}$ e T21 na obtenção de equações de regressão mültipla proporcionaria melhores estimativas nos meses mais frios, o que realmente foi verificado, principalmente para a variável "T21" Todavia essa melhora não foi significativa estatisticamente com relação as estimativas feitas pela equação geral HF< TB=a + bTm + + cRA, (método 7), para qualquer mês e para as temperaturas ba se estudadas, conforme observa-se nas tabelas 4.17 a 4.30 . 
Tabela 4.17 - Valores do coeficiente de correlação $(r)$, da transformação $z(r)$ e de $t_{r}$ para teste $t$ para a correlação entre os totais diários de horas de frio com temperatura abaixo de $13^{\circ} \mathrm{C}$ observados e estimados através dos diferentes métodos, para 0 mès de abril.

\begin{tabular}{|c|c|c|c|c|c|}
\hline Método & $\begin{array}{l}\text { Variāveis } \\
\text { Utilizadas }\end{array}$ & $t_{r}$ & $r$ & $z(r)$ & \\
\hline 1 & $\mathrm{Tm}$ & $22,36 \nRightarrow$ & 0,8915 & $.1,4292$ & de \\
\hline 2 & $T_{9}$ & $13,92 * *$ & 0,7747 & 1,0320 & $f$ \\
\hline 3 & $T_{21}$ & $21,79 * *$ & 0,8867 & 1,4063 & e \\
\hline 4 & $R A$ & $29,01 * *$ & 0,9311 & 1,6666 & $b c d$ \\
\hline 5 & $T m ; T_{0}$ & 23,58 & 0,9009 & 1,4770 & cde \\
\hline 6 & $\mathrm{Tm} ; \mathrm{T}_{21}$ & $29,61 * *$ & 0,9336 & 1,6857 & bc \\
\hline 7 & Tm; RA & $29,20 \%$ & 0,9319 & 1,6726 & $b c$ \\
\hline 8 & $T m ; T_{9} ; T_{21}$ & $30,09 \div$ & 0,9355 & 1,7007 & $b c$ \\
\hline 9 & Tm; Tg; RA & $29,32 \div$ & 0,9324 & 1,6765 & bc \\
\hline 10 & $\mathrm{Tm} ; \mathrm{T}_{21} ; \mathrm{RA}$ & $34,14 * \frac{\pi}{x}$ & 0,9488 & 1,8196 & $b$ \\
\hline 11 & $\mathrm{Tm} ; \mathrm{T}_{9} ; \mathrm{T}_{21} ; \mathrm{RA}$ & $34,16 * \pi$ & 0,9489 & 1,8206 & $b$ \\
\hline 12 & $T_{9} ; T_{21}$ & $24,47 * *$ & 0,9066 & 1,5081 & cde \\
\hline 13 & $T_{9} ; R A$ & $29,15 * *$ & 0,9317 & 1,6711 & bc \\
\hline 14 & $\mathrm{~T}_{21} ; \mathrm{RA}$ & $34,01 * *$ & 0,9485 & 1,8166 & $b$ \\
\hline 15 & $\mathrm{~T}_{9} ; \mathrm{T}_{21} ; \mathrm{RA}$ & $34,03 * *$ & 0,9485 & 1,8166 & $b$ \\
\hline 16 & $T_{1} ; T_{2} ; T m ; T_{21}$ & $49,10 * *$ & 0,9742 & 2,1688 & $a$ \\
\hline
\end{tabular}

** Significativos ao nível de $1 \%$ de probabilidade.

Obs: As letras iguais indicam que os métodos não apresentam diferença significativa ao nivel de $5 \%$ de probabilidade entre si, pelo teste $t$. 
Tabela 4.18 - Valores do coeficiente de correlação $(r)$, da transformação $z(r)$ e de $t_{r}$ para teste $t$ para a correlação entre os totais diários de horas de frio com temperatura abaixo de $13^{\circ} \mathrm{C}$ observados e estimados através dos diferentes métodos, para o mês de maio.

\begin{tabular}{|c|c|c|c|c|c|}
\hline Método & $\begin{array}{l}\text { Variāveis } \\
\text { Utilizadas }\end{array}$ & $t_{r}$ & $r$ & $z(r)$ & \\
\hline 1 & $\mathrm{Tm}$ & $20,86 * *$ & 0,8213 & 1,1608 & $c$ \\
\hline 2 & $T_{9}$ & $20,50 * *$ & 0,8165 & 1,1462 & $c$ \\
\hline 3 & $T_{21}$ & $20,23 * \pi$ & 0,8129 & 1,1355 & $c$ \\
\hline 4 & $R A$ & $33,62 * *$ & 0,9183 & 1,5781 & $b$ \\
\hline 5 & $\mathrm{Tm} ; \mathrm{T}_{9}$ & $22,29 * x$ & 0,8383 & 1,2154 & c \\
\hline 6 & $\mathrm{Tm} ; \mathrm{T}_{21}$ & $24,44 * \pi$ & 0,8601 & 1,2937 & c \\
\hline 7 & $\mathrm{Tm} ; \mathrm{RA}$ & $33,84 * *$ & 0,9192 & 1,5838 & $b$ \\
\hline 8 & $\mathrm{Tm} ; \mathrm{T}_{9} ; \mathrm{T}_{21}$ & $25,47 * *$ & 0,8691 & 1,3294 & $c$ \\
\hline 9 & $\mathrm{Tm} ; \mathrm{T}_{9} ; \mathrm{RA}$ & $34,08 * *$ & 0,9202 & 1,5903 & $b$ \\
\hline 10 & $\mathrm{Tm} ; \mathrm{T}_{21} ; \mathrm{RA}$ & $34,92 * *$ & 0,9236 & 1,6130 & $b$ \\
\hline 11 & $\mathrm{Tm}_{\mathrm{m}} \mathrm{T}_{9} ; \mathrm{T}_{21} ; \mathrm{RA}$ & $35,13 * *$ & 0,9244 & 1,6185 & $b$ \\
\hline 12 & $\mathrm{~T}_{9} ; \mathrm{T}_{21}$ & $24,93 * *$ & 0,8645 & 1,3109 & c \\
\hline 13 & $T_{9} ; R A$ & $34,08 * *$ & 0,9202 & 1,5903 & $b$ \\
\hline 14 & $\mathrm{~T}_{21} ; \mathrm{RA}$ & $34,91 * *$ & 0,9235 & 1,6123 & $b$ \\
\hline 15 & $\mathrm{~T}_{9} ; \mathrm{T}_{21} ; \mathrm{RA}$ & $35,10 x *$ & 0,9243 & 1,6178 & $b$ \\
\hline 16 & $\mathrm{TM}_{1} ; \mathrm{TM}_{2} ; \mathrm{Tm} ; \mathrm{T}_{21}$ & $51,77 *$ & 0,9629 & 1,9843 & $a$ \\
\hline
\end{tabular}

$\stackrel{*}{*}$ Significativos ao nivel de $1 \%$ de probabilidade.

Obs: As letras iguais indicam que os mëtodos não apresentam diferença signi ficativa ao nível de $5 \%$ de probabilidade entre si, pelo teste $t$. 
Tabela 4.19 - Valores do coeficiente de correlação $(r)$, da transformação $z(r)$ e de $t_{r}$ para teste $t$ para a correlação entre os totais diários de horas de frio com temperatura abaixo de $13^{\circ} \mathrm{C}$ observados e estimados através dos diferentes métodos, para o mês de junho.

\begin{tabular}{|c|c|c|c|c|c|}
\hline Método & $\begin{array}{l}\text { Variáveis } \\
\text { Utilizadas }\end{array}$ & $t_{r}$ & $r$ & $z(r)$ & \\
\hline 1 & $\mathrm{Tm}$ & $16,82 \div$ & 0,7404 & 0,9514 & 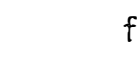 \\
\hline 2 & $T_{9}$ & $18,33 \div *$ & 0,7684 & 1,0164 & $f$ \\
\hline 3 & $T_{21}$ & $20,40 \div$ & 0,8006 & 1,3211 & c \\
\hline 4 & RA & $32,74 \div$ & 0,9063 & 1,5064 & $\mathrm{~b}$ \\
\hline 5 & $T_{m} ; T_{9}$ & 18,77 춧․ & 0,7758 & 1,0347 & ef \\
\hline 6 & $\mathrm{Tm} ; \mathrm{T}_{21}$ & $21,08 \div$ & 0,8099 & 1,1267 & def \\
\hline 7 & $T m$; RA & $33,32 \%$ & 0,9091 & 1,5223 & $b$ \\
\hline 8 & $\mathrm{Tm} ; \mathrm{T}_{9} ; \mathrm{T}_{21}$ & $23,56 \div$ & 0,8392 & 1,2185 & $c d$ \\
\hline 9 & $T_{m} ; T_{g} ; R A$ & $34,06 * *$ & 0,9125 & 1,5423 & $\mathrm{~b}$ \\
\hline 10 & $\mathrm{Tm} ; \mathrm{T}_{21} ; \mathrm{RA}$ & $34,82 \star x$ & 0,9158 & 1,5624 & b \\
\hline 11 & $\mathrm{Tm}_{\mathrm{m}} \mathrm{T}_{9} ; \mathrm{T}_{21} ; \mathrm{RA}$ & $35,94 \div *$ & 0,9204 & 1,5916 & $b$ \\
\hline 12 & $T_{9} ; T_{21}$ & $23,19 \div$ & 0,8353 & 1,2054 & cde \\
\hline 13 & $T_{9} ; R A$ & $34,04 \ldots$ & 0,9124 & 1,5417 & b \\
\hline 14 & $\mathrm{~T}_{21} ; \mathrm{RA}$ & $34,81 \div *$ & 0,9158 & 1,5624 & $b$ \\
\hline 15 & $\mathrm{~T}_{9} ; \mathrm{T}_{21} ; \mathrm{RA}$ & $35,24 \div$ & 0,9176 & 1,5736 & b \\
\hline 16 & $\mathrm{TM}_{1} ; \mathrm{TM}_{2} ; \mathrm{Tm} ; \mathrm{T}_{21}$ & $44,49 x+$ & 0,9458 & 1,7904 & a \\
\hline
\end{tabular}

** Significativos ao nivel de $1 \%$ de probabilidade.

Obs: As letras iguais indicam que os métodos não apresentam diferença sig nificativa ao nivel de $5 \%$ de probabilidade entre si, pelo teste $t$. 
Tabela 4.20 - Valores do coeficiente de correlação $(r)$, da transformação $z(r)$ e de $t_{\text {; }}$ para teste $t$ para a correlação entre os totais diärios de horas de frio com temperatura abaixo de $13^{\circ} \mathrm{C}$ observados e estimados atravēs dos diferentes métodos, para o mês de julho.

\begin{tabular}{|c|c|c|c|c|c|}
\hline Método & $\begin{array}{l}\text { Variáveis } \\
\text { Utilizadas }\end{array}$ & $t_{r}$ & $r$ & $z(r)$ & \\
\hline 1 & $\mathrm{Tm}$ & $17,01 *$ & 0,7463 & 0,9646 & e \\
\hline 2 & $T_{9}$ & $18,40 * *$ & 0,7717 & 1,0245 & $\mathrm{e}$ \\
\hline 3 & $T_{21}$ & $17,70 * \star$ & 0,7592 & 0,9943 & $\mathrm{e}$ \\
\hline 4 & $\mathrm{RA}$ & $19,00 * \hbar$ & 0,7815 & 1,0492 & e \\
\hline 5 & $\mathrm{Tm} ; \mathrm{T}_{9}$ & $19,39 * *$ & 0,7876 & 1,0651 & de \\
\hline 6 & $\mathrm{Tm} ; \mathrm{T}_{21}$ & $20,46 * *$ & 0,8033 & 1,1078 & cde \\
\hline 7 & $T m ; R A$ & $24,64 * *$ & 0,8516 & 1,2619 & $\mathrm{bc}$ \\
\hline 8 & $\mathrm{Tm} ; \mathrm{T}_{9} ; \mathrm{T}_{21}$ & $23,86 * * x$ & 0,8439 & 1,2346 & $b c d$ \\
\hline 9 & $\mathrm{Tm} ; \mathrm{Tg} ; \mathrm{RA}$ & $26,42 * *$ & 0,8672 & 1,3217 & $b$ \\
\hline 10 & $\mathrm{Tm} ; \mathrm{T}_{21} ; \mathrm{RA}$ & $26,03 * *$ & 0,8640 & 1,3089 & $b$ \\
\hline 11 & $\mathrm{Tm} ; \mathrm{T}_{9} ; \mathrm{T}_{21} ; \mathrm{RA}$ & $28,59 * *$ & 0,8834 & 1,3910 & $b$ \\
\hline 12 & $\mathrm{~T}_{9} ; \mathrm{T}_{21}$ & $23,84 * *$ & 0,8436 & 1,2335 & $b c d$ \\
\hline 13 & $\mathrm{~T}_{9} ; \mathrm{RA}$ & $25,94 \ldots *$ & 0,8632 & 1,3058 & $b$ \\
\hline 14 & $\mathrm{~T}_{21} ; \mathrm{RA}$ & $23,84 * *$ & 0,8436 & 1,2335 & bcd \\
\hline 15 & $\mathrm{~T}_{9} ; \mathrm{T}_{21} ; \mathrm{RA}$ & $28,58 \approx$ & 0,8833 & 1,3906 & $b$ \\
\hline 16 & $\mathrm{TM}_{1} ; \mathrm{TM}_{2} ; \mathrm{Tm} ; \mathrm{T}_{21}$ & $39,65 * *$ & 0,9340 & 1,6888 & $a$ \\
\hline
\end{tabular}

** Significativos ao nivel de $1 \%$ de probabilidade.

Obs: As letras iguais indicam que os mëtodos não apresentam diferença significativa ao nivel de $5 \%$ de probabilidade entre si, pelo teste $t$. 
Tabela 4.21 - Valores do coeficiente de correlação $(r)$, da transformação $z(r)$ e de $t_{r}$ para teste $t$ para a correlação entre os totais diārios de horas de frio com temperatura abaixo de $13^{\circ} \mathrm{C}$ observados e estimados atravēs dos diferentes métodos, para o mês de agosto.

\begin{tabular}{|c|c|c|c|c|c|}
\hline Método & $\begin{array}{l}\text { Variáveis } \\
\text { Utilizadas }\end{array}$ & $t_{r}$ & $r$ & $z(r)$ & \\
\hline 1 & $\mathrm{Tm}$ & $14,74 * 2 \%$ & 0,6900 & 0,8480 & $d$ \\
\hline 2 & $T_{9}$ & $18,32 * *$ & 0,7642 & 1,0062 & $c d$ \\
\hline 3 & $T_{21}$ & 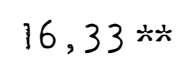 & 0,7262 & 0,9206 & $d$ \\
\hline 4 & $R A$ & $30,24 \approx$ & 0,8903 & 1,4234 & $b$ \\
\hline 5 & $T m ; T_{9}$ & $18,66 *$ & 0,7700 & 1,0203 & $c d$ \\
\hline 6 & $\mathrm{Tm} ; \mathrm{T}_{21}$ & $18,40 \div$ & 0,7656 & 1,0096 & $c d$ \\
\hline 7 & $\mathrm{Tm} ; \mathrm{RA}$ & $30,25 \div$ & 0,8904 & 1,4239 & b \\
\hline 8 & $\mathrm{Tm} ; \mathrm{T}_{9} ; \mathrm{T}_{21}$ & $22,37 \approx$ & 0,8226 & 1,1648 & $c$ \\
\hline 9 & $\mathrm{Tm} ; \mathrm{T}_{9} ; \mathrm{RA}$ & $32,67 *$ & 0,9038 & 1,4926 & $b$ \\
\hline 10 & $\mathrm{Tm} ; \mathrm{T}_{21} ; \mathrm{RA}$ & $30,79 \div \div$ & 0,8936 & 1,4395 & $b$ \\
\hline 11 & $\mathrm{Tm}_{\mathrm{m}} \mathrm{T}_{9} ; \mathrm{T}_{21} ; \mathrm{RA}$ & $33,42 * x$ & 0,9075 & 1,5132 & $b$ \\
\hline 12 & $\mathrm{~T}_{9} ; \mathrm{T}_{21}$ & $22,31 \stackrel{2}{x}$ & 0,8218 & 1,1624 & $c$ \\
\hline 13 & $T_{g} ; R A$ & $31,90 \div$ & 0,8998 & 1,4712 & $b$ \\
\hline 14 & $\mathrm{~T}_{21} ; \mathrm{RA}$ & $30,77 \div$ & 0,8935 & 1,4390 & $b$ \\
\hline 15 & $\mathrm{~T}_{9} ; \mathrm{T}_{21} ; \mathrm{RA}$ & $30,21 \div$ & 0,9015 & 1,4802 & $b$ \\
\hline 16 & $T M_{1} ; T M_{2} ; T m ; T_{21}$ & $43,99 * *$ & 0,9434 & 1,7681 & $a$ \\
\hline
\end{tabular}

$*$ Significativos ao nível de $1 \%$ de probabilidade.

Obs: As letras iguais indicam que os métodos não apresentam diferença significativa ao nível de $5 \%$ de probabilidade entre si, pelo teste $t$. 
Tabela 4.22 - Valores do coeficiente de correlação $(r)$, da transformação $z(r)$ e de $t_{r}$ para teste $t$ para a correlação entre os totais diários de horas de frio com temperatura abaixo de $13^{\circ} \mathrm{C}$ observados e estimados atravës dos diferentes métodos, para o mês de setembro.

\begin{tabular}{|c|c|c|c|c|c|}
\hline Método & $\begin{array}{l}\text { Variäveis } \\
\text { Utilizadas }\end{array}$ & $t_{r}$ & $r$ & $z(r)$ & \\
\hline 1 & $T m$ & $15,39 * 2$ & 0,7312 & 0,9313 & d \\
\hline 2 & $T_{9}$ & $16,58 \div *$ & 0,7559 & 0,9866 & $c d$ \\
\hline 3 & $T_{21}$ & $18,20 * x$ & 0,7851 & 1,0585 & bcd \\
\hline 4 & $R A$ & $32,96 * *$ & 0,9168 & 1,5686 & a \\
\hline 5 & Tm; $T_{9}$ & $18,65 * *$ & 0,7924 & 1,0778 & bed \\
\hline 6 & $T m ; T_{21}$ & $20,01 \div$ & 0,8125 & 1,1343 & $b c$ \\
\hline 7 & $T m ; R A$ & $33,38 \div *$ & 0,9186 & 1,5800 & a \\
\hline 8 & $T m ; T_{9} ; T_{21}$ & $22,49 \approx$ & 0,8429 & 1,2311 & $b$ \\
\hline 9 & $\mathrm{Tm} ; \mathrm{T}_{9} ; \mathrm{RA}$ & $33,87 *$ & 0,9207 & 1,5936 & a \\
\hline 10 & $\mathrm{Tm} ; \mathrm{T}_{21} ; \mathrm{RA}$ & $33,91 \div x$ & 0,9209 & 1,5949 & a \\
\hline 13 & $T_{m} ; T_{9} ; T_{21} ; R A$ & $34,41 \approx *$ & 0,9229 & 1,6082 & a \\
\hline 12 & $T_{9} ; T_{21}$ & $22,28 \div$ & 0,8406 & 1,2232 & $b$ \\
\hline 13 & $T_{g} ; R A$ & $33,17 \approx$ & 0,9177 & 1,5743 & $a$ \\
\hline 14 & $T_{21} ; R A$ & $33,26 \div$ & 0,9181 & 1,5768 & $a$ \\
\hline 15 & $T_{9} ; T_{21} ; R A$ & $33,44 * x$ & 0,9189 & 1,5819 & a \\
\hline 16 & $T M_{1} ; T_{2} ; T m ; T_{21}$ & $40,00 * 2$ & 0,9412 & 1,7485 & $a$ \\
\hline
\end{tabular}

Signficativos ao nivel de $1 \%$ de probabilidade.

obs: As letras iguais indicam que os métodos não apresentam diferença sig nificativa ao nível de $5 \%$ de probabilidade entre si, pelo teste $t$. 
Tabela 4.23 - Valores do coeficiente de correlação $(r)$, da transformação $z(r)$ e de $t_{r}$ para teste $t$ para a correlação entre os totais diários de horas de frio com temperatura abaixo de $13^{\circ} \mathrm{C}$ observados e estimados através dos diferentes métodos, para o mês de outubro.

\begin{tabular}{|c|c|c|c|c|c|}
\hline Método & $\begin{array}{l}\text { Variāeis } \\
\text { Utilizadas }\end{array}$ & ${ }^{t} r_{r}$ & $r$ & $z(r)$ & \\
\hline 1 & $T m$ & $20,44 * *$ & 0,8563 & 1,2793 & cde \\
\hline 2 & $T_{9}$ & $13,33 \approx$ & 0,7341 & 0,9376 & $f$ \\
\hline 3 & $T_{21}$ & $15,77 *$ & 0,7878 & 1,0656 & ef \\
\hline 4 & RA & $32,01 \stackrel{\cdots}{\cdots N}$ & 0,9331 & 1,6818 & $a b$ \\
\hline 5 & $T m ; T_{9}$ & $23,78 \div \div$ & 0,8878 & 1,4114 & $c d$ \\
\hline 6 & $T m ; T_{21}$ & $23,99 \approx$ & 0,8893 & 1,4186 & $c d$ \\
\hline 7 & $T m ; R A$ & $32,60 \div \div$ & 0,9353 & 1,6991 & $a b$ \\
\hline 8 & $T m ; T_{9} ; T_{21}$ & $26,35 \cdots$ & 0,9057 & 1,5031 & $b c$ \\
\hline 9 & $T m ; T_{g} ; R A$ & $32,87 \div$ & 0,9363 & 1,7072 & $a b$ \\
\hline 10 & $\mathrm{Tm} ; \mathrm{T}_{21} ; \mathrm{RA}$ & $33,73 \approx$ & 0,9392 & 1,7312 & a \\
\hline 11 & $T_{m} ; T_{9} ; T_{2\}} ; R A$ & $33,94 *$ & 0,9398 & 1,7363 & a \\
\hline 12 & $T_{9} ; T_{2\}}$ & $19,59 *$ & 0,8463 & 1,2430 & de \\
\hline 13 & $T_{g} ; R A$ & $32,47 \approx$ & 0,9348 & 1,6951 & $a b$ \\
\hline 14 & $T_{21}^{\prime} ; R A$ & $33,18 \div$ & 0,9373 & 1,7153 & $a b$ \\
\hline 15 & $T_{0} ; T_{21} ; R A$ & $33,55 \approx$ & 0,9386 & 1,7262 & $a b$ \\
\hline 16 & $T M_{1} ; T M_{2} ; T m ; T_{21}$ & 39,80 ㅊ & 0,9552 & 1,8880 & a \\
\hline
\end{tabular}

* Significativos ao nivel de $1 \%$ de probabilidade.

obs: As letras iguais indicam que os métodos não apresentam diferença sịg nificativa ao nive? de $5 \%$ de probabilidade entre si, pelo teste $t$. 
Tabela 4.24 - Valores do coeficiente de correlação (r), da transformação $z(r)$ e de $t_{r}$ para teste $t$, para a correlação entre os totais diarios de horas de frio com temperatura abaixo de $7^{\circ} \mathrm{C}$ observados e estimados através dos diferentes métodos, para o més de abri\}.

\begin{tabular}{|c|c|c|c|c|c|}
\hline Método & $\begin{array}{l}\text { Variäveis } \\
\text { Utilizadas }\end{array}$ & $t_{r}$ & $r$ & $z(r)$ & \\
\hline 1 & $\operatorname{Tm}$ & $11,08 * x$ & 0,9306 & 1,6628 & $a b$ \\
\hline 2 & $T_{9}$ & $5,58 * \pi$ & 0,7881 & 3,0664 & $b c$ \\
\hline 3 & $T_{21}$ & $2,38 *$ & 0,4786 & 0,5212 & $c$ \\
\hline 4 & RA & $9,41 \div \div$ & 0,9072 & 1,5115 & $a b$ \\
\hline 5 & $T m ; T_{g}$ & $11,17 \times \div$ & 0,9316 & 1,6704 & $a b$ \\
\hline 6 & $T m ; T_{21}$ & 14,$09 ; *$ & 0,9553 & 1,8892 & $a$ \\
\hline 7 & $T m ; R A$ & $11,09 * *$ & 0,9307 & 1,6636 & $a b$ \\
\hline 8 & $T_{m} ; T_{9} ; T_{21}$ & $14,18 \div *$ & 0,9558 & 1,8949 & a \\
\hline 9 & $T m ; T_{g} ; R A$ & $11,17 \approx *$ & 0,9316 & 1,6704 & $a b$ \\
\hline 10 & $T m ; T_{21} ; R A$ & $14,25 * *$ & 0,9562 & 1,8996 & a \\
\hline 11 & $T_{m} ; T_{9} ; T_{21} ; R A$ & $14,28 \div$ & 0,9564 & 1,9019 & a \\
\hline 12 & $T_{9} ; T_{21}$ & $5,90 \div$ & 0,8042 & 1,1304 & $b c$ \\
\hline 13 & $T_{g}^{\prime} ; R A$ & $9,45 * x$ & 0,9080 & 1,5160 & $a b$ \\
\hline 34 & $T_{21} ; R A$ & $10,59 \approx$ & 0,9247 & 1,6205 & $a b$ \\
\hline 15 & $T_{9} ; T_{21} ; R A$ & $10,60 *$ & 0,9248 & 1,6212 & $a b$ \\
\hline 16 & $T M_{1} ; T M_{2} ; T m ; T_{21}$ & $16,51 \%$ & 0,9668 & 2,0408 & a \\
\hline
\end{tabular}

Significativo ao nivel de $1 \%$ de probabilidade.

* Significativo ao nivel de $5 \%$ de probabilidade.

obs: As letras iquais indicam que os métodos não apresentam diferença signi ficativa entre si, ao nivel de $5 \%$ de probabilidade, pelo teste $t$. 
Tabela 4.25 - Valores do coeficiente de correlação (r), da transformação $z(r)$ e de $t_{r}$ para teste $t$, para a correlação entre os totais diärios de horas de frio com temperatura abaixo de $7^{\circ} \mathrm{C}$ observados e estimados através dos diferentes métodos, para o mês de malo.

\begin{tabular}{|c|c|c|c|c|c|}
\hline Método & $\begin{array}{l}\text { Variáveis } \\
\text { Utilizadas }\end{array}$ & $r$ & $r$ & $z(r)$ & \\
\hline 1 & $T m$ & $16,47 * *$ & 0,9076 & 1,5137 & $a b$ \\
\hline 2 & $T_{9}$ & $11,94 \approx \%$ & 0,8430 & 1,2315 & $b c$ \\
\hline 3 & $T_{21}$ & 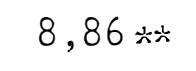 & 0,7581 & 0,9917 & c \\
\hline 4 & RA & $18,43 \ldots$ & 0,9242 & 1,6171 & $a$ \\
\hline 5 & $\mathrm{Tm} ; \mathrm{T}_{\mathrm{g}}$ & $17,26 \div$ & 0,9148 & 1,5562 & $a b$ \\
\hline 6 & $T m ; T_{21}$ & $17,78 \%$ & 0,9191 & 1,5832 & $a b$ \\
\hline 7 & $\mathrm{Tm} ; \mathrm{RA}$ & 19,07 茨 & 0,9286 & 1,6481 & a \\
\hline 8 & $T m ; T_{9} ; T_{21}$ & $18,82 \approx$ & 0,9269 & 1,6359 & a \\
\hline 9 & $T m ; T_{g} ; R A$ & $19,30 \ldots$ & 0,9301 & $1,659\}$ & $a$ \\
\hline 10 & $T \mathrm{~m} ; \mathrm{T}_{21} ; \mathrm{RA}$ & 19,55 L & 0,9318 & 1,6719 & a \\
\hline 11 & $T_{m} ; T_{9} ; T_{21} ; R A$ & $19,97 * *$ & 0,9343 & 1,6912 & $a$ \\
\hline 12 & $T_{9} ; T_{21}$ & $15,38 \div 2$ & 0,8961 & 1,4521 & $a b$ \\
\hline 13 & $T_{g} ; R A$ & $18,83 \approx \approx$ & 0,9270 & 1,6366 & a \\
\hline 14 & $T_{21} ; R A$ & $18,84 \%$ & 0,9270 & 1,6366 & a \\
\hline 15 & $\mathrm{~T}_{9} ; \mathrm{T}_{21} ; \mathrm{RA}$ & $19,46 \approx$ & 0,9312 & 1,6674 & $a$ \\
\hline $16($ AN. $)$ & $T M_{1} ; T M_{2} ; T m ; T_{21}$ & $20,61 \cdots$ & 0,9379 & 1,7203 & $a$ \\
\hline
\end{tabular}

Significativo ao nivel de $1 \%$ de probabilidade.

Obs: As letras iguais indicam que os métodos não apresentam diferença signi ficativa entre si, ao nivel de 5\% de probabilidade, pelo teste " $t$ ". 
Tabela 4.26 - Valores do coeficiente de correlação $(r)$, da transformação $z(r)$ e de $t_{r}$ para teste $t$, para a correlação entre os totais diārios de horas de frio com temperatura abaixo de $7^{\circ} \mathrm{C}$ observados e estimados através dos diferentes métodos, para o mês de junho.

\begin{tabular}{|c|c|c|c|c|c|}
\hline Método & $\begin{array}{l}\text { Variāveis } \\
\text { Utilizadas }\end{array}$ & $t_{r}$ & $r$ & $z(r)$ & \\
\hline 1 & $\mathrm{Tm}$ & $23,54 \cdots$ & 0,9086 & 1,5194 & $a b$ \\
\hline 2 & $T_{9}$ & $16,23 \stackrel{x}{x}$ & 0,8321 & 1,1949 & $c$ \\
\hline 3 & $T_{21}$ & $13,20 *$ & 0,7735 & 1,0290 & $c$ \\
\hline 4 & RA & $22,25 * *$ & 0,8993 & 1,4686 & $b$ \\
\hline 5 & $T m ; T_{g}$ & $24,24 * *$ & 0,9132 & 1,5465 & $a b$ \\
\hline 6 & $\mathrm{Tm} ; \mathrm{T}_{21}$ & $25,50 \div$ & 0,9206 & 1,5929 & $a b$ \\
\hline 7 & $\mathrm{Tm} ; \mathrm{RA}$ & $24,84 * 2$ & 0,9168 & 1,5686 & $a b$ \\
\hline 8 & $\mathrm{Tm} ; \mathrm{T}_{9} ; \mathrm{T}_{21}$ & $26,67 \stackrel{2}{x}$ & 0,9267 & 1,6345 & $a b$ \\
\hline 9 & $T m ; T_{g} ; R A$ & $25,16 *$ & 0,9186 & 1,5800 & $a b$ \\
\hline 10 & $\mathrm{Tm} ; \mathrm{T}_{21} ; \mathrm{RA}$ & $26,26 \%$ & 0,9246 & 1,6198 & $a b$ \\
\hline 11 & $T_{m} ; T_{9} ; T_{21} ; R A$ & $27,01 \approx$ & 0,9283 & 1,6459 & $a b$ \\
\hline 12 & $T_{9} ; T_{21}$ & $22,01 \approx$ & 0,8974 & 1,4587 & $b$ \\
\hline 13 & $T_{9} ; R A$ & $23,12 \div$ & 0,9057 & 1,5031 & a \\
\hline 14 & $\mathrm{~T}_{21} ; \mathrm{RA}$ & $23,75 \div$ & 0,9100 & 1,5275 & $a$ \\
\hline 15 & $\mathrm{~T}_{9} ; \mathrm{T}_{21} ; \mathrm{RA}$ & $25,25 *$ & 0,9192 & 1,5838 & a \\
\hline $16(\mathrm{AN})$. & $T M_{1} ; T M_{2} ; T m ; T_{2 l}$ & $30,12 *$ & 0,9411 & 1,7476 & a \\
\hline
\end{tabular}

$* \dot{*}$ Significativo ao nivel de $1 \%$ de probabilidade.

Obs: As letras iguais indicam que os métodos não apresentam diferença significativa entre si, ao nivel de $5 \%$ de probabilidade, pelo teste $t$. 
Tabela 4.27 - Valores do coeficiente de correlação $(r)$, da transformação $z(r)$ e de $t_{r}$ para teste $t$, para a correlação entre os totais diärios de horas de frio com temperatura abaixo de $7^{\circ} \mathrm{C}$ observados e estimados atravës dos diferentes mëtodos, para o mês de julho.

\begin{tabular}{|c|c|c|c|c|c|}
\hline Método & $\begin{array}{l}\text { Variäveis } \\
\text { Utilizadas }\end{array}$ & $t_{r}$ & $r$ & $z(r)$ & \\
\hline 1 & $\mathrm{Tm}$ & $13,79 \approx$ & 0,7868 & 1,0630 & de \\
\hline 2 & $T_{g}$ & $11,58 \div$ & 0,7309 & 0,9307 & e \\
\hline 3 & $T_{21}$ & $13,42 \div$ & 0,7784 & 1,0413 & de \\
\hline 4 & RA & $21,40 \div \frac{1}{x}$ & 0,8924 & 1,4336 & $a b c$ \\
\hline 5 & $T m ; T_{9}$ & $14,41 \stackrel{\circ}{\circ}$ & 0,7998 & 1,0981 & de \\
\hline 6 & $T_{m} ; T_{21}$ & $17,88 *$ & 0,8556 & 1,2767 & bcd \\
\hline 7 & $\mathrm{Tm} ; \mathrm{RA}$ & $21,80 \div$ & 0,8958 & 1,4505 & $a b c$ \\
\hline 8 & $T m ; T_{9} ; T_{21}$ & 18,22 火火 & 0,8598 & 1,2926 & bcd \\
\hline 9 & $\mathrm{Tm} ; \mathrm{T}_{9} ; \mathrm{RA}$ & $21,85 *$ & 0,8962 & 1,4526 & $a b c$ \\
\hline 10 & $\mathrm{Tm} ; \mathrm{T}_{21} ; \mathrm{RA}$ & $23,41 \stackrel{x}{x}$ & 0,9077 & 1,5143 & $a b$ \\
\hline 11 & $\mathrm{Tm} ; \mathrm{T}_{9} ; \mathrm{T}_{21} ; \mathrm{RA}$ & $23,44 \approx$ & 0,9079 & 1,5154 & $a b$ \\
\hline 12 & $\mathrm{~T}_{9} ; \mathrm{T}_{21}$ & $16,60 *$ & 0,8378 & 1,2137 & $c d$ \\
\hline 13 & $\mathrm{~T}_{9} ; \mathrm{RA}$ & $21,67 \stackrel{2 *}{x}$ & 0,8946 & 1,4445 & $a b c$ \\
\hline 14 & $\mathrm{~T}_{21} ; \mathrm{RA}$ & $23,12 \stackrel{2 * 2}{x}$ & 0,9057 & 1,5031 & $a b$ \\
\hline 15 & $T_{9} ; T_{21} ; R A$ & $23,30 \div$ & 0,9070 & 1,5103 & $a b$ \\
\hline 16 & $T M_{1} ; T M_{2} ; T m ; T_{21}$ & 27,53 추 & 0,9307 & 1,6636 & $a$ \\
\hline
\end{tabular}

** Significativo ao nivel de $1 \%$ de probabilidade.

Obs: As letras iguais indicam que os métodos não apresentam diferença significativa entre si, ao nivel de $5 \%$ de probabilidade, pelo teste $t$. 
Tabela 4.28 - Valores do coeficiente de correlação $(r)$, da transformação $z(r)$ e de $t_{r}$ para teste $t$, para a correlação entre os totais diärios de horas de frio com temperatura abaixo de $7^{\circ} \mathrm{C}$ observados e estimados atravēs dos diferentes métodos, para o mês de agosto.

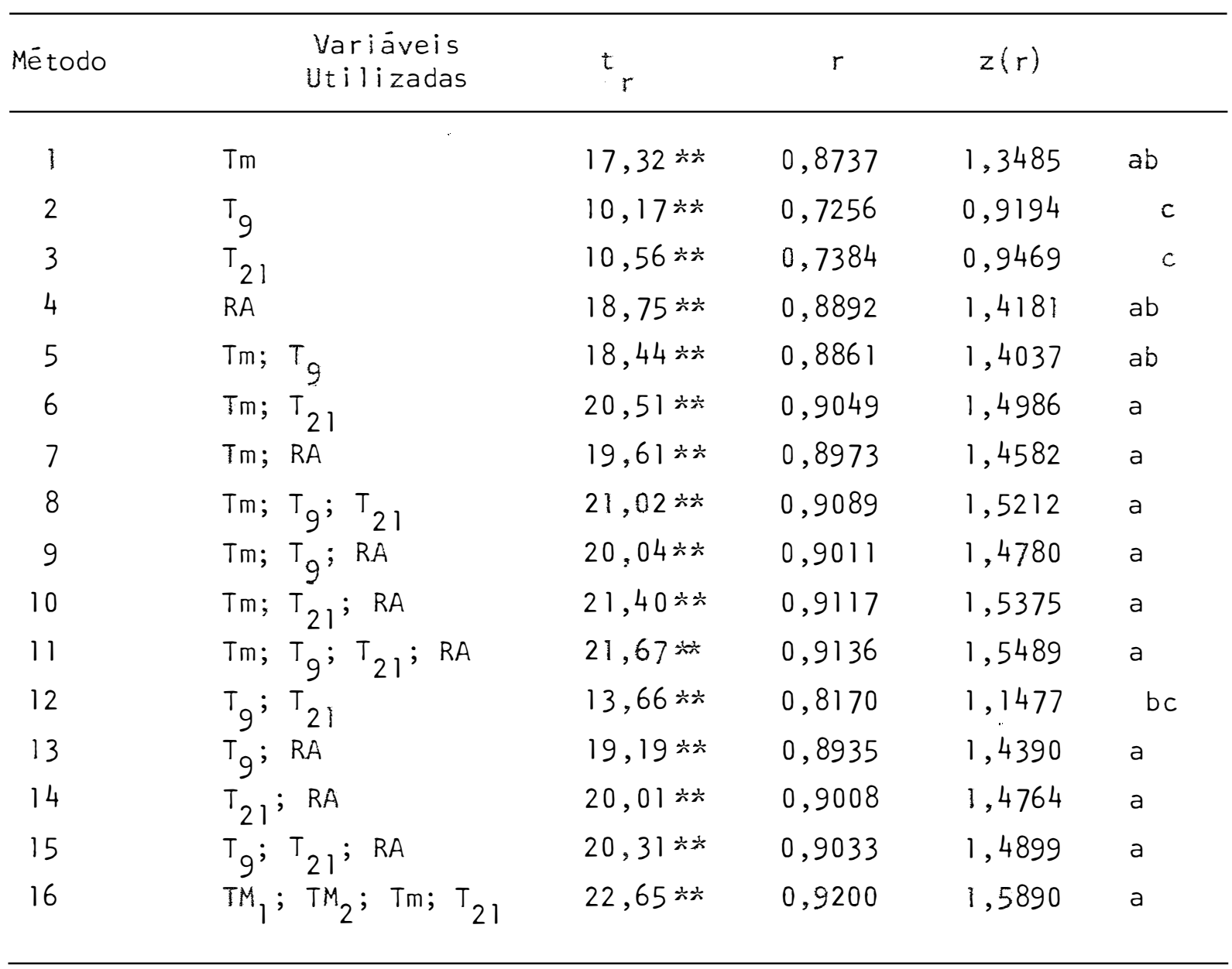

$\stackrel{*}{*} \times$ Significativo ao nivel de $1 \%$ de probabilidade.

Obs: As letras iguais indicam que os métodos não apresentam diferença significativa entre si, ao nivel de $5 \%$ de probabilidade, pelo teste $t$. 
Tabela 4.29 - Valores do coeficiente de correlação $(r)$, da transformação $z(r)$ e de $t_{i}$ para teste $t$, para a correlação entre os totais diârios de horas de frio com temperatura abaixo de $7^{\circ} \mathrm{C}$ observados e estimados atravēs dos diferentes métodos, para o mês de setembro.

\begin{tabular}{|c|c|c|c|c|c|}
\hline Método & $\begin{array}{l}\text { Variäveis } \\
\text { Utilizadas }\end{array}$ & $t_{r}$ & $r$ & $z(r)$ & \\
\hline 1 & $\mathrm{Tm}$ & $18,08 \div$ & 0,9145 & 1,5543 & $\mathrm{bc}$ \\
\hline 2 & $T_{0}$ & $6,19 \div$ & 0,6119 & 0,719 & $d$ \\
\hline 3 & $T_{21}^{z}$ & $13,55 \div$ & 0,8611 & 1,2976 & $c$ \\
\hline 4 & $\mathrm{RA}$ & $18,05 \div 2$ & 0,9142 & 1,5525 & $\mathrm{bc}$ \\
\hline 5 & $T m ; T_{9}$ & $18,34 \div 2$ & 0,9165 & 1,5667 & $\mathrm{bc}$ \\
\hline 6 & $\mathrm{Tm} ; \mathrm{T}_{21}$ & $24,52 \div$ & 0,9506 & 1,8380 & $a b$ \\
\hline 7 & $\mathrm{Tm} ; \mathrm{RA}$ & $18,65 \div$ & 0,9190 & 1,5826 & bc \\
\hline 8 & $\mathrm{Tm}_{\mathrm{m}} \mathrm{T}_{9} ; \mathrm{T}_{21}$ & $24,61 \pm$ & 0,9510 & 1,8421 & $a b$ \\
\hline 9 & $\mathrm{Tm} ; \mathrm{T}_{9} ; \mathrm{RA}$ & $18,74 \stackrel{x}{\circ}$ & 0,9196 & 1,5864 & $b c$ \\
\hline 10 & $\mathrm{Tm} ; \mathrm{T}_{21} ; \mathrm{RA}$ & $24,54 \therefore$ & 0,9507 & 1,8390 & $a b$ \\
\hline 11 & $\mathrm{Tm} ; \mathrm{T}_{9} ; \mathrm{T}_{21} ; \mathrm{RA}$ & $24,61 *$ & 0,9510 & 1,8421 & $a b$ \\
\hline 12 & $\mathrm{~T}_{9} ; \mathrm{T}_{21}$ & $14,75 \div$ & 0,8790 & 1,3714 & $c$ \\
\hline 13 & $T_{9} ; R A$ & $18,07 \approx$ & 0,9144 & 1,5537 & bc \\
\hline 14 & $\mathrm{~T}_{21} ; \mathrm{RA}$ & $22,91 \div$ & 0,9440 & 1,7736 & $a b$ \\
\hline 15 & $\mathrm{~T}_{9} ; \mathrm{T}_{21} ; \mathrm{RA}$ & $22,91 \div$ & 0,9441 & 1,7745 & $a b$ \\
\hline 16 & $\mathrm{TM}_{1} ; \mathrm{TM}_{2} ; \mathrm{Tm} ; \mathrm{T}_{21}$ & $30,58 * *$ & 0,9674 & 2,0501 & $a$ \\
\hline
\end{tabular}

* Significativo ao nivel de $1 \%$ de probabilidade.

Obs: As letras iguais indicam que os métodos não apresentam diferença significativa entre si, ao nível de $5 \%$ de probabilidade, pelo teste $t$. 
Tabela 4.30. - Valores do coeficiente de correlação (r), da transformação $z(r)$ e de $t_{r}$ para teste $t$, para a correlação entre os totais diārios de horas de frio com temperatura abaixo de $7^{\circ} \mathrm{C}$ observados e estimados através dos diferentes métodos, para o mês de outubro.

\begin{tabular}{|c|c|c|c|c|c|}
\hline Método & $\begin{array}{l}\text { Variāveis } \\
\text { Utilizadas }\end{array}$ & $t_{r}$ & $r$ & $z(r)$ & \\
\hline 1 & $\mathrm{Tm}$ & $10,78 \approx x$ & 0,9271 & 1,6373 & a \\
\hline 2 & $T_{9}$ & 1,65 & 0,3536 & 0,3696 & $b$ \\
\hline 3 & $\mathrm{~T}_{21}$ & $3,27 \stackrel{2}{3}$ & 0,6005 & 0,6939 & $\mathrm{~b}$ \\
\hline 4 & $R A$ & $11,77^{\mathrm{x} \alpha \mathrm{x}}$ & 0,9377 & 1,7186 & $a$ \\
\hline 5 & $\mathrm{Tm} ; \mathrm{T}_{9}$ & $10,84 *$ & 0,9279 & 1,6431 & $a$ \\
\hline 6 & $\mathrm{Tm} ; \mathrm{T}_{21}$ & $11,55 *$ & 0,9355 & 1,7007 & $a$ \\
\hline 7 & $\mathrm{Tm} ; \mathrm{RA}$ & $11,81 * *$ & 0,9381 & $1,7,220$ & $a$ \\
\hline 8 & $\mathrm{Tm} ; \mathrm{T}_{9} ; \mathrm{T}_{21}$ & $11,57 * *$ & 0,9357 & 1,7023 & a \\
\hline 9 & $\mathrm{Tm} ; \mathrm{T}_{9} ; \mathrm{RA}$ & $12,55 \approx$ & 0,9446 & 1,7791 & $a$ \\
\hline 10 & $\mathrm{Tm} ; \mathrm{T}_{21} ; \mathrm{RA}$ & $12,36 \approx$ & 0,9430 & 1,7645 & $\mathrm{a}$ \\
\hline 11 & $\mathrm{Tm} ; \mathrm{T}_{9} ; \mathrm{T}_{21} ; \mathrm{RA}$ & $13,18 * *$ & 0,9494 & 1,8257 & $a$ \\
\hline 12 & $T_{9} ; T_{21}$ & $3,50 \star$ & 0,6260 & 0,7348 & b \\
\hline 13 & $\mathrm{~T}_{9} ; \mathrm{RA}$ & $12,31 *$ & 0,9426 & 1,7609 & $a$ \\
\hline 14 & $\mathrm{~T}_{21} ; \mathrm{RA}$ & $12,28 \stackrel{\mathrm{st}}{\mathrm{N}}$ & 0,9423 & 1,7582 & $a$ \\
\hline 15 & $\mathrm{~T}_{9} ; \mathrm{T}_{21} ; \mathrm{RA}$ & $12,97 * *$ & 0,9479 & 1,8107 & $a$ \\
\hline 16 & $\mathrm{TM}_{1} ; \mathrm{TM}_{2} ; \mathrm{Tm} ; \mathrm{T}_{21}$ & 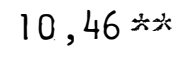 & 0,9230 & 1,6089 & $a$ \\
\hline
\end{tabular}

$*$ Significativo ao nivel de $1 \%$ de probabilidade.

Obs: As letras iguais indicam que os métodos não apresentam diferença significativa entre si, ao nivel de $5 \%$ de probabilidade, pelo teste $t$. 
Tabela 4.31 - Coeficientes de determinação $\left(r^{2}\right)$ para a correlação entre os totais diários de horas de frio observados e estimados pelos diferentes métodos, nos meses de duril a uulubro, para a tempera tura base de $13^{\circ} \mathrm{C}$.

\begin{tabular}{|c|c|c|c|c|c|c|c|}
\hline \multirow{2}{*}{ Método } & \multicolumn{7}{|c|}{$r^{2}$} \\
\hline & Abril & Maio & junho & jultho & Agosto & Setembro & Outubro \\
\hline 1 & 0,7948 & 0,6745 & 0,5483 & 0,5571 & 0,4761 & 0,5347 & 0,7332 \\
\hline 2 & 0,6002 & 0,6667 & 0,5904 & 0,5955 & 0,5841 & 0,5715 & 0,5390 \\
\hline 3 & 0,7864 & 0,6608 & 0,6409 & 0,5765 & 0,5274 & 0,6164 & 0,6206 \\
\hline 4 & 0,8671 & 0,8433 & 0,8214 & 0,6107 & 0,7928 & 0,8406 & 0,8704 \\
\hline 5 & 0,8117 & 0,7029 & 0,6019 & 0,6204 & 0,5930 & 0,6279 & 0,7882 \\
\hline 6 & 0,8717 & 0,7398 & 0,6559 & 0,6452 & 0,5862 & 0,6601 & 0,7910 \\
\hline 7 & 0,8685 & 0,8450 & 0,8265 & 0,7252 & 0,7929 & 0,8439 & 0,8748 \\
\hline 8 & 0,8753 & 0,7553 & 0,7044 & 0,7123 & 0,6767 & 0,7106 & 0,8203 \\
\hline 9 & 0,8695 & 0,8468 & 0,8327 & 0,7521 & 0,8170 & 0,8477 & 0,8766 \\
\hline 10 & 0,9003 & 0,8531 & 0,8388 & 0,7465 & 0,7986 & 0,8480 & 0,8821 \\
\hline 11 & 0,9004 & 0,8545 & 0,8472 & 0,7804 & 0,8237 & 0,8518 & 0,8834 \\
\hline 12 & 0,8220 & 0,7474 & 0,6977 & 0,718 & 0,6755 & 0,7067 & 0,7163 \\
\hline 13 & 0,8682 & 0,8468 & 0,8325 & 0,7452 & 0,8097 & 0,8423 & 0,8739 \\
\hline 14 & 0,8996 & 0,8529 & 0,8387 & 0,718 & 0,7984 & 0,8430 & 0,8787 \\
\hline 15 & 0,8997 & 0,8543 & 0,8420 & $0,780.3$ & 0,8127 & 0,8444 & 0,8810 \\
\hline 16 & 0,9492 & 0,9273 & 0,8946 & 0,8723 & 0,8900 & 0,8859 & 0,9124 \\
\hline
\end{tabular}


Tabela 4.32 - Coeficientes de determinação $\left(r^{2}\right)$ para a correlação entre os to tais diārios de horas de frio observados e estimados pelos diferentes métodos, nos meses de abril a outubro, para a tempera tura base de $7{ }^{\circ} \mathrm{C}$.

\begin{tabular}{|c|c|c|c|c|c|c|c|}
\hline \multirow{2}{*}{ Mé todo } & \multicolumn{7}{|c|}{$r^{2}$} \\
\hline & Abril & Ma io & Junho & Julho & Agos to & Setembro & Outubro \\
\hline .1 & 0,8660 & 0,8238 & 0,8257 & 0,6192 & 0,7633 & 0,8363 & 0,8596 \\
\hline 2 & 0,6212 & 0,7107 & 0,6924 & 0,5342 & 0,5264 & 0,3745 & 0,1250 \\
\hline 3 & 0,2291 & 0,5748 & 0,5983 & 0,6060 & 0,5453 & 0,7416 & 0,3606 \\
\hline 4 & 0,8235 & 0,8541 & 0,8088 & 0,7965 & 0,7907 & 0,8357 & 0,8793 \\
\hline 5 & 0,8678 & 0,8369 & 0,8339 & 0,6396 & 0,7852 & 0,8400 & 0,8610 \\
\hline 6 & 0,9126 & 0,8449 & 0,8475 & 0,7320 & 0,8188 & 0,9038 & 0,8753 \\
\hline 7 & 0,8662 & 0,8624 & 0,8405 & 0,8024 & 0,8052 & 0,8446 & 0,8800 \\
\hline 8 & 0,9136 & 0,8593 & 0,8587 & 0,7393 & 0,8261 & 0,9044 & 0,8756 \\
\hline 9 & 0,8678 & 0,8652 & 0,8439 & 0,8031 & 0,8120 & 0,8458 & 0,8922 \\
\hline 10 & 0,9143 & 0,8682 & 0,8549 & 0,8240 & 0,8312 & 0,9039 & 0,8894 \\
\hline 11 & 0,9147 & 0,8730 & 0,8617 & 0,8243 & 0,8346 & 0,9044 & 0,9014 \\
\hline 12 & 0,6467 & 0,8030 & 0,8054 & 0,7019 & 0,6675 & 0,7727 & 0,3919 \\
\hline 13 & 0,8245 & 0,8594 & 0,8204 & 0,8004 & 0,7984 & 0,8361 & 0,8885 \\
\hline 14 & 0,8551 & $0,859.5$ & 0,8282 & 0,8204 & 0,8114 & 0,8912 & 0,8880 \\
\hline 15 & 0,8552 & 0,8671 & 0,8449 & 0,8226 & 0,8159 & 0,8913 & 0,8985 \\
\hline 16 & 0,9348 & 0,8798 & 0,8857 & 0,8662 & 0,8465 & 0,9359 & 0,8520 \\
\hline
\end{tabular}


Durante a cotação dos totais diários de horas de frio dos termogramas, observou-se que nos meses menos frios, co mo abril, maio, setembro e outubro, a condição $T m$ < TB, emgran de parte dos casos, ocorria em dias que apresentavam a marcha diāria da temperatura do ar bastante similar a um padrão de va riação típico de períodos diuturnos livres de nebulosidade e da entrada de massas de ar com caracteristicas diferentes, nos quais, os momentos de ocorrência das temperaturas extremas diá rias apresentam pequena variabilidade. Nos meses mais frios en tretanto, a forma da variação diária da temperatura do ar foi mais diversificada. Essa observação é reforçada. pelo número de dados enquadrados nos diferentes casos considerados para o método analitico, conforme mostra a tabela 4.15 e constitui-se em uma das causas da obtenção de estimativas menos precisas nos meses mais frios.

os métodos 4 e 7 proporcionaram a obtenção de:coe ficientes de determinação $\left(r^{2}\right)$ acima de 0,7900 com excessão pá ra "HF < 13 " no mês de julho, em que os coeficientes de determinação obtidos foram iguais a 0,6107 e 0,7252 , para os méto dos 4 e 7 , respectivamente. Considerando apenas a temperatura base de $7^{\circ} \mathrm{C}$, o método 1 proporcionou a obtenção de coeficientes de determinação acima de 0,8200 , exceto nos meses de julho e a gosto em que proporcionou $r^{2}$ iguais a 0,6192 e 0,7633 , mostrañ do-se estatisticamente inferior aos métodos 4 e 7 apenas nomês de julho para essa temperatura base.

Dessa forma, para diminuir os custos operacionais de um estudo a nível meso-climático para a região de San ta Maria-RS, as melhores alternativas seriam: o método 4 para estimar "HF < 7" nos meses de maio, julho, setembro e outubro e para estimar "HF < 13 " nos meses de abril, maio, junho, agos to, setembro e outubro; o método 7 para estimar "HF< 7 " nos meses de junho e agosto e para estimar "HF $<13^{\prime \prime}$ no mês de juIho; o método l para estimar "HF $<7^{\prime \prime}$ no mês de abril. Todavia, 
para que se utilizasse uma metodologia padrão, a melhor opção seria a utilização da equação de regressão mûltipla em que são empregadas as variāveis "Tm" e "RA" (método 7), emboraque o método 4 não determinasse erros significativamente maiores no caso de se estimar "HF < 7", isto porque a variāvel "Tm" na e quação de regressão do método 7 , proporcionou coeficientes angulares não significativos pelo teste t, em 5 dos 7 meses analisados, e também porque os métodos 4 e 7 não difere esta tisticamente entre si em qualquer mês, para esta temperaturaba se.

Os métodos 4 ou 7 podem constituir-se também na op ção mais viável para estimar horas de frio em outros locais onde se dispõe apenas de dados de temperatura mínima e de temperatura māxima, desde que os parâmetros das equações sejamajustados para o local, além de servirem de apoio paraestudos a nível meso-cli mático mais detalhados, principalmente por exigirem apenas um ter mômetro de mínima e um termômetro de māxima para a obtenção dos dados de cada local e também porminimizarem os custosoperacionais.

Para a estimativa de horas de frio com temperatü ra abaixo de $13^{\circ} \mathrm{C}$, o método analítico (método 16), mostrou-sé superior aos demais, apenas não apresentando diferença signifi cativa ao nível de $5 \%$ com relação ao métodos de regressão em que se incluiu a variável RA, nos meses de setembro e outubro. os coeficientes de correlação, obtidos pela correlação entre os totais diários de horas de frio, com temperatura abaixo de $13^{\circ} \mathrm{C}$; cotados nos termogramas e os estimados pela utilização das equações analiticas do método, oscilaram entre 0,9340 e 0,9742 nos diferentes meses, conforme as tabelas 4.17 à 4.23 . Além da boa correlação, as figuras $3 a, 5 b, 8 a, 10 d, 13 b, 15 a$ e $17 c$ mos tram que a variáncia apresentada foi pequena, o que demonstra que o método é bastante preciso e deve ser o preferido para es timar horas de frio com temperatura abaixo de $13^{\circ} \mathrm{C}$, para períodos diārios, em Santa Maria-RS, apesar de que alguns ajus tes empíricos nas equações $3.3,3.4,3.5,3.6$ e 3.7 , possam me 
lhorar pouco mais essas estimativas.

Considerando a temperatura base igual a $7^{\circ} \mathrm{C}, \quad \mathrm{O}$ método 16 proporcionou a obtenção de coeficientes de correlação entre os valores observados e estimados, de 0,9200à 0,9674, nos diferentes meses. Entretanto não foi estatisticamente supe rior a grande parte dos outros métodos, apesar de proporcionar os mais elevados coeficientes de correlação, em seis dos sete meses analisados. Analisando-se as tabelas 4.24 a 4.30 , verifi ca-se que os métodos $10,11,14$ e 15 foram estatisticamente i guais ao método 16 em todos os meses; os métodos 6, 7, 8, 9 e 13 foram significativamente inferiores em apenas um dos meses, ao passo que os métodos 4 e 5 foram estatisticamente inferiores ao método analítico, em dois dos meses analisados, ao nível de $5 \%$ de probabilidade. Nesse caso poderia-se deduzir erro neamente que o método analítico foi menos preciso na estimativa de horas de frio com temperatura abaixo de $7^{\circ} \mathrm{C}$, do que para estimar horas de frio com temperatura abaixo de $13^{\circ} \mathrm{C}$. Entretan to, verifica-se que para a temperatura base de $7^{\circ} \mathrm{C}$ os demais métodos, em geral proporcionaram melhores estimativas do que para a temperatura base de $13^{\circ} \mathrm{C}$ e que o menor nümero de dados disponíveis para a análise propiciou a obtenção de maiores "in tervalos de tolerância", para a comparação dos métodos pelotes te $t$. Essa constatação, aliada ao fato de que os coeficientes de correlação obtidos quando da utilização da temperatura base de $7^{\circ} \mathrm{C}$ não se caracterizam como inferiores aos coeficientes de correlação obtidos para a temperatura base de $13^{\circ} \mathrm{C}$ nos respectivos meses, sugere que o método é igualmente preciso para estimar horas de frio com temperatura abaixo de $7^{\circ} \mathrm{C}$ ou com tem peratura abaixo de $13^{\circ} \mathrm{C}$.

A tabela 4.16 mostra os valores médiosmensais do total diário de horas de frio observados e estimados através das diferentes equações analiticas. Verifica-se que as equações 3.3 e 3.6 em geral proporcionaram subestimativas, as equações 3.4 e 3.5 proporcionaram superestimativas, enquanto 
que as equações 3.8 e 3.9 foram de precisão absoluta. A equação 3.7 não é passível de crítica devido ao pequeníssimo nüme ro de dados enquadrados nesse caso. Entretanto pode-se verificar que o erro médio em reiação aos valores médios das observa ções, na grande maioria dos casos foi menor que $10 \%$. Na tabela 4.15 pode-se verificar que aproximadamente $85 \%$ e $96 \%$ de tados os dados de horas de frio com temperatura abaixo de $13^{\circ} \mathrm{C}$ e $7^{\circ} \mathrm{C}$, respectivamente, foram estimados pelas equações analíticas 3.3 e 3.4 .

Para preservar o caráter analítico do método e em função das boas estimativas obtidas, não efetuou-se os ajus tes empíricos das equações analíticas. Dessa forma, em função dos resultados obtidos nesse trabalho e em função dos resultados obtidos por ANGELOCCl et aZii (1979), o método analítico pode ser recomendado para estimar totais diärios de horas de frio com temperatura abaixo de $13^{\circ} \mathrm{C}$, para todos os locais do Estado do Rio Grande do Sul onde os horários de ocorrência das temperaturas mínima e máxima diārias apresentem um comportamen to idéntico ao apresentado para Santa Maria-RS. Para os demais locais do Estado ou para qualquer local da Região Sul do Brasil, bastaria um ajuste nas equações $3.3 ., 3.4,3.5,3.6$ e.3.7, em função do horário de ocorrência das temperaturas extremas diárias, para viabilizar a utilização do método. Além disso, conforme ANGELOCCl et alii (1979), a principal vantagem do método é de não exigir a utilização de termogramas na obtenção das equações analíticas. 
Em função dos métodos utilizados e dos resultados obtidos para Santa Maria-RS, pode-se concluir que:

- o método analítico foi o melhor para estimar totais diários de horas de frio com temperatura abaixo de $13^{\circ} \mathrm{C}$;

- para estimar totais diários de horas de frio com temperatura abaixo de $7^{\circ} \mathrm{C}$, deve-se dar preferência ao método analítico;

- para minimizar os custos operacionais de um estudo do frio invernal a nível meso-climático, deve-se optar pelas equações de regressão dos métodos 4 ou 7 , conforme o mês a ser avaliado e a temperatura base escolhida;

- para a temperatura base de $7^{\circ} \mathrm{C}$, as estimativas poderão ser efetuadas com as equações obtidas pelo método l em substitui ção aos métodos 4 e 7 , desde que se tolere erros significativamente maiores no mês de julho. 
ABBOTT,D.L., 1962. The effect of four controlled winter temperatures on the flowering and fruiting of the apple. J.Hort. Science. London, $37: 272-284$.

ANGELOCCI, L.R.; M.B.P. de CAMARGO; M.J. PEDRO JUNIOR; A.A.ORTOLANI e E.R. ALFONSI, 1979. Estimativa de total de horas abaixo de determinada temperatura-base através das medidas diärias da temperatura do ar. Bragantia. Campinas, $38(4)$ : $27-36$.

ARON, R.H., 1975. A method for estimating the number of hours below a selected temperature threshold. Journal of Applied. Meteorology. 14(8):1415-1418.

CHANDLER, W.H.; M.H. KIMBALL; G.L. PHILIP; W.P. THFTS e G.P. WELDON, 1937. Chilling requirements for opening of buds on deciduous orchard trees and some other plants in California. Calif. Agric. Exp. Station Bulletin. Berkeley, 611:1-63.

DAMARI0, E.A., 1969. Carta estimada de horas de frio de la República Argentina. Rev. de la Facultad de Agron. Y Veterinaria de Buenos Aires. Buenos Aires, 17(2): 25-38. 
EREZ, A. e S. LAVEe, 1971. The effect of climatic conditions on dormancy development of peach buds 1. Temperature. Proc. Am. Soc. for Hort. Science. New York, 96:711-714.

FERREIRA, A.A., 1975. Estudo da via.bilidade tëcnico-econômica da fruticultura de clima temperado no Estado de Minas Gerais. Viçosa, Univ. Fed. de Viçosa, 128 p. (Tese de Mestrado) .

GOMES, F.P., 1973. Curso de Estatistica Experimental, 5. edição. Livraria Nobel. São Paulo, $430 \mathrm{p}$.

HIGDON, R.J., 1950. The effects of insufficient chilling on peach varieties in South Carolina in de winter of 1948-49. Proc. Am. Soc. for Hort. Science. New York, 55:236-238.

LEDESMA, N.R., 1950. Consecuencias del frio invernal insuficiente en los arboles de follage caduco. Rev. de la Facultad. de Agronomia de la Plata. Buenos Aires, 27(2):181-196.

LITTLE, T.M., 1966. Correlation and Regression. Davis, Univ.of California Agr. Extension Service. 62 p. Experimental Methods for Extension Workers.

MARKUS, R., 1952. Um estudo estatístico dos invernos de Porto Alegre em relação às exigências de frio das frutíferas de clima temperado. Rev.Agronómica. Porto Alegre, 16:231-248.

MASIP, J.M.F.; J.M.H. GONZALEZ e M.A. GONZALEZ, 1976. Comportamiento de varias variedades de melocotonero bajo condicio nes de poco frio invernal. Comunicaciones del Inst. Nac. de Investigaciones Agrárias (sērie produccion vegetal). Madrid, $13: 5-15$.

MOTA, F.S. da, 1957. Os invernos de Pelotas-RS, em relação às exigências das árvores frutíferas de folhas caducas. Bol. Tecnico do Inst. Agron. do Sul. Pelotas, 18:1-38. 
PASCALE, A.J. e C. ASPIZAO, 1965. Rëgimen de horas de frio durante el invierno en Buenos Aires. Rev. de la Facultad de. Agr. y Vet. de B.Aires. Buenos Aires, 16(2):62-82.

PEDRO JUNIOR, M.J.; A.A. ORTOLANI; O. RIGITANO;R.R. ALFONSI; H.S. PINTO e 0. BRUNINI, 1979. Estimativa de horas de frio abaixo de 7 e de $13^{\circ} \mathrm{C}$ para regionalização da fruticultura de clima temperado no Estado de São Paulo. Bragantia. Campi nas, $38(13): 123-130$.

PETRI, J.L. e M.PASQUAL, 1982. Quebra da dormência em macieira. Boletim Técnico-EMPASC. Florianöpolis, 18:1-54.

SAMISH, R.M., 1954. Dormancy in woody plants. An.Rev. of Plant Physiology. Palo Alto, California, 5:183-201.

TABUENCA, M.C., 1965. Influencia del clima en plantaciones f.ru tales. Bul. Consejo Superior de Investigaciones Científicas. Zaragoza, $8: 55-63$.

WEINBERGER, J.H., 1950. Chilling requirements of peach varieties. Proc. Am. Soc. for Hort. Science. New York, 56:122-128.

WEINBERGER, J.H., 1954. Effects of hig temperatures during the breaking of the rest of sullivan elberta peach buds. Proc. Am. Soc. for Hort. Science. New York, 63:157-162.

WEINBERGER, J.H., 1956. Prolonged dormancy trouble in peaches in the southeast in relation to winter temperature. Proc. Am. Soc. for Hort. Science. New York, 67:107-112.

WEINBERGER, J.H., 1967. Some temperature relations in natural breaking of the rest of peach flower buds in the San Joaquin Valley, California. Am. Soc. for Hort Science. New York, 91: 84-89. 